Governance of Small-scale Irrigation Schemes in Northern Ghana The Role of User Groups

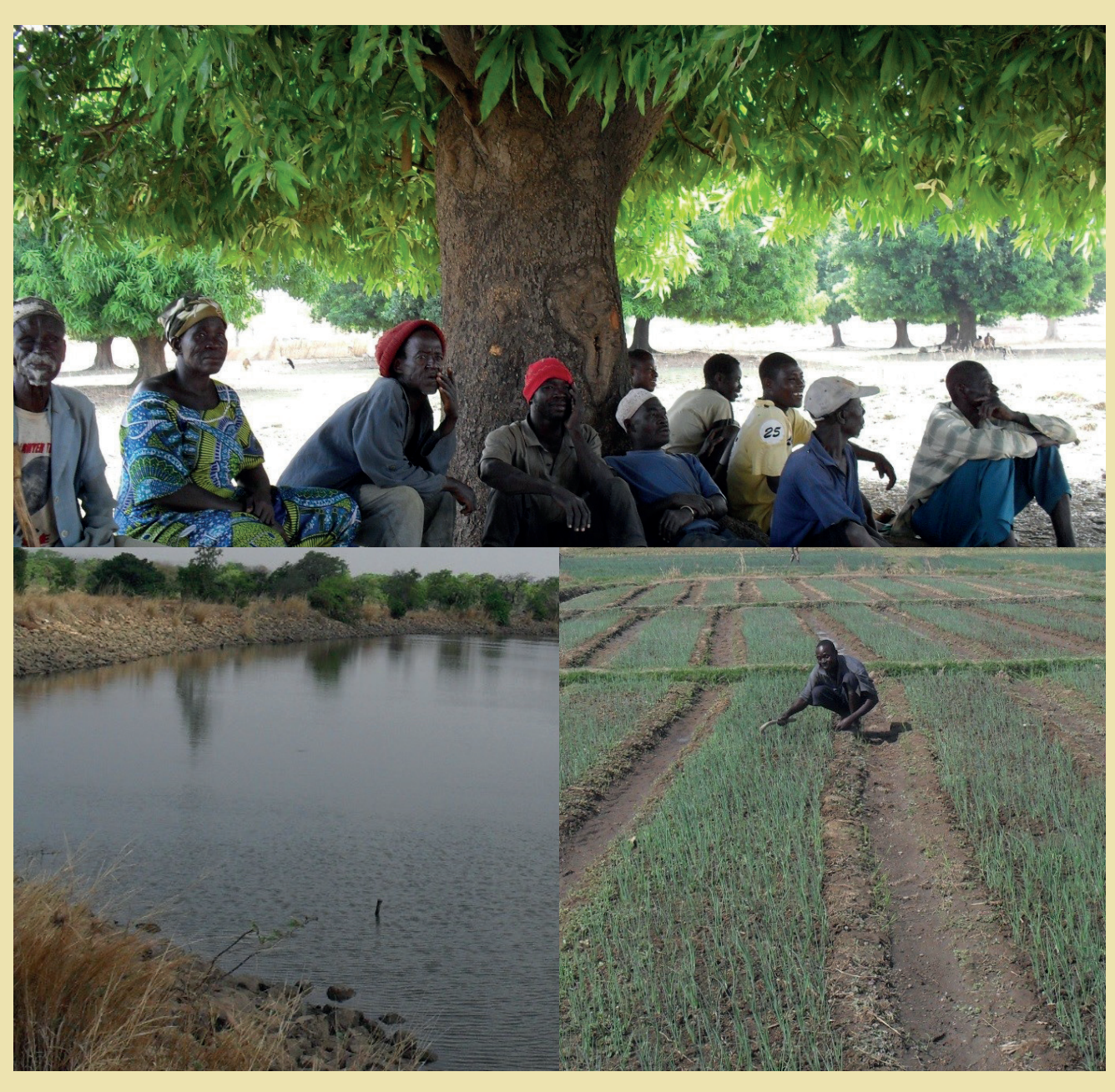

Margaret Atosina Akuriba 
Governance of Small-scale Irrigation Schemes in Northern Ghana

\section{The Role of User Groups}

Margaret Atosina Akuriba 


\section{Thesis committee}

\section{Promotor}

Prof. Dr E.H. Bulte

Professor of Development Economics

Wageningen University \& Research

\section{Co-promotors}

Dr R. Haagsma, Assistant professor, Development Economics Group

Dr.N.B.M. Heerink, Associate professor, Development Economics Group

Prof. S. Dittoh, University for Development Studies, Tamale, Ghana

\section{Other members}

Prof. Dr W.J.M. Heijman, Wageningen University \& Research

Prof. Dr A.J. Dietz, Leiden University, Leiden, the Netherlands

Prof. Dr A. Dewulf, Wageningen University \& Research

Dr G.J.A. Veldwisch, Wageningen University \& Research

This research was conducted under the auspices of the Wageningen School of Social Science (WASS) 


\title{
Governance of Small-scale Irrigation Schemes in Northern Ghana \\ The Role of User Groups
}

\author{
Margaret Atosina Akuriba
}

\section{Thesis}

submitted in fulfilment of the requirements for the degree of doctor at Wageningen University by the authority of the Rector Magnificus Prof. Dr A.P.J. Mol, in the presence of the Thesis Committee appointed by the Academic Board to be defended in public on Monday 29 October 2018 at 1.30 p.m. in the Aula. 
Margaret Atosina Akuriba

Governance of Small-scale Irrigation Schemes in Northern Ghana: The Role of User Groups 158 pages.

$\mathrm{PhD}$ thesis, Wageningen University, Wageningen, the Netherlands (2018)

With references, with summary in English

ISBN 978-94-6343-331-0

DOI: $10.18174 / 458141$ 



\section{Contents}

Page

Contents $\quad$ vii

Chapter 1 Introduction 1

Chapter 2 Measuring governance of irrigation systems: A user-based approach $\quad 13$

Chapter 3 Irrigation governance and performance: the case of smallholder-irrigated agriculture in northern Ghana 43

Chapter 4 Sustaining small-scale irrigation systems: the role of users

Chapter 5 Governance, time preference, and collective maintenance: the case of small-scale irrigation in northern Ghana

Chapter 6 Synthesis

References

Summary

Acknowledgements

Completed training and supervision plan 



\section{CHAPTER 1}

\section{Introduction}

\subsection{Background}

Over $80 \%$ of working people in the dry areas of West Africa, such as northern Ghana, are smallholder farmers and herders, cultivating between half a hectare and two hectares on average (Dittoh et al., 2013). Despite significant growth of the economy and reduction of poverty in Ghana since the 1990s (World Bank, 2007; Cooke et al., 2016), high levels of food insecurity and vulnerability exist in the northern regions of the country (Cooke et al., 2016), partly due to small land areas being cultivated once a year, within a short rainy season, and most farmers being virtually unemployed for most of the year. Irrigated agriculture in such areas is, therefore, a great step forward in improving rural livelihoods. Research has shown that investments in irrigation impact positively on livelihood outcomes of farmers such as income, food security and health (Akudugu et al., 2016; Namara et al., 2010). Climate change and the threat of an increase in desertification in West Africa (Dietz et al., 2004) also make irrigation development in the sub-continent an important development imperative since it allows high levels of agricultural production to take place with limited amounts of water. Attempts at irrigation development in West Africa have however been characterized by construction, maintenance and governance challenges (Balmisse et al., 2003; Venot and Hirvonen, 2013). At the national level, difficulties have often arisen over types of irrigation systems that governments should invest in. Problems associated with large-scale irrigation are well documented and governance issues with regard to management and coordination are prominent (Birner et al., 2010).

To address some of these challenges, small-scale irrigation (rather than large-scale) is being promoted by some development agencies in Africa (Tafesse, 2003; Akudugu et al., 2016). 
Most of these schemes are managed by Water User Associations (WUAs) as a way of broadening user participation in the establishment and operation of schemes. Small-scale irrigation is however not without challenges. There have been both technological and institutional (governance) challenges in small-scale irrigation. Birner et al. (2010) report that a high number of small reservoirs in the Upper East Region of Ghana are not in use due to governance challenges, including a lack of clear roles of stakeholders in the management and maintenance of irrigation structures, the non-involvement of community members in the making of key decisions, and a lack of trust between government agents and community members. Thus, WUAs still face formidable governance challenges.

Governance in several spheres of life is complex because relationships between pluralities of actors can be complex (Chhotray and Stoker, 2009 pp.215). It is even more difficult when we consider common pool resources such as public irrigation systems with limited regulations and policing of water use. In irrigation infrastructures in Africa, contributions and roles of stakeholders in public irrigation systems are often ill-defined. As pointed out by Ostrom (1990), without strong and effective institutions, common pool resources will be overexploited. Several private companies are also taking over a number of medium/large irrigation systems in Africa (Cotula et al., 2009) and one wonders if this is a desirable irrigation governance arrangement. Anderies et al. (2011) indicated that "in such com m on pool resource dilemmas, the incentives are such that each individual would be better off if everyone else cooperated".

Governance is not limited to production and trade, as is generally perceived, but also impacts on important factors of production including land and water use (Burger et al., 2010). As explained by various researchers, water resource use is determined by the interaction between water users, technology and water availability, and is therefore a socio-technical process (Mollinga, 2008; Pahl-Wostl, 2007). That means that governance impacts on the technical (biochemical) processes of irrigated agriculture. Hence, water users and how they are organized play important roles in the sustenance of irrigation systems. The key to sustaining irrigation resources as commons may be through the enforcement of governance strategies and adherence to such strategies by users who are considered as main stakeholders. 
Governance embraces several dimensions, such as participation, accountability and conflict management, which may play different roles in sustaining irrigation resources. Little is known about the relative importance of these different dimensions. There is a strong need for scientific analyses to ascertain governance dimensions that can best optimize investments in irrigated agriculture. What is regarded as a best strategy depends on the impact of such strategies on individuals and how satisfied individuals are with the strategies. Users' perceptions on how irrigation resources are governed may thus play a role in their adherence to the rules and regulations put in place for the sustainable governance of resources. This study therefore assesses the dimensions of WUAs' perceived governance quality that relate to performance and sustainability of small-scale irrigation, using northern Ghana as the case study region. The focus on perceived governance is necessary because users' actions towards sustaining irrigation resources may be largely based on their perceptions and views, and because some governance dimensions are difficult to measure objectively (Kaufmann et al., 2011, 2009, 2004).

\subsection{Sustaining irrigation resources as commons}

Public irrigation facilities are classified as common pool resources (CPRs) with open-access to multiple users (Ostrom and Gardner, 1993; Ostrom, 2000). Open access often leads to the overuse of resources by some individuals, thereby creating negative externalities for others (Birner et al., 2005; Ostrom, 2000). Good governance is thus required in sustaining CPRs: governance which involves procedures by which decisions are made at different levels, involving different institutions. The challenge in most instances is the ability to involve the public, private and civil society actively and directly in solving problems or creating opportunities that will satisfy all actors in the use of communal resources (Chea et al., 2011; Dietz et al., 2003).

For the sustenance of CPRs, research has stressed the need to include users, who are the main stakeholders, in the design and management of CPRs. Ostrom (2000) explained the need for users of CPRs to organize themselves into associations that effectively and sustainably $m$ anage resources. The 'tragedy of the comm ons' is not unavoidable, and sustainability of common resources does not require authorities to intervene top-down, as for example 
confirmed in China by Zhang et al. (2013). Ostrom (2000) based her view on many empirical findings that show that associations are more likely to succeed when the properties of the resource are better known and when members are sufficiently motivated and capable (in terms of experience, trust, autonomy). These associations are the more successful if their institutions follow design principles including clear rules on boundaries, payments proportional to benefits, arrangements for collective action, monitoring, graduated sanctions, conflict resolution mechanisms, and rights to organize.

Advancing the need for user involvement in managing CPRs, the WUA concept has been advocated as appropriate in governing water resources at the community level in developing economies. WUAs have been quite successful in India and other countries (Bassi et al., 2010; Hoogesteger, 2014) and may be effective in sustaining community irrigation resources. Tortajada (2010) indicated that local stakeholders may often be more familiar with peculiarities of local economic, social, cultural and environmental situations, and may therefore be efficient in managing resources entrusted unto them. Additionally, poor performance of government-controlled irrigation schemes worldwide has necessitated the involvement of user organisations in the governance of irrigation resources (Howarth et al., 2007).

\subsection{Irrigation governance in Ghana}

The practice of irrigation in Ghana on a small scale dates back to the early 1880s (KyeiBaffour and Ofori, 2007). Irrigation resources were then governed by customary institutions, and chiefs and priests were custodians of land and water and therefore had the mandate to ensure that the resources were not overexploited (Opoku-Ankomah et al., 2006). During colonial and post-independence regimes, a number of reforms were instituted to complement customary laws and to coordinate a sustainable management of water resources in the country.

The first formal irrigation in Ghana (established by government) dates back to the $1920 \mathrm{~s}$ (Kyei-Baffour and Ofori, 2007; Opoku-Ankomah et al., 2006). After independence in 1957, several public sector irrigation projects were established in the coastal and northern savannah ecological areas of the country, managed by governmental agencies. The public schemes are 
still largely managed by the Ghana Irrigation Development Authority (GIDA), a semiautonomous public agency, even though at the scheme levels Water User Associations (WUAs) undertake several governance responsibilities.

GIDA was established as a public sector organization to promote irrigated agriculture by providing irrigation infrastructure and relevant water and soil management techniques. It was also to promote the concept of Water User Associations (WUAs) as a national strategy for the management of small-scale irrigation schemes in order to encourage stakeholder participation in the governance of agricultural water resources (Birner et al., 2010; Namara et al., 2011). This was a response to calls from international donor agencies to include water users in decision making and management (Svendsen and Meinzen-Dick, 1997). These calls were informed by the view that collective efforts of local users towards maintenance of common pool resources are effective in managing the commons (Ostrom, 1990). User involvement inculcates a sense of ownership into users for sustainable management of irrigation resources and also eases the burden on the government.

With the WUA model, the central government through GIDA maintains the duty to construct and/or rehabilitate irrigation schemes in Ghana. GIDA co-manages large and medium-scale schemes with farmers, while governance of small-scale schemes is transferred to WUAs. WUAs are responsible for the general operation and maintenance of dams and canals, the allocation of land and water, and the collection of water fees ( van Edig et al., 2003; Mul et al., 2015). The sustenance of small-scale irrigation schemes is thus the responsibility of WUAs. As such, most WUAs have set rules and regulations to guard their operations.

There are no records of specific directions for WUAs governance in Ghana prior to the decentralisation of irrigation management. Based on their core mandate (operation and maintenance) however, WUAs generally rely on self-made rules and regulations, ranging from participation of users in decision making, to accountability of leaders on resource use, to manage resources under their care. The most common operational rules are labour contributions from users for maintenance activities, and a zero tolerance to farming in the catchment areas of water reservoirs, among others. These rules and regulations, though 
similar across WUAs, are influenced by local conditions, and consequently, enforcement strategies may vary across schemes.

\subsection{Research questions and objectives}

Despite efforts to sustain small-scale irrigation in Ghana, there are still reports suggesting that their governance is ineffective and poorly coordinated (Namara et al., 2011; OpokuAnkomah et al., 2006). Small-scale schemes are characterized by breakage of canals, choking of canals with weeds, and siltation, among others, in spite of the presence of WUAs to maintain them (Namara et al., 2011). Birner et al. (2010) reported that governance challenges led to the abandonment of a number of small-scale reservoirs in the Upper East Region of Ghana. Their work focused on the quality of infrastructure, which captured the physical characteristics of small reservoirs, and concluded that, though construction problems are a major challenge, particularly maintenance issues such as lack of cleaning of canals and prevention of siltation play a role. These identified problems cut across the two main phases of irrigation systems - construction of systems and operation and maintenance of systems which may require different forms of governance (Abernethy, 2010). The first phase is an issue of national governance involving procurement and financing of projects, while the second phase involves WUAs' governing strategies. Assum ing the first phase is successful and the facility is constructed, the activities of WUAs will then be determining factors for long-term sustainable use of irrigation resources.

Governance affects the quality of decisions that users make. Better quality decisions are those that make more positive contributions to the overall welfare of user groups. This includes aspects of effectiveness, efficiency and equity of measures decided on. The result of good governance should therefore be visible in terms of increased productivity of individual irrigated plots and well-maintained systems necessary for sustainable production. Abernethy (2010) indicated that good governance of irrigation systems produces three kinds of impacts: high production performance, satisfied users (quality of life and benefits from irrigation systems), and sustainable systems over a long period of time. Sustainability is not a physical property of irrigation structures that can be measured at a particular point in time, but takes the effort of users to sustain the systems, making the requirem ent for users' satisfaction 
essential (Ibid). Efforts that users put in to sustain irrigation resources are forms of investments with expected returns, and may therefore be affected by user time preferences, among others.

Understanding the interlinkages that yield better performance and sustainability of irrigation systems is necessary for improving irrigated agriculture. The overall objective of this study is to examine the relationship between a WUAs' governance quality and the sustainability of small-scale irrigation systems in northern Ghana. To this end, an empirical analysis is made of the role that irrigation farmers' perceptions of WUA governance quality play in the performance of irrigated farms and in users' contributions to collective action. The main research questions addressed in the following chapters are as follows.

1. What measures of irrigation governance can be used to assess the performance and sustainability of WUA-managed irrigation schemes?

2. To what extent are users' perceptions of different dimensions of irrigation governance related to the performance of irrigation schemes?

3. Are users' governance perceptions and cooperativeness related to users' contributions towards irrigation resource maintenance?

4. To what extent is a farm er's labour contribution to irrigation scheme maintenance associated with his or her perception of local governance performance and with his or her time preference?

Each research question is a self-standing contribution to the debate on CPR governance. However, as governance is the main interest of the study, crosscutting is necessary in understanding interrelationships that exist. Overlaps may thus occur in the chapters. The measures of irrigation governance, discussed in Chapter 2, are based on individual perceptions of users. In Chapter 3, performance of irrigation systems (in terms of productivity) as influenced by governance, among other factors, is described. The effort of users to maintain irrigation systems (Chapter 4) is also shaped by how good governance is perceived to be. Similarly, in Chapter 5, as time preference may have an effect on collective 
maintenance as an investment, it may be shaped by several characteristics of the user, and the character of the irrigation resource, which are all governance concerns.

\subsection{Methodology}

\subsubsection{Study area and data collection}

The study was carried out in the savannah zones of Ghana (Northern, Upper East, and Upper West Regions). These regions are located in the north of Ghana (see Figure 1). The area is relatively dry and has a short rainy season stretching from May to September. Annual rainfall is an average of 1,000 $\mathrm{mm}$ and only one cropping season exists. Dry-season irrigation is practised by communities with water bodies to complement rain-fed harvest for livelihoods. Surface water irrigation from small reservoirs, constructed by government and donor organizations, are predominant and it is a wish of every community to have such facilities. Irrigated crops are mainly rice and vegetables, including tomatoes, onions, pepper, and leafy vegetables.

Multi-level stakeholder interviews (of key informants and focus groups) were undertaken at national, regional, and community levels to obtain multiple perspectives on irrigation governance in Ghana. Data collection involved obtaining extensive primary data from irrigation-related households and Water User Associations (WUA). In all, 370 households from 37 small-scale irrigation schemes (using dams with canals) were selected for the study. The survey was carried out from November 2014 to April 2015. Three crops were considered in the study: tomatoes, onions, and pepper. The interrelations that exist in irrigation governance are likely to vary across crops. Group discussions at the community level were held in segregated groups (men and women) using the Participatory Assessment of Development (PADev) approach, developed by Dietz et al. (2013). This helped in understanding governance structures at the community level.

The survey data was complemented with field experiments. Experiments help in understanding what individuals actually do in common pool resource management and are increasingly combined with other methods to minimise uncertainty of its external validity and 
to generate better information (Anderies et al., 2011). A Voluntary Contribution Mechanism (VCM) experiment was performed in 19 schemes to elicit the willingness of users to contribute towards irrigation maintenance. The experiment aimed at estimating the cooperative nature of users, which was used as a variable to check if being cooperative or altruistic plays a role in users' involvem ent in maintenance activities. Following Andreoni and Sprenger (2012), a time-discounting experiment was also conducted with water users in 18 schemes to investigate how maintenance of irrigation resources by user groups correlates with time preference. Details of these methods are described in the individual chapters.

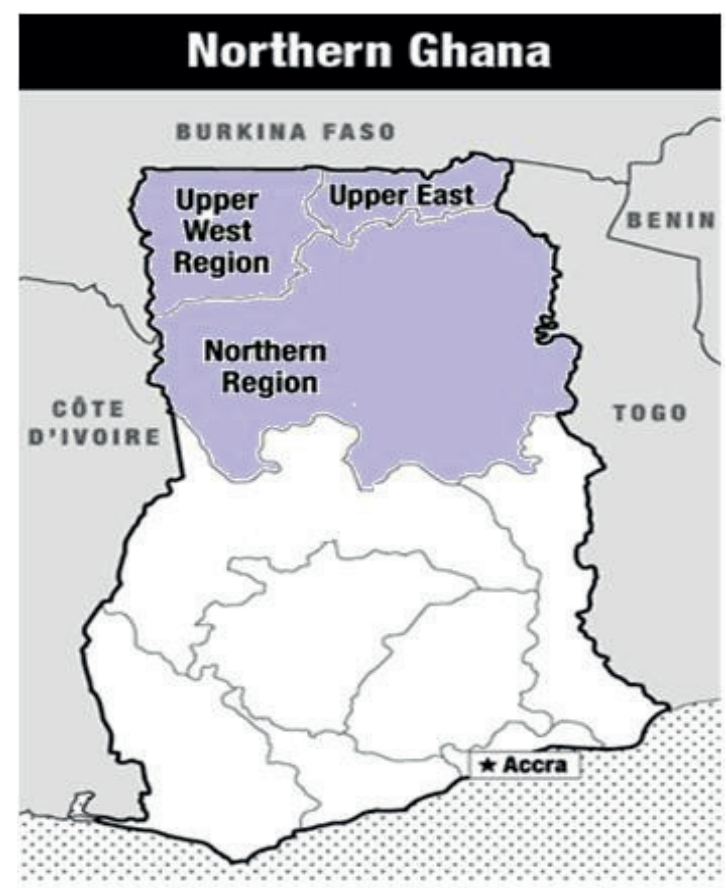

Figure 1.1: Map of Study Area (adapted and modified from http://www.un.org/africarenewal/magazine/october-2008/closingghana $\%$ E2\%80\%99s-national-poverty-gap ) 


\subsubsection{Empirical strategies}

In Chapter 2, the perceptions of water users were used to estimate a number of dimensions characterizing irrigation governance. Forty-six features of governance, grouped into six dimensions, were incorporated into a household questionnaire for respondents to rate using a 5-point Likert scale. This subjective approach is supported by the assumption that users of common pool resources have the greatest stake in the sustainability of resources (Abernethy, 2010). Kaufmann et al. $(2011,2009,2004)$ explained that subjective assessments are relevant in the assessment of governance because agents base their actions on their perceptions, impressions, and views. Moreover, not every indicator of governance can be measured objectively and those that can be measured objectively may not reflect the reality on the ground. In rural settings with high illiteracy rates, such as in northern Ghana, records on governance outcomes are often incomplete or non-existent. In well-organized irrigation settings, it may be possible to assess governance from daily records of water use, income and expenditures. This is however missing in our study setting. To test the validity of our hypotheses, we examined the relationship between governance scores per dimension and factors that could be associated with governance perceptions using Tobit regression analysis.

Chapter 3 examines the extent to which users' perceptions of different dim ensions of irrigation governance relate to the performance of irrigation schemes using a Cobb-Douglas production function. Performance is measured as yield per unit area of irrigated plots. Using a Cobb-Douglas function, we specified that the yield of a household farm is an increasing function of governance (given that the availability of water depends positively on governance), land, variable inputs such as labour and fertilizer, and capital.

In Chapter 4, it is hypothesized that the amount of labour a user contributes towards irrigation resource maintenance associates with user characteristics (governance perceptions among others), the cooperative nature of the user, and scheme/group characteristics. This is estimated using two-stage least squares regressions. Labour contributions are calculated as the number of days a plot owner participated in maintenance activities in the past year. User cooperativeness is measured as the number of tokens a user contributes in the VCM experiment. 
In Chapter 5, we assess the relationship between a farm er's labour contribution to irrigation scheme maintenance and his or her perception of local governance performance and time preference using a Tobit regression. The Tobit approach considers the zero lower bound and takes into account that a user may not participate in maintenance activities. A Generalized Linear Model (GLM) and OLS regressions are estimated to test the robustness of the results. The GLM method is able to estimate regressions with arbitrary and/or skewed continuous distributions in a consistent manner compared to standard methods like OLS (McCulloch, 2000). Estim ations of a user's tim e preference are retrieved from a Convex Tim e Budget (CTB) game.

It should be noted that ideally a user's cooperativeness and time preference should be incorporated in one equation to jointly estimate contributions to maintenance. However, elicitation methods were elaborate, requiring much time. Due to challenges such as respondent fatigue, influence of com munication on respondents' choices when research is carried over to the next day, and possibility of first game played having an influence on respondents' choices in the second game, among other factors, each variable (cooperativeness and time preference) is obtained from separate groups of respondents in Chapters 4 and 5, respectively.

\subsection{Outline}

The chapters in this thesis are organized as follows. Chapter 2 describes and estimates some of the governance dimensions that could affect the sustainability of WUA-managed irrigation schemes in northern Ghana from the user perspective. It also analyses possible factors that can associate with the perceptions of users regarding irrigation governance. Chapter 3 assesses the influence of governance perceptions on irrigation performance in terms of productivity. Chapter 4 examines the role of users in sustaining irrigation resources. It pays particular attention to effects of user cooperativeness in contributing towards maintenance activities. Chapter 5 analyses the correlations between governance perceptions, time preferences, and labour contributions to maintenance. Chapter 6 synthesizes the main findings of the thesis and discusses their implications for the development of irrigated agriculture. 


\title{
CHAPTER 2
}

\section{Measuring governance of irrigation systems: A user-based approach}

\begin{abstract}
Current advocacies are in favour of irrigation development in dry areas of developing countries to reduce poverty. Attempts at irrigation development in Ghana, as in many other parts of sub-Saharan Africa, have however been characterized by governance challenges at various levels. This paper presents an empirical assessment of irrigation governance in northern Ghana from a user-based approach. We first construct measures of irrigation governance from ratings provided by local water users. We also examine the relationship between resulting irrigation governance indicators and some objective factors that possibly drive users' assessments of governance. We find that the availability of water through high precipitations and plot locations of irrigators are factors that significantly influence irrigation governance perceptions. We note that though the number of users in a scheme influences governance perceptions in some dimensions of governance, it is not significant in the overall assessment of irrigation governance. We conclude that the lack of progress in some irrigation facilities in northern Ghana being attributed to bad governance is specific to some dimensions of governance. We recommend routine repairs of major infrastructural damages beyond the capacity of famer groups in sustaining irrigation facilities.
\end{abstract}

Publication status: Akuriba, M.A, Haagsma R., Heerink N., and Dittoh S., 2018. Measuring Governance of Irrigation Systems in Ghana: A User-Based Approach. Working paper. 


\subsection{Introduction}

Agriculture is an important sector and a major element in development policies in subSaharan Africa. Current advocacies are in favour of irrigation development to help mitigate effects of erratic and unevenly distributed rainfall patterns. The New Partnership for Africa Developm ent (NEPAD)'s Com prehensive African Agriculture Developm ent Program me stresses the need to rapidly increase the area equipped with irrigation, especially small-scale water control, in order to provide farmers with opportunities to raise output on a sustainable basis and contribute to the reliability of food supplies (NEPAD, 2003).

The evolution of formal irrigation in Ghana thrived in the 1960s with the construction of public irrigation schemes to encourage farmers to practice irrigation. Attempts at irrigation development in Ghana, as in many other parts of sub-Saharan Africa, have however been characterized by construction, maintenance, management and coordination problems at various levels over the years (Balmisse et al., 2003; Dittoh et al., 2013a). Envisaging these challenges, many developmental programs encouraged African countries to switch to participatory approaches for irrigation management in the 1980s. With the participatory approach, authority is transferred to Water User Associations and the private sector for irrigation management. Moreover, the prominence of management and coordination challenges in large-scale irrigation schemes has created a preference for small-scale irrigation (Birner et al., 2010; van Edig et al., 2003).

Construction of small-scale irrigation schemes in Ghana usually aims at economic empowerment of less-privileged communities in terms of livelihoods. Most of these smallscale infrastructures are located in the northern part of Ghana, where rainfalls are monomodal, erratic, and unevenly distributed. The Ghana Irrigation Development Authority (GIDA) designs and constructs the facilities with funding from donor agencies. Learning from Ghana's unsuccessful experience in public managem ent of irrigation schem es in the past, water users associations (WUA) are formed in most cases to manage small-scale irrigation schemes after construction (Namara et al., 2011).

Small-scale irrigation is however not without challenges. Birner et al. (2010) assessed whether small-scale reservoirs can avoid the governance challenges experienced in large- 
scale irrigation in Ghana and reported that a high number of small reservoirs in the Upper East Region of Ghana are not in use due to governance failures. Other studies show that the institutional mandates on irrigation development in Ghana are unclear, while in many schemes poor operation and maintenance of facilities have led to low rates of utilisation (Dittoh et al., 2013a; Lamptey et al., 2011). As pointed out by Ostrom (1990), without strong and effective institutions, common pool resources such as irrigation facilities will generally be overexploited.

Good governance is essential for irrigation systems to work effectively (Dittoh et al., 2013b; Howarth et al., 2005; Norton, 2004). The success of irrigation resource governance may differ from one resource to the other depending on the characteristics of the governing WUA (Agrawal, 2003; Zhang et al., 2013) and the physical features of the resource such as its geographical location and/or the dominant crop grown. The nature of the resource informs the governance strategies to be employed by WUAs for long-term sustainable use of the resource. Similar strategies applied to resources with different physical characteristics may yield different degrees of governance success.

The question that arises is: what measures of irrigation governance can be used to assess the performance and sustainability of WUA-managed irrigation schemes? It is difficult to find and agree on appropriate indicators since good governance carries political connotations (Hyden and Court, 2002; Kaufmann et al., 2011). The World Governance Indicators developed by Kaufmann et al. $(2004,2009,2011)$ include both objective and perceptions data to measure and compare governance across countries. It was noted that data for objective governance dimensions are often not available; when they are available, they may capture what the regulatory environment requires, which often differs substantially from the realities on the ground. Moreover, subjective perceptions of governance are assumed to matter as well. The 2013 Resource Governance Index also includes both objective and subjective indicators to measure governance of the extractive sector (Index, 2013). At the micro level, composite indicators that comprise both objective and subjective measures have been used to evaluate, for instance, Lake Basin water governance (Cookey et al., 2016) and the performance of urban water utilities that can inform governance directions (Gallego-Ayala et al., 2014). 
Even though the low performance of public irrigation schemes in Ghana is commonly attributed to bad irrigation governance (Dittoh et al., 2013b; Poussin et al., 2015; Venot and Hirvonen, 2013), indicators of irrigation governance have not yet been developed to our knowledge, neither for Ghana nor for other regions in the world. Such indicators can be used to compare the levels of governance of different irrigation systems, and relate them to the performance of those irrigation systems. This paper presents an empirical assessment of irrigation governance in northern Ghana from a user-based approach, with measures of irrigation governance constructed from ratings provided by local water users. We also examine the relationship between the resulting irrigation governance indicators (IGIs) and som e objective factors that possibly drive the users' ratings of governance in order to obtain insight into what explains variation in IGIs across irrigation systems.

We employed a user-based approach because "local users are often the ones with the greatest stakes in sustainability of resources and institutions" (Agrawal, 2002), and sustainability of irrigation resources is not only about the physical property of the systems but also about the incentives of local users to sustain the systems (Abernethy, 2010). Users' satisfaction with management strategies can be an important incentive for sustainable use of irrigation facilities. Hence, stakeholder opinion is vital in assessing governance. Inadequate records of irrigation management data in Ghana and the fact that certain aspects of governance are difficult to measure objectively (Kaufmann et al. 2011, 2009, 2004) also motivated the use of subjective measures in this study.

Following Agrawal's (2003) resource governance framework, we developed questions related to factors considered relevant for sustainable governance of irrigation system s. Users' perceptions were rated using a five-point Likert scale. The responses were mapped into six dimensions of governance. Tobit-Cluster-Robust regressions were performed to examine the relationship between each of these dimensions and factors that potentially explain their variation across and within irrigation systems.

In Section 2.2 we present a conceptual background encompassing the assessment of governance through perceptions, critical factors influencing governance perceptions, and our 
hypotheses. The research methodology is presented in Section 2.3, followed by results and conclusions in Section 2.4 and Section 2.5 respectively.

\subsection{Conceptual background and hypotheses}

\subsubsection{Assessing governance through perceptions}

Public irrigation schemes are so-called common pool resources, which are resources characterized by rivalry in consumption and non-exclusiveness (Ostrom and Gardner, 1993; Ostrom, 2000). Their open access nature can lead to overuse of the resource by some individuals and thereby create negative externalities for others in the short or long run (Birner et al., 2005; Ostrom, 2000). Without proper governance, therefore, public irrigation schemes are likely to suffer from the "tragedy of the commons" (GWP, 2009; Ostrom, 2000; Tortajada, 2010).

Following Herrera et al. (2014), irrigation governance in this paper concerns the rules and regulations that determine the use of irrigation resource by local users. There are several dimensions of governance that one can use to assess whether a resource is properly governed or not, including participation, transparency, accountability, equity, control of corruption, and sustainable management (GWP, 2009; Lautze et al., 2011; Mansungu, 2004; Rogers and Hall, 2003; Tortajada, 2010). These dimensions are often difficult to measure objectively and, therefore, generally require additional subjective assessments by stakeholders.

Common pool resources such as irrigation facilities are indeed best assessed on governance effectiveness when perceptions of stakeholders are taken into consideration for the reasons explained by Kaufmann et al. (2011, 2006). They argue that for certain dimensions of governance, such as corruption, it is almost impossible to get objective data. Campbell (2007) adds that resource managers take decisions based on their perceptions of the most pressing need, which also makes perceptions data valid. Whether perceptions-based management decisions are appropriate also depends on the physical outcomes of these decisions and the 
perceived effect this has on stakeholders. Perceptions data particularly allow greater detail when discussing governance dimensions (Joshi, 2010).

However, perceptions data come with some challenges. Joshi (2010) explains that perceptions data is sometimes exposed to judgement bias of the author or the evaluating body. Kaufmann et al. (2006) and Gelb et al. (2007), argue that questions about perceptions are sometimes vague and open to different interpretations. A systematic approach to limit or avoid these biases, according to Mainhardt-Gibbs (2010), is to apply questionnaires to relevant stakeholders. Jones and Tanner (2015) add that, for comparative purposes, it is then better to use closed-ended questions instead of open and semi-structured interviews. The latter may allow for in-depth understandings, but also increases the risk for bias when authors try to quantify the results for comparative purposes.

This study is mainly concerned with the perceptions of members of water user groups as measures of irrigation governance. Water User Associations (WUAs) are the main bodies in charge of operation and maintenance of public irrigation facilities at the community levels in Ghana. The irrigation facilities are mostly dams with canals using gravity-flow systems. The Global Water Partnership (Rogers and Hall, 2003) and UNDP (2004) emphasize the importance of active involvement of society or end users in water governance. Moreover, Ostrom (1990) pointed out that when users of a common resource organize themselves into associations, they may manage the resource effectively and sustainably. The effectiveness of governing strategies of WUAs may therefore be best assessed when opinions of the main stakeholders (WUA members) are considered.

\subsubsection{Critical factors influencing governance perceptions}

Governance perceptions are influenced by several factors exogenous to users. We briefly discuss here the impact of the size of irrigation schemes, geographical location of schemes, main crop grown at a scheme and location of individual plots. 
Wade (1994) and Agrawal (2001) see the size of a resource as one of the factors affecting sustainable governance of common pool resources, because smaller resources are easier to manage than large-scale resources. Ratner et al. (2013) notes that small-scale resources allow for more effective monitoring. The management of water resources is particularly affected by the size of the scheme, because large-scale schemes are usually managed by state agencies while small-scale schemes are managed by private user groups (Kyei-Baffour and Ofori, 2007). The size of a resource relative to the number of users also determines whether the resource is scarce or abundant to users. There are two divergent views in relation to natural resource availability (especially water and forest) and implications on resource governance (Mildner et al., 2011). One school of thought explains that scarcity of resources leads to violent conflicts, which impacts negatively on resource governance. The other school argues that resource abundance leads to conflicts over resource use due to the so-called resource curse. Though some of the discussions are at the macro level, the issues raised are evident at community common pool resources (CPRs) and may influence CPRs governance assessment. The size of an irrigation scheme may be a blessing when large schemes meet users' expectations. However, it becomes a curse when leaders (at both local and national level) dwell on its nature to cheat users in terms of resource allocation and imposition of unacceptable laws that potentially lead to conflicts. The size of an irrigation scheme can thus have any directional effect on users' assessm ent of irrigation governance effectiveness.

Geographical location of the resources also affects governance. In the case of irrigation, both physical and natural features of the locality are critical determinants in siting and managing irrigation facilities. Drier localities generally need irrigation facilities more for sustainable agricultural production than relatively wet areas, making irrigation especially relevant for regions with low annual rainfall (Pimentel et al., 2004). The rapid urbanization of rural settings coupled with climate change also threatens irrigation development (Faures and Mukherji, 2009; UNESCO, 2007). When livelihoods are tied to the existence of irrigation facilities, users may sometimes impose stringent rules to avoid overuse and negative externalities. A user's assessment of the governance of such resources is informed by this need for sustainable use amidst climatic variability.

The kind of crop grown at an irrigation facility can also affect its governance. Water demands vary from crop to crop, from as little as twice a week as in the case of alefu, an indigenous 
vegetable in northern Ghana, to as high as seven times a week in the case of okra and tomatoes (Namara et al., 2011). To ensure equal access to water use, WUAs sometimes have to agree on one particular crop to grow in a season, taking into account water availability, prices, and diseases, among other factors. The choice for a specific crop restricts users' strategies in maximizing farming as a business and may thus affect their perceptions on governance.

The location of one's plot in an irrigation scheme equally plays an important role on how one assesses the governance of a facility. Managing irrigation water can be challenging when there are diverging interests between head-enders and tail-enders (Cardenas, 2011; Ostrom and Gardner, 1993). Aida (2012) explains that head-enders and tail-enders have different access to water and failure of irrigation management is often a result of this heterogeneity. As pointed out by Bardhan and Dayton-Johnson (2002), the presence of heterogeneity among irrigators makes it difficult to implement equitable management strategies. Figure 1 is a schematic illustration of factors that influence users' assessments of irrigation governance.

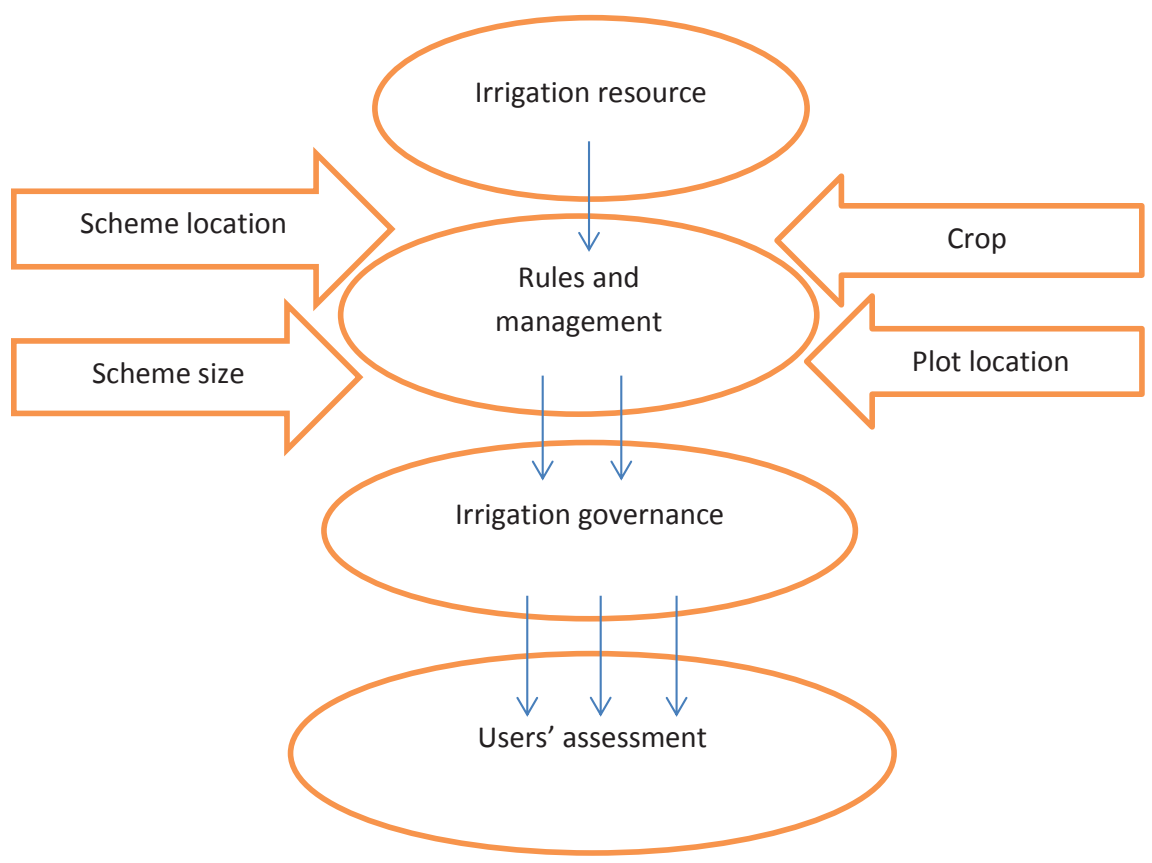

Figure 2.1: Irrigation governance framework 


\subsubsection{Hypotheses}

In line with the above discussion of four critical factors that may influence governance perceptions, this study investigated the following four hypotheses:

1. Scheme Location hypothesis. Given that irrigation is practised at different locations in Ghana, we expect that the governance of irrigation schemes differs by region because of the following. Irrigation reservoirs can store water from upstream rivers and underground recharge. However, water supply from most rivers is insufficient due to their short tributaries, so that most schemes also rely on local precipitations. Especially the annual precipitation within the immediate confines of the reservoir influences the amount of water stored and/or recharged. Low annual precipitation may thus lead to low water availability for irrigation. Water scarcity is likely to increase tensions among users, thereby creating challenges for good governance that may be hard to face. Therefore, we hypothesize that

Users in dry locations will report lower governance ratings.

2. Crop hypothesis. Because crops differ in water demand, the dominant crop grown at a scheme may affect the governance of irrigation facilities. Some crops demand frequent irrigations for short or long periods, while other crops require lower frequencies of irrigation. Uncertainties in estimated volumes of water in reservoirs and in water demands of users make it especially difficult to govern the irrigation of more water-demanding crops. Our hypothesis, therefore, is that

Users of schemes growing more water-demanding crops will report worse irrigation governance.

3. Size hypothesis. Management strategies differ from scale to scale. Schemes with larger reservoirs have more users, and therefore increase demands on strategies that can ensure equity among users and long-term sustainable use. At the same time, schemes managed by more users raise problems of collective action, which is critical 
for the sustainable governance of common pools. We therefore represent size by number of users in a WUA, and hypothesize that

Users in larger WUAs will report worse irrigation governance.

4. Plot hypothesis. The location of an irrigator's plot usually influences the tim eliness of water allocated to the plot. Head-enders (those who are closest to the reservoir) are normally first to be allocated, before middle- and tail-enders, respectively. In the event of water shortage or reservoir defects, it is likely that tail-enders will suffer the most impact. Hence, plot location will affect expectations as well as evaluations of irrigation water governance, with tail-enders being the most critical. Thus we hypothesize that

Tail-enders will report lower governance ratings.

\subsection{Methodology}

\subsubsection{Context and data collection}

Irrigation in Ghana is broadly classified into two systems: conventional/public and emerging systems (Namara et al., 2011). Public systems are designed and developed by the government or by non-governmental organizations for public use and most of them are surface irrigation systems. Emerging systems are privately owned and employ various irrigation technologies such as drip, or pumping machines (for underground water) to grow crops mostly for export. Though small reservoirs in northern Ghana have several uses, including fishing, block moulding, and livestock watering, WUAs are mostly composed of irrigators (Acheampong and Venot, 2010; Gyasi et al., 2005). The size of the developed area for irrigation is the main criteria used in classifying schemes in Ghana. Those up to 200 ha are regarded as small-scale, between 200 ha and 1,000 ha as medium-scale, and 1,000 ha and above as large-scale (KyeiBaffour and Ofori, 2007; Namara et al., 2011). The small-scale schemes of this study consist 
of a main canal that conveys water from the dam and a number of laterals that convey water from the main canal across plots.

A questionnaire was designed to collect primary data from 370 irrigators in 37 small-scale irrigation schemes. Data was collected by teaching assistants from the University for Development Studies in Tamale with supervision from the principal researcher from November 2014 to April 2015. Respondents were randomly sampled from membership lists of WUAs.

For each scheme, the WUA Chairman (or Assembly man in the case of Gbache and Balawa communities) was informed about the research. The chairmen then announced to all group members who cultivated a particular crop (whichever one was predominant in the scheme) to attend a meeting on a scheduled date. In some instances the chairmen passed the information through lateral leaders, in other instances through community leaders (in cases where the dam served more than two communities). In each community there are designated people who beat drums to draw people's attention to announcements. It is the usual method used if information is required to reach all members of a community. However, social activities such as funerals, which are performed in the dry season, may have prevented a few users from attending. Selected farmers who were not present were replaced (this only happened in two schemes). We assume that the few absentees do not have characteristics fundamentally different from the majority who attended. Because of the heavy presence of NonGovernmental Organisations (NGOs) in northern Ghana, water users are active when meetings are called.

At each scheme, the objectives of the research were explained to WUA members. Those who did not want to take part had an option to leave, but in every scheme, everyone that attended also wanted to take part in the research. Simple Random Sampling technique (lottery method) was used to select ten respondents for the household interviews at each scheme. Those remaining were free to take part in group discussions. Table 2.1 presents the characteristics of respondents and irrigation schemes. 
Table 2.1: Characteristics of water users

\begin{tabular}{|c|c|c|c|}
\hline Characteristic & Distribution & Frequency & Percentage \\
\hline \multirow[t]{3}{*}{ Age (years) } & Mean & 41.5 & - \\
\hline & Min & 16 & - \\
\hline & Max & 85 & - \\
\hline \multirow[t]{2}{*}{ Sex } & Male & 252 & 63 \\
\hline & Female & 148 & 37 \\
\hline \multirow[t]{3}{*}{ Household size } & Mean & 8.45 & - \\
\hline & Min & 2 & - \\
\hline & Max & 18 & - \\
\hline \multirow[t]{3}{*}{ Mobility* } & Mean & 2.95 & - \\
\hline & Min & 0 & - \\
\hline & Max & 28 & - \\
\hline \multirow[t]{3}{*}{ Experience in irrigation (years) } & Mean & 16.15 & - \\
\hline & Min & 1 & - \\
\hline & Max & 63 & - \\
\hline \multirow[t]{3}{*}{ Irrigated land per user (acres) } & Mean & 0.93 & \\
\hline & Min & 0.13 & \\
\hline & Max & 8 & \\
\hline \multirow[t]{3}{*}{ Region** } & UER & 290 & 72.5 \\
\hline & UW & 70 & 17.5 \\
\hline & NR & 40 & 10 \\
\hline \multirow[t]{3}{*}{ Plot location*** } & Head & 109 & 27.25 \\
\hline & Middle & 179 & 44.75 \\
\hline & Tail & 112 & 28 \\
\hline \multirow[t]{3}{*}{ Crop } & Tomatoes & 190 & 47.5 \\
\hline & Pepper & 110 & 27.5 \\
\hline & Onions & 100 & 25 \\
\hline \multirow[t]{3}{*}{ Number of users in scheme } & Mean & 75.92 & - \\
\hline & Min & 17 & - \\
\hline & Max & 200 & - \\
\hline \multirow{3}{*}{$\begin{array}{l}\text { Average annual precipitation in } \\
2012(\mathrm{~mm})\end{array}$} & Mean & 980.27 & - \\
\hline & Min & 917 & - \\
\hline & Max & 1091 & - \\
\hline
\end{tabular}

* Number of times a water user migrated during the irrigation season

** Upper East Region (UER), Upper West Region (UWR), and Northern Region (NR)

$* * *$ Head-enders are upstream irrigators whose plots are within $1 / 3$ of whole irrigable area close to the headworks. Tail-enders are the 1/3 downstream and middle-enders are the $1 / 3$ between head and tail. 
Data collected included information on crop/livestock production, farm inputs, land tenure arrangements, use of water, WUAs management structure and their activities (governance in general), and yields and prices. From the regional directorates of GIDA, expert opinions were sorted on sampling and validation of the issues that needed to be assessed by users.

Three crops were considered in the study: tomatoes, onions, and pepper (see Table 2.1). Even though a variety of crops are under irrigation in northern Ghana, each scheme has a dominant crop. Households have little control in their choice of crop, and very much rely on group choice or recommendations, because of uncertainty relating to recurring problems such as diseases (for instance presence of nematodes), crop destruction by livestock requiring joint action, and limited market availability. The selected crops are the dominant, if not the only, irrigated crops at most schemes in the study area.

Tomatoes and onions are the most grown cash vegetables. These crops have varying needs of water allocation with an average of about 36 irrigations in onion production per period (thrice a week for three months) to a high of about 84 irrigations in tomato production per period (once a day for three months). Pepper demands on average only two irrigations per week for at least four months (36 irrigations per period, but for a longer period). This means that the water demands of onions and pepper are similar in that they both require about 36 irrigations per period, and only differ in the length of the period; tomatoes demand the most water.

\subsubsection{Defining dimensions of irrigation governance}

Governance can be measured along several dimensions, where each of these dimensions should consider an aspect of governance that is desirable to measure. For common resources like irrigation schemes managed by users, the selected dimensions should in any case include aspects of sustainable use and equal access. Below we explain six dimensions of governance that we selected for our study, largely based on the available literature on preconditions for successful governance of irrigation resources (GWP, 2009; Lautze et al., 2011; Mansungu, 2004; Rogers and Hall, 2003; Tortajada, 2010). The six dimensions are summarized and grouped in Table 2.2 . 


\section{Participation}

Understanding and willingness by users to participate in the management of a common resource is important in irrigation development (Howarth et al., 2005; Mansungu, 2004; Ostrom, 2000; Rogers and Hall, 2003). It is not only important in ensuring strong and effective WUAs (Howarth et al., 2005), but also gives users a voice in management decisions (Kaufmann et al. , 2011). Participation at the design stage of the irrigation resource is recommended, but this is mostly ignored in the case of Ghana. Women are sometimes marginalized in the use of resources due to socio-cultural and physical reasons, but their inclusion is recommended for the sustainable management of water resources (Phirun and Chhuong, 2014; UNDP, 2004). The different roles of men and women recognized at community level may complement each other in completing maintenance tasks. Maintenance activities involve the stacking of embankments and canals with gravel and stones, desilting of canals and waterways, weeding around facilities, and other activities. They improve water flows downstream and encourage on-farm water management for higher yields.

We measure participation by assessing the extent to which users have access to good irrigation facilities and can influence their access through participation in WUAs. Thus, we asked, among other things, whether decisions on management and maintenance are taken jointly involving all users; whether users have rights to use all facilities; whether this holds for both men and women; and whether WUAs are determined to gain recognition by higher authorities like the District Assembly (and thus to be considered for best farmer awards among other incentives) (see Table 2.2).

\section{Accountability}

WUAs are required to be accountable to their members, with clear procedures and rights of appeal (Howarth et al., 2005; Marimbe and Manzungu, 2003). This is accomplished through either the formation of unit committees or the election of leaders from WUAs. Whichever form it takes, the leadership should be accountable to its members (Howarth et al., 2005; Marimbe and Manzungu, 2003). Leadership is also required to show commitment to its 
responsibilities by allowing free flow of information concerning all activities (Norton, 2004). When there is trust in the way a scheme is being managed and led, users will be encouraged to adopt best practices needed for sustainable productivity increases.

We assessed accountability by asking users about their access to general information from their leaders and specifically on expenditure and financial standings of WUAs. We further asked whether they thought that their WUA leaders were committed to tasks for which they were appointed and whether WUA members had confidence in the way their executives carried out their duties, especially on management of finances.

\section{Conflict management}

Conflicts in irrigation schemes often occur over the direct extraction of water from canals between users, and about regulations concerning use of the facility (Kramm and Wirkus, 2010). Conflicts may also arise from land and water allocation, tensions in leadership, price negotiation, and expenditures. As noted by Howarth et al. (2005), disputes over the use of financial resources are common reasons for WUAs to become dormant. Being able to manage conflicts among water users is important in successfully governing irrigation facilities. There is a need for rules concerning conflicts, and a step-by-step process in sanctioning rule breakers in the use of common pool resources. However, arenas for conflict resolution should be low-cost for sustainable common pool resources (Ostrom, 1990).

Our index for conflict management is assessed from several indicating factors of proper conflict resolutions including WUAs' ability to: resolve conflicts to the satisfaction of parties involved; handle tensions in leadership; resolve price- and market-related conflicts; and use graduated sanctions as recommended in Agrawal (2003). 


\section{Transparency and cooperation}

Transparency is a key component of good resource governance (Index, 2013). Sustainable use of irrigation resources at the community level particularly requires cooperation between water users ( van Edig et al., 2003). Transparency is needed at all levels of information, procedures, finances, and distribution of water to an agreed schedule (Howarth et al., 2005). WUA executives have to be transparent in order to gain trust and cooperation from WUA members.

We assessed transparency and cooperation from about 15 indicating factors ranging from democracy to effective monitoring and control of water discharge (Table 2.2). In terms of democracy, we enquired whether group members had the freedom of expression regarding management decisions, and for corruption we assessed the existence of fraudulent acts in groups, such as stealing of group money by leaders or execution of transactions unapproved by groups.

\section{Equity and fairness}

Equity and fairness are important in governing irrigation resources (Hussain and Hanjra, 2003; Namara et al., 2010). All rightful users have rights to be allocated land and water. However, tensions sometimes arise due to disparities in allocating land and water to users. Men and women are treated differently in some traditional settings and this affects their rights to economic resources like land and water. Also, head-enders and tail-enders are in some instances made to pay the same water charge even when they do not benefit from water allocation equally. These are some of the challenges influencing irrigation-governing decisions.

We assessed this dimension by making enquiries about whether users of the irrigation resource in question are well-defined. "Well-defined users" as indicated in Agrawal (2003) is one characteristic of users that is required for successful resource governance. The first step to ensuring equity and fairness is to allocate irrigation resources to rightful users without biases. Other indicators included availability of irrigable land, equitable access to irrigation 
water and land, adequacy of water charge, and available buyers and good prices for irrigated products (Table 2.2).

\section{Sustainable use}

Sustainable use of water resources is critical in irrigation governance (Mansungu, 2004; Marimbe and Manzungu, 2003; Rogers and Hall, 2003; UNESCO, 2015). As proposed by FAO (2014), responsible and effective governance mechanisms are required for a sustainable food and agriculture sector. In the governance of irrigation facilities under water scarcity, care needs to be taken so that strong competition for water does not worsen the limiting resource for agriculture (FAO, 2011; Pereira et al., 2002; Wichelns and Oster, 2006). For an irrigation facility to be sustainable it should show signs of producing enough water for the present and the future through effective maintenance and monitoring mechanisms. It is stated in the Ghana Irrigation Development Policy that irrigation development planning should pay attention to "the need for sustainability in term s of operation, $\mathrm{m}$ aintenance, com peting needs and the conservation and responsible use of natural resources" (Lamptey et al., 2011). The output levels, availability of markets, and good prices are also indicating factors of the sustainability of an irrigation facility. When prices are good, irrigators will make good profits to keep them in production and this motivates them to use the facility judiciously. We assessed sustainable use from various indicators including: availability and sufficiency of water in the facilities over the past years; water availability in the future; soil and water quality; irrigated outputs and prices; management and maintenance of irrigation facilities; and trust in the WUA and District Assembly in the general management and support of irrigation facilities (Table 2.2). 
Table 2.2: Summary of irrigation governance dimensions and their variables ${ }^{1}$

\begin{tabular}{|c|c|c|c|c|c|}
\hline Participation & Accountability & $\begin{array}{l}\text { Conflict } \\
\text { management }\end{array}$ & Transparency and cooperation & $\begin{array}{l}\text { Equity and } \\
\text { fairness }\end{array}$ & Sustainable use \\
\hline $\begin{array}{l}\text { Participation of } \\
\text { eligible users } \\
\text { in the use and } \\
\text { management of } \\
\text { facility (right } \\
\text { of use) } \\
\text { Participation in } \\
\text { decision } \\
\text { making } \\
\text { involving all } \\
\text { users (joint } \\
\text { decisions) } \\
\text { Recognition of } \\
\text { users by higher } \\
\text { authority (e.g. } \\
\text { participation in } \\
\text { best farmer } \\
\text { awards) } \\
\text { Participation } \\
\text { by gender } \\
\text { (women } \\
\text { involvement in } \\
\text { irrigation } \\
\text { management) } \\
\text { Participation of } \\
\text { all users in } \\
\text { maintenance }\end{array}$ & $\begin{array}{l}\text { Access to } \\
\text { information by } \\
\text { users } \\
\text { Dissemination } \\
\text { of expenditure } \\
\text { and financial } \\
\text { standing of } \\
\text { WUA } \\
\text { Leaders' } \\
\text { commitment to } \\
\text { duties } \\
\text { Confidence of } \\
\text { users in leaders } \\
\text { Management of } \\
\text { finances }\end{array}$ & $\begin{array}{l}\text { Satisfaction } \\
\text { of conflicting } \\
\text { parties in } \\
\text { land- and } \\
\text { water-related } \\
\text { conflicts } \\
\text { Handling of } \\
\text { tensions in } \\
\text { leadership } \\
\text { Price- and } \\
\text { market- } \\
\text { related } \\
\text { conflict } \\
\text { resolutions } \\
\text { Use of } \\
\text { graduated } \\
\text { sanctions }\end{array}$ & 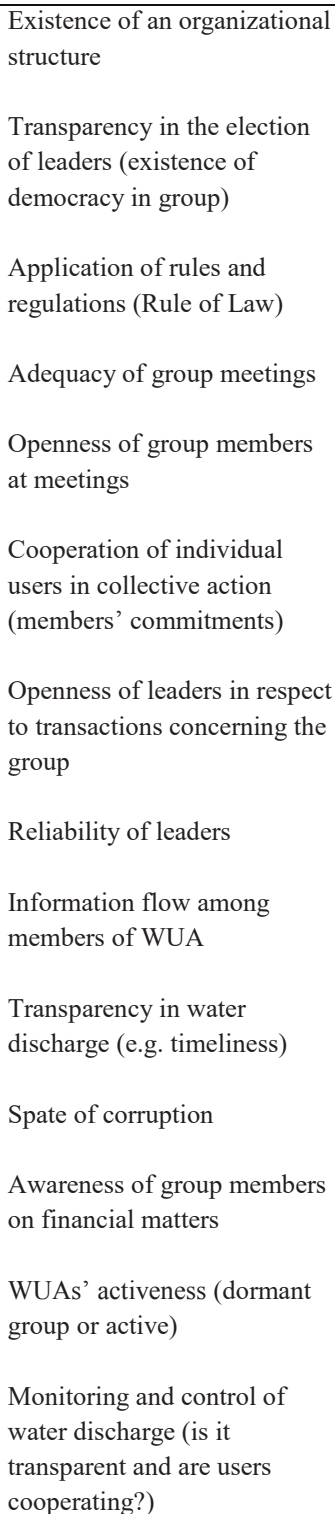 & $\begin{array}{l}\text { Well-defined } \\
\text { users } \\
\text { Adequacy of } \\
\text { irrigable land } \\
\text { (compared to } \\
\text { number of } \\
\text { users) } \\
\text { Equitable } \\
\text { access to } \\
\text { water } \\
\text { Adequacy } \\
\text { and fairness } \\
\text { of water } \\
\text { charge } \\
\text { Available } \\
\text { market for } \\
\text { irrigated } \\
\text { produce }\end{array}$ & $\begin{array}{l}\text { Suitability of soil } \\
\text { for irrigation } \\
\text { Management of } \\
\text { facility } \\
\text { (effective?) } \\
\text { Availability of } \\
\text { water over the } \\
\text { years } \\
\text { Sufficiency of } \\
\text { water for } \\
\text { irrigation in the } \\
\text { current year } \\
\text { Availability of } \\
\text { water in coming } \\
\text { year } \\
\text { Water quality } \\
\text { maintenance of } \\
\text { facility } \\
\text { putput from } \\
\text { products } \\
\text { irrigated } \\
\text { irrigation } \\
\text { Trust in WUA } \\
\text { for the general } \\
\text { management of } \\
\text { facility } \\
\text { Support from } \\
\text { assembly and } \\
\text { district officials } \\
\text { pood } \\
\text { pod }\end{array}$ \\
\hline
\end{tabular}

\footnotetext{
${ }^{1}$ Chosen variables were motivated by governance frameworks (Agrawal, 2003; Ostrom, 2009) and the management structure of WUAs
} 


\subsubsection{Estimation and analytical approach}

\section{Governance estimation}

The 46 features of governance listed in Table 2.2 were incorporated into the household questionnaire in the form of positive statements. Respondents were asked to rate these statements using the following 5-point Likert scale:

1. Strongly disagree

2. Disagree

3. Neither agree nor disagree

4. Agree

5. Strongly agree

Statements were mapped into the six indicated dimensions of governance. To calculate a composite indicator for each dimension, we employed an equal weighting system, which is the most common technique at both macro and micro levels (Cookey et al., 2016; Mazziotta and Pareto, 2013; OECD, 2008). Also, each dimension of irrigation governance is considered equally important in assessing overall irrigation governance.

\section{Hypotheses testing}

To test the validity of our hypotheses, we examined the relationship between governance scores per dimension and factors that could be associated with governance perceptions using regression analysis. In studies where a single survey item is unlikely to fully capture a concept being assessed, like irrigation governance dimensions in our case, the Likert-scale approach where several Likert items are created and grouped into a "survey scale" as presented in Table 2.2 is the recommended practice (Gliem and Gliem, 2003; Sullivan and Artino Jr, 2013). Parametric analysis can then be carried out using total scores or mean scores calculated for the scale items provided the scale passes the Cronbach alpha test of internal consistency (Sullivan and Artino Jr, 2013). The Cronbach alpha test for our governance assessment scales are presented in Table 2.3. The Cronbach alpha has an upper value of 1 and 
has no lower limit. As a rule of thumb, Cronbach alpha greater than or equal to 0.7 is acceptable (George and Mallery, 2003) and implies that the components of the scale are intercorrelated and the grouped items sufficiently measure the underlying variable. Cronbach alpha close to or equal to 1 is discouraged for this may mean that the variables in the scale only measure one aspect of the concept under study and not the variability required.

Table 2.3: Cronbach alpha test of irrigation governance dimensions scales

\begin{tabular}{lccc}
\hline $\begin{array}{l}\text { Irrigation Governance } \\
\text { Dimension }\end{array}$ & $\begin{array}{c}\text { Number of Variables } \\
\text { Participation }\end{array}$ & $\begin{array}{l}\text { Average Interim } \\
\text { Covariance }\end{array}$ & $\begin{array}{l}\text { Scale Reliability } \\
\text { Coefficient }(\alpha)\end{array}$ \\
$\begin{array}{l}\text { Accountability } \\
\text { Conflict management }\end{array}$ & 5 & 0.27045 & 0.72 \\
Transparency and & 4 & 0.30676 & 0.70 \\
cooperation & 14 & 0.24497 & 0.82 \\
Fairness and equity & 7 & 0.36959 & 0.85 \\
Sustainable use & 11 & 0.22681 & 0.71 \\
- Note: $\alpha \geq 0.7$ is reliable & & 0.23550 & 0.70 \\
\cline { 2 - 4 }
\end{tabular}

Table 2.3 indicates that the set of items included in each governance dimension are closely related as a group. Therefore, we take an average response for indicators in each dimension as an irrigator's governance perception in that dim ension to be the dependent variable. Since irrigation governance dimensions are given equal weights, overall governance response of an irrigator is an average of the six dimensions. A score closer to 1 signifies bad governance, while that closer to 5 will signify good governance. The range is classified as:

$$
\begin{array}{ll}
1 \leq \mathrm{IGR}_{i}<2 & =\text { very bad governance } \\
2 \leq \mathrm{IGR}_{i}<3 & =\text { bad governance } \\
3<\mathrm{IGR}_{i} \leq 4 & =\text { good governance } \\
4<\mathrm{IGR}_{i} \leq 5 & =\text { very good governance }
\end{array}
$$


Given that the dependent variable is limited and censored, we used a Tobit regression approach. The model is formulated as

$$
\begin{aligned}
& I G R_{i k}=f\left(R_{i}, U_{i}, C_{i}, P_{i}, O_{i}\right)+\varepsilon_{i k} \quad \text { for } i=1, \ldots, 370 \quad k=1, \ldots, 6 \\
& I G R_{i}=f\left(R_{i}, S_{i}, C_{i}, P_{i}, O_{i}\right)+\varepsilon_{i}
\end{aligned}
$$

Where;

$I G R_{i}=$ overall governance rating by user $i$

$I G R_{i k}=$ rating of dimension $k$ by user $i$

$R_{i} \quad=$ annual precipitation of the location of user $i$

$U_{i} \quad=$ number of users in the irrigation scheme of user $i$

$\mathrm{Ci} \quad=$ main crop (pepper, onions, tomatoes) in scheme to which user $i$ belongs

$\mathrm{Pi} \quad=$ plot location (head-, middle-, tail-end) of user $i$

$\mathrm{O} i \quad=$ control factors (sex, age, mobility and experience) of user $i$

$\varepsilon_{i} \quad=$ error term

We employed the Variance Inflation Factor (VIF) approach to check for potential multicollinearity. VIF quantifies the severity of multicollinearity in Ordinary Least Squares regressions (Farrar and Glauber, 1967; Kock and Lynn, 2012). As a rule of thumb, VIF greater than 10 may be seen as signalling the presence of multicollinearity in the predictor variables. None of the VIF estimates of our predictors exceeded 3.

The six equations were estimated independently, even though their error terms may be correlated. As the equations have identical explanatory variables, seemingly unrelated regressions methods will not give more efficient estimates as compared to independently estimated equations (Greene, 1993: p. 488).

From Cameron and Miller (2015), a control is needed in regression models where observations can be grouped into clusters, with model errors uncorrelated across clusters but likely correlated within-cluster. An exam ple of "clustered errors" cited is individual-level cross-section data with clustering on geographical region (scheme in our case). The model 
errors for individuals in the same scheme may be correlated, while model errors for individuals in different schemes are uncorrelated. Failure to control for within-cluster error correlation can lead to misleading small standard errors, narrow confidence intervals, large tstatistics and low p-values (Cameron and Miller, 2015). In this case, we estimated clusterrobust standard errors. Table 2.4 summarizes the definitions of the variables in our estimated models and their measurements.

Table 2.4: Variable definitions and measurements

\begin{tabular}{ll}
\hline Variable & Definition and measurement \\
\hline Gov (P,A,C,TC,FE,S) & Individual governance ratings, where $\mathrm{P}=$ participation, $\mathrm{A}=$ \\
& accountability, $\mathrm{C}=$ conflict management, $\mathrm{TC}=$ transparency and \\
& cooperation, $\mathrm{FE}=$ fairness and equity, $\mathrm{S}=$ sustainable use \\
Sex & Male=1, Female= 0 \\
Age & Age of irrigator (in years) \\
HHsize & Household size \\
Mob & Mobility (number of times irrigator migrated last season) \\
Exp & Experience (number of years irrigator has been irrigating) \\
IrriArea & Irrigable area of scheme (in acres) \\
Users & Number of users of the scheme \\
Rain & Annual precipitations (mm) \\
CropdumP & Dummy for main crop in scheme (pepper = 1) \\
CropdumO & Dummy for main crop in scheme (onions = 1) \\
PlotdumH & Dummy for plot location (head-end = 1) \\
PlotdumT & Dummy for plot location (tail-end = 1)
\end{tabular}




\subsection{Results and discussion}

\subsubsection{Irrigation governance ratings (IGRs)}

Table 2.5 presents a summary of the ratings by users of the six governance dimensions and overall governance. The mean ratings of the governance dimensions are all above average. Sustainable use scores worst (3.42), but an indication of good governance. Conflict management scores best (4.22), indicating very good governance in managing irrigationrelated conflicts. None of the dimensions rates excellent (5) or poor (1). The overall governance score is 3.82 , signifying good governance on average in northern Ghana.

Table 2.5: Descriptive statistics of irrigation governance dimensions

\begin{tabular}{lccccc}
\hline \multicolumn{1}{c}{ Dimension } & $\begin{array}{c}\text { No of } \\
\text { variables }\end{array}$ & Mean & Min & Max & $\begin{array}{c}\text { Standard } \\
\text { deviation }\end{array}$ \\
\hline Participation & 4 & 4.11 & 1.75 & 5.00 & 0.594746 \\
$\begin{array}{l}\text { Accountability } \\
\text { Conflict }\end{array}$ & 5 & 3.70 & 1.20 & 5.00 & 0.778974 \\
management & 4 & 4.22 & 1.00 & 5.00 & 0.547243 \\
$\begin{array}{l}\text { Transparency and } \\
\text { cooperation }\end{array}$ & 15 & 3.83 & 1.07 & 5.00 & 0.648869 \\
$\begin{array}{l}\text { Equity and } \\
\text { fairness }\end{array}$ & 7 & 3.64 & 1.86 & 5.00 & 0.577031 \\
$\begin{array}{l}\text { Sustainable use } \\
\text { Overall }\end{array}$ & 11 & 3.42 & 1.82 & 4.73 & 0.580615 \\
governance & 46 & 3.82 & 1.76 & 4.79 & 0.479382 \\
\hline & & & & & \\
\hline
\end{tabular}

The high score in conflict management explains that conflict management is better handled than other dimensions in the use of small-scale irrigation schemes in northern Ghana. Conflict management is important where common pool resources are sited at relatively unstable places in terms of peace as in the case of our study area. Unlike in large-scale schemes at the national level such as the Vea and Tono irrigation schemes, where usage is 
opened to a wide range of people from all ethnicities with little or no role of traditional leaders, small-scale schemes in general are enclosed, involving the use of traditional authority at a low cost to resolve conflicts. Conflict resolutions are often seen as a responsibility of formal institutions but the presence and role of traditional leaders aids in resolving irrigationrelated conflicts in small-scale schemes and this may explain the high score. Sokile and van Koppen (2004) confirmed in Tanzania that informal channels are more effective in resolving water-related conflicts than formal channels and recommended an amalgamation of both for effective management of water resources.

The standard deviation is relatively high in accountability assessments, indicating much varied degrees of assessments among irrigators. Accountability is a contentious issue in any social group. What one may see as being accountable may not be acceptable to others. There is however close agreement in the overall assessment of irrigation governance, as signified by a low standard deviation.

\subsubsection{Irrigation governance by hypotheses}

In this section we present empirical results of the hypotheses on factors associated with individual's assessm ents of IGRs. The Tobit Cluster-Robust results are presented in Table 2.6 .

\section{Location of irrigation facility}

In Table 2.6, schemes located in areas having relatively high annual precipitations report better irrigation governance. This is significant in accountability assessments and in the overall governance score. This implies that WUA leaders are more open in information dissemination to members, and in return, are more trusted when annual precipitations are high. The results thus confirm a positive relation between the location of a scheme and the general assessment of irrigation governance. 
Table 2.6: Tobit regression results of governance dimensions

\begin{tabular}{|c|c|c|c|c|c|c|c|}
\hline & $\begin{array}{l}\text { Partici- } \\
\text { pation }\end{array}$ & $\begin{array}{l}\text { Account- } \\
\text { ability }\end{array}$ & $\begin{array}{c}\text { Conflict } \\
\text { manage- } \\
\text { ment }\end{array}$ & $\begin{array}{l}\text { Transpa- } \\
\text { rency and } \\
\text { cooperation }\end{array}$ & $\begin{array}{l}\text { Equity } \\
\text { and } \\
\text { fairness }\end{array}$ & $\begin{array}{l}\text { Sustaina- } \\
\text { ble use }\end{array}$ & Overall \\
\hline Sex & $\begin{array}{c}0.006 \\
(0.101)\end{array}$ & $\begin{array}{c}-0.057 \\
(-0.815)\end{array}$ & $\begin{array}{c}-0.006 \\
(-0.090)\end{array}$ & $\begin{array}{c}0.011 \\
(0.158)\end{array}$ & $\begin{array}{c}0.021 \\
(0.403)\end{array}$ & $\begin{array}{c}0.003 \\
(0.046)\end{array}$ & $\begin{array}{c}-0.004 \\
(-0.090)\end{array}$ \\
\hline Age & $\begin{array}{c}0.000 \\
(0.110)\end{array}$ & $\begin{array}{c}0.003 \\
(0.969)\end{array}$ & $\begin{array}{c}0.002 \\
(0.483)\end{array}$ & $\begin{array}{c}0.002 \\
(0.822)\end{array}$ & $\begin{array}{c}-0.001 \\
(-0.285)\end{array}$ & $\begin{array}{c}0.001 \\
(0.541)\end{array}$ & $\begin{array}{c}0.001 \\
(0.568)\end{array}$ \\
\hline HHsize & $\begin{array}{c}0.004 \\
(0.336)\end{array}$ & $\begin{array}{c}-0.014 \\
(-1.003)\end{array}$ & $\begin{array}{c}-0.012 \\
(-1.159)\end{array}$ & $\begin{array}{c}-0.020 \\
(-1.569)\end{array}$ & $\begin{array}{c}-0.009 \\
(-0.847)\end{array}$ & $\begin{array}{c}-0.010 \\
(-0.947)\end{array}$ & $\begin{array}{c}-0.010 \\
(-1.162)\end{array}$ \\
\hline Mob & $\begin{array}{l}-0.012 * \\
(-1.807)\end{array}$ & $\begin{array}{l}-0.013^{*} \\
(-1.677)\end{array}$ & $\begin{array}{c}-0.009 \\
(-1.489)\end{array}$ & $\begin{array}{c}-0.005 \\
(-0.846)\end{array}$ & $\begin{array}{c}-0.015 * * \\
(-2.585)\end{array}$ & $\begin{array}{c}-0.001 \\
(-0.188)\end{array}$ & $\begin{array}{l}-0.009 * \\
(-1.836)\end{array}$ \\
\hline Exp & $\begin{array}{c}0.003 \\
(0.906)\end{array}$ & $\begin{array}{l}0.009 * * \\
(2.367)\end{array}$ & $\begin{array}{c}0.005 \\
(1.254)\end{array}$ & $\begin{array}{c}0.003 \\
(0.771)\end{array}$ & $\begin{array}{c}-0.002 \\
(-0.692)\end{array}$ & $\begin{array}{c}-0.002 \\
(-0.698)\end{array}$ & $\begin{array}{c}0.002 \\
(0.771)\end{array}$ \\
\hline IrriLand & $\begin{array}{l}0.234 * * \\
(2.116)\end{array}$ & $\begin{array}{l}0.243 * \\
(1.821)\end{array}$ & $\begin{array}{l}0.205^{*} \\
(1.730)\end{array}$ & $\begin{array}{l}0.227^{*} \\
(1.822)\end{array}$ & $\begin{array}{c}0.089 \\
(0.779)\end{array}$ & $\begin{array}{c}-0.023 \\
(-0.192)\end{array}$ & $\begin{array}{c}0.153 \\
(1.600)\end{array}$ \\
\hline IrriLand $^{2}$ & $\begin{array}{l}-0.024 * \\
(-1.773)\end{array}$ & $\begin{array}{c}-0.023 \\
(-1.340) \\
\end{array}$ & $\begin{array}{c}-0.023 \\
(-1.583) \\
\end{array}$ & $\begin{array}{c}-0.020 \\
(-1.253)\end{array}$ & $\begin{array}{c}-0.007 \\
(-0.513)\end{array}$ & $\begin{array}{c}0.010 \\
(0.656)\end{array}$ & $\begin{array}{c}-0.013 \\
(-1.093) \\
\end{array}$ \\
\hline Users & $\begin{array}{l}0.004 * * \\
(2.441)\end{array}$ & $\begin{array}{l}0.004 * * \\
(2.060)\end{array}$ & $\begin{array}{c}-0.001 \\
(-0.467)\end{array}$ & $\begin{array}{c}0.003 \\
(1.632) \\
\end{array}$ & $\begin{array}{c}0.001 \\
(0.956)\end{array}$ & $\begin{array}{c}0.002 \\
(1.056)\end{array}$ & $\begin{array}{c}0.002 \\
(1.610)\end{array}$ \\
\hline Rain & $\begin{array}{c}0.003 \\
(1.591) \\
\end{array}$ & $\begin{array}{c}0.005 * * \\
(1.992)\end{array}$ & $\begin{array}{c}0.001 \\
(0.922)\end{array}$ & $\begin{array}{c}0.003 \\
(1.606)\end{array}$ & $\begin{array}{c}0.001 \\
(0.683)\end{array}$ & $\begin{array}{c}0.002 \\
(1.503)\end{array}$ & $\begin{array}{c}0.003 * \\
(1.830)\end{array}$ \\
\hline CropdumP & $\begin{array}{c}-0.311 \\
(-1.446)\end{array}$ & $\begin{array}{c}-0.664 * * \\
(-2.040)\end{array}$ & $\begin{array}{c}-0.213 \\
(-1.200)\end{array}$ & $\begin{array}{c}-0.514 * * \\
(-2.339)\end{array}$ & $\begin{array}{c}-0.273 \\
(-1.461)\end{array}$ & $\begin{array}{c}0.066 \\
(0.455)\end{array}$ & $\begin{array}{l}-0.312 * \\
(-1.897)\end{array}$ \\
\hline CropdumO & $\begin{array}{c}0.335 * * \\
(2.416)\end{array}$ & $\begin{array}{c}0.408 * * \\
(2.403)\end{array}$ & $\begin{array}{c}0.188 \\
(1.185)\end{array}$ & $\begin{array}{c}0.135 \\
(0.970)\end{array}$ & $\begin{array}{c}0.070 \\
(0.497)\end{array}$ & $\begin{array}{c}0.015 \\
(0.101)\end{array}$ & $\begin{array}{c}0.175 \\
(1.440)\end{array}$ \\
\hline PlotdumH & $\begin{array}{c}-0.057 \\
(-0.774)\end{array}$ & $\begin{array}{c}-0.207 * * \\
(-2.418)\end{array}$ & $\begin{array}{c}0.020 \\
(0.270)\end{array}$ & $\begin{array}{c}-0.207 * * * \\
(-2.920)\end{array}$ & $\begin{array}{c}-0.096 \\
(-1.390)\end{array}$ & $\begin{array}{c}-0.178 * * \\
(-2.565)\end{array}$ & $\begin{array}{c}-0.123 * * \\
(-2.322)\end{array}$ \\
\hline PlotdumT & $\begin{array}{c}-0.046 \\
(-0.838) \\
\end{array}$ & $\begin{array}{c}-0.037 \\
(-0.578) \\
\end{array}$ & $\begin{array}{c}-0.034 \\
(-0.592) \\
\end{array}$ & $\begin{array}{c}-0.067 \\
(-1.328)\end{array}$ & $\begin{array}{l}-0.110^{*} \\
(-1.667)\end{array}$ & $\begin{array}{c}-0.182 * * \\
(-2.589) \\
\end{array}$ & $\begin{array}{l}-0.077^{*} \\
(-1.816) \\
\end{array}$ \\
\hline Constant & $\begin{array}{c}0.645 \\
(0.339)\end{array}$ & $\begin{array}{c}-1.896 \\
(-0.726)\end{array}$ & $\begin{array}{l}2.753^{*} \\
(1.690)\end{array}$ & $\begin{array}{c}0.536 \\
(0.267)\end{array}$ & $\begin{array}{l}2.800^{*} \\
(1.940)\end{array}$ & $\begin{array}{c}1.408 \\
(0.944)\end{array}$ & $\begin{array}{c}1.102 \\
(0.745)\end{array}$ \\
\hline $\begin{array}{l}\text { Observa- } \\
\text { tions }\end{array}$ & 370 & 370 & 370 & 370 & 370 & 370 & 370 \\
\hline $\begin{array}{l}\text { Pseudo } \\
\text { R-squared }\end{array}$ & 0.126 & 0.1422 & 0.0388 & 0.1052 & 0.0559 & 0.0495 & 0.1501 \\
\hline
\end{tabular}

Note: $* * *$, and $* * *$ indicate statistical significance at $10 \%, 5 \%$, and $1 \%$ respectively. The

Tobit-Cluster-Robust t-statistics are in parentheses. 


\section{Crop grown}

Onion and pepper as main crops have a statistically significant relationship with some of the irrigation governance dimensions. Table 2.6 indicates that farmers growing onions have more positive governance perceptions than farmers growing tomatoes, and farmers growing pepper have a lower perception of irrigation governance dimensions as compared to famers growing tomatoes. The perceptions of pepper irrigators is significant in the overall governance assessment.

Various reasons could explain these results, including water demands of crops, the length of season a crop is irrigated (period), and the economic value of crops. Compared with tomatoes, onions demand less water even though both crops have relatively similar periods of irrigation (Namara et al., 2011). The results then imply that irrigators growing less waterdemanding crops (onions) are more positive. Furthermore, onions are mostly grown in the north-eastern corridor (Bawku precisely) of Ghana, the driest place in the country. Participation and accountable leadership is needed in maintaining dams for continuous production of onions, the main cash crop of indigenes. This may also explain why onion irrigators are more positive even though insignificant in the overall governance assessment.

On the other hand, tomatoes are more water-demanding than peppers but peppers take a longer period compared to tomatoes. From the results, irrigators growing crops of longer periods (pepper) tend to be more negative in governance assessments compared to irrigators of short-period crops (tomatoes) and this proved significant in the overall governance assessment. Therefore, the main crop grown in a scheme indeed associates with irrigation governance assessment but the period of irrigation may be the determining factor and not necessarily the frequency of irrigation. High temperatures in the months leading to the rainy season dries up water bodies, and crops that span up to this period likely suffer water insufficiency. Water shortage makes it difficult for leaders to coordinate activities in irrigation, a reason for the lack of transparency and cooperation, and accountability as rated by pepper irrigators.

Due to agro-climatic and other factors, the main crop grown in a scheme varies between regions.. Hence, the crop dummies are also likely to reflect regional variation between irrigation schemes in many other aspects besides irrigation frequency and growing period of 
the crop. In particular, higher layers of governance may differ between regions (and crops) and affect local governance perceptions of farmers in the small-scale irrigation schemes that we surveyed.

\section{Size of scheme (number of users)}

In Table 2.6, the number of users in a scheme generally has a positive association with irrigation governance perception except in conflict management. This general trend is only statistically significant in participation and accountability in irrigation governance, implying that users in large WUAs are more positive in their assessments. One striking thing about user management of irrigation systems is the collective power in maintaining irrigation facilities. In large WUAs, contribution in cash and kind towards maintenance activities is an advantage due to the high numbers. As evident in our results, participation in large WUA schemes is high. On the other hand, it is worth noting that large user groups have insignificant (negative) associations with conflict management. Increasing numbers of users increases divergent ideas and misunderstandings, which may raise tensions in groups making governance uneasy. These results however do not show sufficient evidence to suggest that the number of users in a schem e influences users' assessm ents of irrigation governance as the number of users is insignificant in the overall governance assessment.

\section{Plot location}

Plot location is negatively associated to irrigation governance assessment for both headenders and tail-enders, and this is significant in the overall irrigation governance assessment. Both head- and tail-enders are indifferent towards their assessments of sustainable use compared to mid-enders and this is negative and significant in both cases. Specifically, headenders are significantly negative in transparency and cooperation, and accountability assessments. Tail-enders on the other hand are more concerned about equity and fairness treatments in irrigation governance. Fairness and equity is questionable where one is allocated a plot at the tail-end. Tail-enders are normally the last to be allocated water and in cases of water shortage they are usually the hardest hit. 
From group discussions and participant observations, it was noticed that head-enders suffer dam malfunction effects directly and in most cases will want leaders to act promptly in curbing negative impacts, but this does not always happen. More than 50\% of small-scale irrigation schemes visited had problems of seepage and broken canals. The seepage in most instances occurs in plots of head-enders, causing plots to flood, which may explain the trend of head-enders' assessm ents. Collective action requires transparency from leaders and cooperation from users for effective governance. The sustainability of the WUA model in irrigation governance is questionable when cooperation in particular is non-existent in groups. Lack of transparency and/or cooperation can lead to a divergent use of resources contrary to agreed principles, which poses challenges for long-term use.

\section{Control variables}

Among the control variables, mobility, experience, and irrigable land per irrigator associate with the assessment of some irrigation governance dimensions. Experience generally has a positive association but is only statistically significant in accountability. If the adage of "learning by doing" holds, then m ore experienced irrigators are able to decipher odds from normal practices of good governance to give good judgements. In this study, the more experienced irrigators are positive in assessing accountability in irrigation governance.

High mobility has a significant negative influence in participation, accountability, and equity and fairness assessments. In Agrawal's sustainable resource governance framework (Agrawal, 2003), low mobility is recommended in terms of resource mobility. Similarly, users of common pool resources need infrequent migrations and more participation in the operation and maintenance of common pools for effective governance. Migration of farmers from northern Ghana to southern Ghana in search of greener pastures is common during irrigation periods, which imparts collective action in governance negatively, hence the negative assessments. Mobile irrigators miss out on a lot of activities in WUAs including decision-taking consensus. Good ideas that could be contributed by absentees from meetings end up affecting the governance of irrigation resources. Fairness and equity in groups demands high representations of WUA members in decision making. 
The amount of irrigable land per irrigator indicates the degree of dependence of an irrigator on the irrigation facility. Irrigators who depend more on the resource are more positive in their assessments. In other words, irrigators who have access to more land are more satisfied about governance. The square of land showed a negative influence but the turning point of land in each dimension is estimated as high and positive, which means that irrigation land per user generally has a positive association with governance assessment. The availability of irrigable land to meet land demands of irrigators can thus be a reason for positive governance assessments.

\subsection{Conclusions}

This study aimed at measuring irrigation governance using users' assessm ents to generate scores for irrigation governance dimensions. We further examined which factors associate with irrigation governance dimensions assessments. In the results and discussions section, we have presented our results by hypotheses with two rejected hypotheses (size and crop hypotheses). Factors that significantly associate with irrigation governance perceptions are the availability of water through high precipitations and plot locations of irrigators. Even though the number of users (size) in a scheme influences governance assessments in some dimensions, it is not significant in the overall assessment of irrigation governance, and hence rejected. The main crop grown in a scheme also associates with governance assessments but it is not necessarily the crops with lower water demands that have a positive association as hypothesized. Crops with shorter growing periods yield more positive governance assertions. But regional variation in other factors, like higher layers of governance, may confound these results.

On average, the overall irrigation governance scores signify "good" irrigation governance in northern Ghana from users perspectives even though one would have preferred "very good" governance. The lack of progress in some irrigation facilities in northern Ghana being attributed to bad governance (Dittoh et al., 2013a; Poussin et al., 2015; Venot and Hirvonen, 2013) may be specific to some dimensions of governance, depending on the physical conditions and characteristics of the governing WUA, which may need attention. 
A question that arises from the assessments of the head-enders is whether the sustainability of an irrigation facility is better looked at as an issue of infrastructural functionality or that of WUA's functionality. In other words, could sustainability be more tied to infrastructural existence? Birner et al. (2010) reported infrastructural defects as a reason why most smallscale schemes have been abandoned in the Upper East Region of Ghana. Both head-enders and tail-enders in our study significantly rated sustainability low because most dams have damaged infrastructure needing urgent attention. Water wastage through seepage and broken canals causes dams to run out of water, thereby making irrigators jobless. Routine repairs of major infrastructural damages beyond the capacity of famer groups are important in sustaining irrigation facilities. Harmancioglu et al. (2013) pointed out that water resources need to be developed and managed on a sustainable basis. It is important to invest in constructing reservoirs for rural livelihoods but it is even more important to invest in maintaining such facilities so that the poor can continue to live. The existence of cooperation, transparency, and accountability, among other dimensions, are good conditions for group existence, but once a reservoir collapses, production ceases, and this is not sustainable. All activities and every dimension of irrigation governance should have a bearing on the longterm sustainable use of the resource. Group existence is important for the sustainable management of the commons but the survival of the commons should be the main aim of sustainable production. Prompt repairs of malfunctioning valves and broken canals by GIDA are highly desirable.

Another concern of interest is whether surface water irrigation through canals is a good approach in tackling agricultural production in dry climates. Sustainable use had the lowest score among irrigation governance dimensions in this study. The method of water allocation in Ghana is not volumetric (not measured by quantity) but judged through time allowed for water use per day. A lot of water is wasted by this method coupled with wastage through seepage and evapotranspiration in high temperatures. Dams are good communal resources but may be better maintained for domestic and livestock watering. Promoting the use of waterconserving irrigation techniques such as drip irrigation and ground water techniques is essential. 


\title{
CHAPTER 3
}

\section{Irrigation governance and performance: the case of smallholder- irrigated agriculture in northern Ghana ${ }^{2}$}

\begin{abstract}
In dry areas in Africa, crop production is largely dependent on rainfall. Overall performance is poor, and considered to be one of the major barriers to development in Africa. Implementing irrigation in such areas is advocated as a great step forward in improving agricultural performance and rural livelihoods. Over the years, small-scale irrigation schemes have been constructed for this purpose, but these schemes are not without challenges. There are reports of poor performances of small-scale schemes, partly blamed on the weak management by Water User Associations (WUAs). In general, proper governance of common pool resources, such as communal irrigation schemes, depends on the specific institutional arrangements that are in place. In group-managed irrigation schemes, governance entails the use of rules and regulations to ensure a sustainable use of resources. These rules and regulations refer to different dimensions of governance, such as accountability, participation, and transparency and cooperation in the management of resources. In this paper we contribute to the debate on the role of governance in sustaining common pool resources by empirically testing the association between different governance dimensions and irrigation performance as measured by crop yields. For this we collected household survey data on governance perceptions of farm ers about the m anagem ent by their WUAs and on farm ers' irrigated activities in 37 small-scale irrigation schemes in the north of Ghana. Regression results show that the yield per unit area of irrigated vegetables is positively associated with farmer perceptions of participation but negatively associated with conflict management perceptions.
\end{abstract}

Publication status: Akuriba, M.A, Haagsma R., Heerink N., and Dittoh S., 2018. Irrigation governance and performance: the case of smallholder-irrigated agriculture in northern Ghana. Working paper.

\footnotetext{
${ }^{2}$ Versions of this paper were presented at the annual conferences of the Ghana Association of Agricultural Economists (GAAE), 2017 and the Centre for the Study of African Economies (CSAE), 2018.
} 


\subsection{Introduction}

The role of agriculture in economic growth has been discussed extensively in development literature. In the dry areas of West Africa, such as northern Ghana, most of the working people are smallholder farmers and herders. Here, crop production is largely dependent on rainfall, while households cultivate relatively small land areas (Drechsel and Olaleye, 2005; MoFA, 2011; Wood, 2013). Overall performance is poor, and time and again reported to be one of the major barriers to development in Africa (AGRA, 2013). Implementing irrigation in such areas is critical in improving agricultural performance and rural livelihoods (Svendsen et al., 2009; Namara et al., 2011; Dittoh et al., 2013a; Oates et al., 2015). Climate change and desertification make irrigation development an even more important development imperative in West Africa (Dietz et al., 2004).

In Ghana, more than half of the land is in need of irrigation. The development of irrigated land has however remained slow, with less than $2 \%$ of the potential irrigable land being in use (Namara et al., 2011; Mendes et al., 2014). Irrigation by use of small reservoirs is the most common system in place. Most of the small-scale schemes are in the northern part of the country, especially in the Upper East Region, which is the driest region. Small-scale reservoirs are mostly initiated and funded by donors (Namara et al., 2011). For their management and operation, typically Water User Associations (WUAs) are established. This com m unal form of governance is a response to Ghana's unsuccessful experience ithe public management of irrigation schemes (Namara et al., 2011) and general advocacies towards community participation in the management of common pool resources (Ostrom, 1990).

The construction of small-scale irrigation schemes in Ghana aims at the economic empowerment of less-privileged communities by improving their livelihoods. Yield increases are crucial for poverty reduction and sustainable food security. However, relative to the high investment costs, yields from irrigated agriculture are said to be low in Ghana, with vegetables reported as being comparatively more viable (Namara et al., 2011). The reason for this is that not all the reservoirs are in use and that the reservoirs that are actually being used are underperforming. 
In the Upper East Region of Ghana, a high number of small reservoirs are not in use. In their study of 126 small-scale reservoirs (representing 73\% of all reservoirs in the Upper East Region), Birner et al. (2010) find that $58 \%$ of the reservoirs had no irrigation, while $18 \%$ used irrigation in water storage areas, thereby reducing the irrigation potential. They suggest that this is the result of a number of governance challenges, including a lack of clear roles of stakeholders in the management and maintenance of irrigation structures. Lamptey et al. (2011) points out that the institutional mandate for irrigation development in Ghana is unclear, and that this leads to low utilisation of irrigation facilities and hence to poor performance.

A number of studies indicate that the area currently under irrigation is underperforming in terms of yield and cropping intensity (Namara et al., 2011; Venot and Hirvonen, 2013). Some attribute this to poor governance (Venot and Hirvonen, 2013; Dittoh et al., 2013b; Poussin et al., 2015), particularly in the technical and organizational aspects of irrigation governance. Technically, some irrigation facilities have defects in design and construction that need further investment to correct them. Additionally, depending on the organizational structure of a resource, oversight responsibilities are sometimes critical for the sustenance of the resource. Clear roles and responsibilities are key to good performance of irrigation (Lamptey et al., 2011). In their comparative study of smallholder irrigation schemes in Africa and Asia, Mutambara et al. (2016) blame part of the poor performance of African schemes on weak Irrigation Management Committees or WUAs.

In general, proper governance of common pool resources, such as communal irrigation schemes, depends on the specific institutional arrangements that are in place (Agrawal, 2003; Norton, 2004; Howarth et al., 2005; Venot and Hirvonen, 2013; Poussin et al., 2015). In group-managed irrigation schemes, governance entails the use of rules and regulations to ensure sustainable use of communal resources. Rules and regulations are important, especially in multifaceted resources where resource utility varies among users. The rules and regulations refer to different dimensions of governance, such as accountability, participation, transparency, and cooperation (Goran and Court, 2002; GWP 2009; Tortajada, 2010; Lautze et al., 2011). Some rules may be geared towards fairness and equity in a group, while others 
are aimed at sustainable use of resources. Some dimensions of governance may have a more direct impact on the performance of irrigation schemes than others.

This paper tries to contribute to the debate on the role of governance in sustaining common pool resources by empirically testing the extent to which users' perceptions of different dimensions of irrigation governance relate to the performance of irrigation schemes. Assessing which dimensions are the most critical clearly helps in making informed decisions towards improving irrigation development. We do not know of any empirical study of irrigation schemes that has opened this black box of governance and identified the relationship of each dimension with the performance of schemes. Studies exist on general governance of irrigation which evaluate governance by using observations of the physical status of irrigation infrastructures and the availability of concrete institutions for irrigation management. Birner et al. (2010), for instance, discussed the technical aspects of irrigation governance in terms of infrastructural availability and as to whether available schemes in Ghana are functioning or not. For small-scale irrigation schemes managed by WUAs, coordination is the aspect of governance that is key to the sustenance of the schemes. This study therefore seeks to examine to what extent the outcomes of WUAs' governance arrangements associate with irrigation performance. Agrawal (2014), in his concluding thoughts on the commons, noted that the next phase of studies on the commons should not be "doubt daunting", and that an understanding of how specific causal factors influence outcomes related to common pool resource systems is needed. Using a cross-section household survey data set on WUA governance perceptions and irrigated-farm activities, this paper provides empirical estimates of irrigation governance-performance relations in Northern Ghana.

In the remaining sections of this paper, we present the theoretical background in Section 3.2 followed by a description of the methodology in Section 3.3. Results and discussions are in Section 3.4 and our concluding remarks in Section 3.5. 


\subsection{Theory and concepts}

\subsubsection{Irrigation governance-performance relations}

The main goal for irrigation infrastructural investments in dry areas of Africa is to improve the productivity of agriculture in order to reduce hunger and poverty (Oates et al., 2015; Svendsen et al., 2009). However, as indicated by Lam and Ostrom (2010), "unless farm ers encourage local entrepreneurs and organize themselves, create their own rules or use sanctions, and augment their rules through collective action, infrastructure investment alone is not sufficient to achieve sustainable higher performance". Inocencio et al. (2007) pointed out that when farmers contribute to the development of their schemes and take significant management responsibility for them, costs will be low in combination with high performance. Lam and Ostrom (2010) advocate self-governance through user groups for a better performance of irrigation systems. User groups write and enforce rules regarding the general operation and maintenance of irrigation facilities to avoid free riding and over-exploitation of irrigation resources.

For self-governed common pool resources such as public irrigation schemes, sustainability should be a concern to users. The performance of irrigated plots is an important indicator of the sustainability of an irrigation facility. Evaluating the performance of irrigated agriculture is imperative in measuring the impact it has on livelihoods of irrigators (Poussin et al., 2015). Achieving higher and sustainable performance from communal irrigation schemes is dependent on many factors, including the general governance and/or institutional arrangements of irrigation schemes (Agrawal, 2003; Ostrom, 1990; Poussin et al., 2015; Venot and Hirvonen, 2013).

Irrigation governance generally involves the processes in irrigation management and coordination (Ostrom, 2000; Howarth et al., 2007; Lautze et al., 2011). Governance refers to a distinct analytical perspective on regulation and coordination processes; it is not a theory but an analytical approach used to describe and assess reality (Sehring, 2009). The realities in irrigation are the questions on how to maintain irrigation facilities and regulate water extraction for equitable and sustainable use; rules and regulations have to be put in place to avoid misappropriation and damage of irrigation facilities. Irrigation governance is thus the 
use of rules and regulations to guard water extraction from irrigation facilities and to enforce order in the maintenance of irrigation resources for long-term sustainable use.

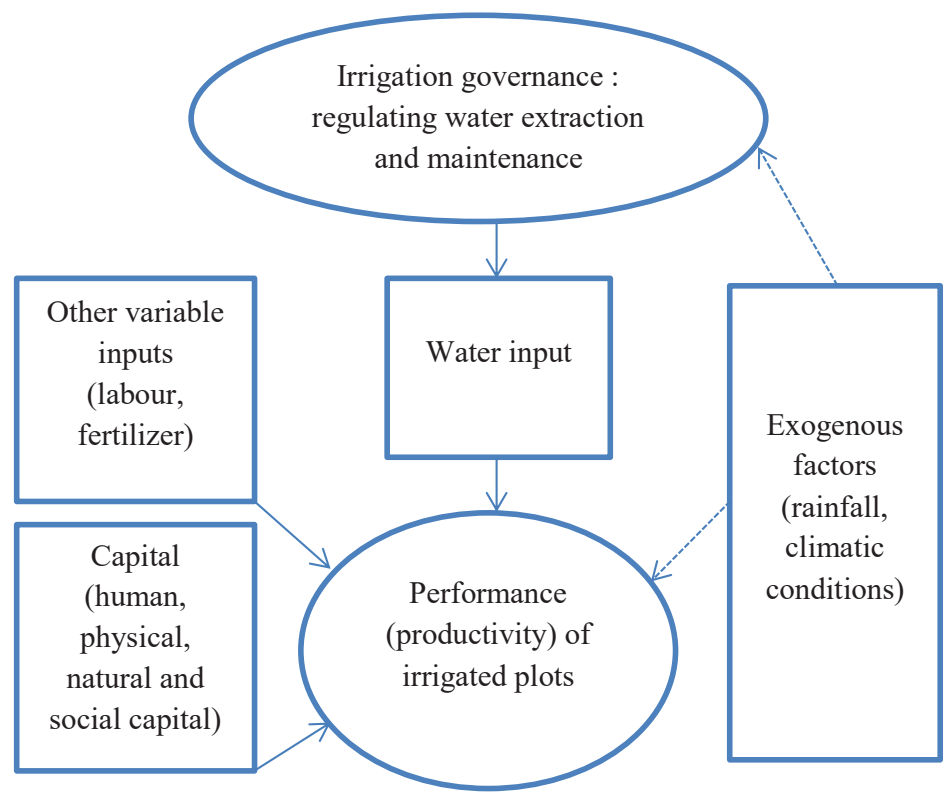

Figure 3.1: Analytical framework

Figure 3.1 presents the analytical framework that we use in this study. Irrigation governance by user groups affects the quantity and timing of irrigation water availability to the households belonging to a scheme. Together with other variable inputs used in agricultural production and assets available to a household, the use of irrigation water determines the performance of irrigated plots under given agro-ecological conditions (such as rainfall, soil quality). Agro-ecological conditions not only affect the performance of plots, but will also influence user group rules and regulations on water extraction and maintenance of irrigation facilities as well as users' perceptions of irrigation governance. The relationships specified in Figure 3.1 are at the basis of specification of the regression model that we estimated. 
There are several approaches to performance assessments of irrigation systems, with the choice of method dependent on the objective of analysis ( Bos et al., 2005; Bos, 1997; Sakthivadivel et al., 1999; Svendsen et al., 2009). Agricultural productivity, i.e. output per unit land (or per unit labour or other input) can be considered the first-order measure of performance of agriculture (Svendsen et al., 2009), especially in Africa, where output is paramount to food security. It is therefore also the focus of this study.

Water availability is a major constraint to agricultural productivity in north-eastern Ghana. We hypothesize that the availability of water to individual farmers is positively influenced by a better performance of irrigation governance (Fig 3.1). So our objective is to establish to what extent yields indirectly depend on irrigation governance through its effect on loosening the constraints that farmers face in their access to water. In constrained instances, communal governing principles determine how much water individual farmers can use on their land. Governance thus increases water availability by loosening the constraints on water, and adequate water supply means higher yields for households.

Note that water productivity (i.e. agricultural output per unit water) is not the focus of this study. In Ghana, it is difficult to measure water use volumetrically. Most small-scale schemes are not fitted with the necessary devices for measuring water use. Studies on water productivity of irrigation reservoirs, such as Faulkner et al. (2008) and Mdemu et al. (2009), are either based on case studies of specific reservoirs (normally about two) in which these devices are fixed, or where researchers install and monitor a few just for the period of the study.

Following our conceptual framework, we may express the yield (Y) of a farmer household as a function $(f)$ of water extraction $(W)$, land size $(L)$, variable inputs such as labour and fertilizer $(V)$, capital $(C)$, and Exogenous factors $(\mathrm{X})$ :

$$
Y=f(W, L, V, C, X)
$$


The availability of water and land is limited by maximum quantities $\bar{W}$ and $\bar{L}$ :

$$
W \leq \bar{W}(G) \text { and } L \leq \bar{L}
$$

$\bar{W}(G)$ indicates that the availability of water depends on governance G. Assuming that the constraints on water and land are binding, we obtain after substitution:

$$
Y=f(\bar{W}(G), \bar{L}, V, C, X)=f^{*}(G, \bar{L}, V, C, X)
$$

The availability of water to a household depends on how users and their leaders adhere to their own governing rules. The outcomes of governance adherences therefore indirectly affect the perform ance (i.e. yields ) of a household's irrigated plots, as shownon the right-hand side of (3).

\subsubsection{Governance dimensions}

In Agrawal's framework, several institutional arrangements contribute to the sustenance of commons, such as simple and easy to understand rules, ease in enforcement of rules, and graduated sanctions (Agrawal, 2003). Such arrangem ents are im portant for users' adherence to laid down principles in the use of communal resources. Different dimensions of governance may be distinguished, with different relationships to sustainable management of irrigation resources (e.g. GWP, 2009; Tortajada, 2010; Lautze et al., 2011). In this study we distinguish between participation, accountability, conflict management, transparency and cooperation, equity and fairness, and sustainable use. Chapter 2 gives a detailed description and measurements of these dimensions. 


\subsection{Methodology}

\subsubsection{Empirical model}

As explained in Section 3.2, we are interested in the indirect relationship between irrigation governance and agricultural yields. We therefore estimate a production function with irrigation water use replaced by the six governance dimensions that we distinguish. For reasons of simplicity and ease of interpretation, we use a Cobb-Douglas specification:

$$
\ln Y=\alpha+\beta \ln G+\gamma \ln \bar{L}+\delta \ln V+\lambda \ln C+\varepsilon
$$

where

$$
\begin{aligned}
& \mathrm{Y}=\text { yield of a household } \\
& \mathrm{G}=\text { ratings of the six governance dimensions } \\
& \bar{L}=\text { land used for irrigation by a household } \\
& \mathrm{V}=\text { variable inputs used on irrigated plot per unit area } \\
& \mathrm{C}=\text { capital used by households for irrigation per unit area } \\
& \alpha, \beta, \gamma, \delta \text {, and } \lambda=\text { parameters to be estimated } \\
& \boldsymbol{\varepsilon}=\text { the error term }
\end{aligned}
$$

Table 3.1 presents the definitions of the variables that we used in our analysis, and their descriptive statistics. Out of the six governance dimensions that we distinguish, conflict management receives the highest mean score (4.22). Interestingly, it also shows the lowest variation among all surveyed irrigators, indicating that there is general agreement about appropriate conflict management in the irrigation schemes where we did the survey. Participation also receives a relatively high average score (4.11) among the six governance dimensions, but it shows more variation. Sustainable use has the lowest mean score (3.42), while the mean scores of equity and fairness (3.64) and accountability (3.70) are also relatively low. We expect positive associations between the six governance indicators and the value of the yields, although governance dimensions such as conflict management, which are aimed at group co-existence, may have adverse consequences on production and may therefore have a relatively minor relationship with yields. 
Table 3.1: Definition and descriptive statistics of variables in the model

\begin{tabular}{|c|c|c|c|c|c|}
\hline Variable & Description & Mean & Std. & Min. & Max. \\
\hline Yield value & $\begin{array}{l}\text { Market value of yield harvested per acre } \\
\text { (in GHC) }\end{array}$ & $1,141.77$ & 836.305 & 140 & 4,081 \\
\hline \multicolumn{6}{|c|}{ Governance dimensions } \\
\hline Participation & $\begin{array}{l}\text { Mean score per scheme from five Likert } \\
\text { items using a } 1-5 \text { scale }\end{array}$ & 4.11 & 0.454 & 2.98 & 5 \\
\hline Accountability & $\begin{array}{l}\text { Mean score per scheme from five Likert } \\
\text { items using a } 1-5 \text { scale }\end{array}$ & 3.70 & 0.662 & 2.16 & 4.6 \\
\hline $\begin{array}{l}\text { Conflict } \\
\text { management }\end{array}$ & $\begin{array}{l}\text { Mean score per scheme from four Likert } \\
\text { items using a } 1-5 \text { scale }\end{array}$ & 4.22 & 0.331 & 3.45 & 4.8 \\
\hline $\begin{array}{l}\text { Transparency } \\
\text { and } \\
\text { cooperation }\end{array}$ & $\begin{array}{l}\text { Mean score per scheme from fourteen } \\
\text { Likert items using a } 1-5 \text { scale }\end{array}$ & 3.83 & 0.522 & 2.67 & 4.54 \\
\hline $\begin{array}{l}\text { Equity and } \\
\text { fairness }\end{array}$ & $\begin{array}{l}\text { Mean score per scheme from seven Likert } \\
\text { items using a } 1-5 \text { scale }\end{array}$ & 3.64 & 0.405 & 2.67 & 4.37 \\
\hline $\begin{array}{l}\text { Sustainable } \\
\text { use }\end{array}$ & $\begin{array}{l}\text { Mean score per scheme from eleven } \\
\text { Likert items using a } 1-5 \text { scale }\end{array}$ & 3.42 & 0.401 & 2.33 & 3.93 \\
\hline \multicolumn{6}{|c|}{ Land } \\
\hline Land & Size of land used for crop (in acres) & 0.293 & 0.172 & 0.125 & 1 \\
\hline \multicolumn{6}{|c|}{ Other variable inputs } \\
\hline Seedlings & $\begin{array}{l}\text { Value of seedlings of specific crop } \\
\text { (tom atoes, pepper, onions) (in GHC) }\end{array}$ & 79.497 & 49.093 & 10 & 300 \\
\hline Fertilizer & $\begin{array}{l}\text { Expenditure on fertilizers used on crop (in } \\
\text { GHC) }\end{array}$ & 108.500 & 71.019 & 17.500 & 490 \\
\hline Chemicals & $\begin{array}{l}\text { Expenditure on other chemicals used on } \\
\text { crop (in GHC) }\end{array}$ & 20.986 & 14.289 & 4 & 120 \\
\hline \multicolumn{6}{|c|}{ Capital } \\
\hline \multicolumn{6}{|l|}{ Human capital } \\
\hline Labour & Labour time spent on crop (in man-days) & 55.505 & 15.090 & 30 & 113 \\
\hline \multicolumn{6}{|l|}{ Natural capital } \\
\hline Head & Plot location: $1=$ head-end, $0=$ otherwise & 0.276 & 0.447 & 0 & 1 \\
\hline Tail & Plot location: $1=$ tail-end, $0=$ otherwise & 0.270 & 0.445 & 0 & 1 \\
\hline Tomatoes & Main crop: $1=$ tomatoes, $0=$ otherwise & 0.459 & 0.499 & 0 & 1 \\
\hline Onions & Main crop: $1=$ onions, $0=$ otherwise & 0.270 & 0.445 & 0 & \\
\hline \multicolumn{6}{|l|}{ Physical capital } \\
\hline Tools & $\begin{array}{l}\text { Value of tools (like hoes and scythes) } \\
\text { used on irrigated plot (in GHC) }\end{array}$ & 55.0230 & 19.189 & 22 & 154 \\
\hline \multicolumn{6}{|c|}{ External factors } \\
\hline Extension & Number of visits by extension agents & 2.616 & 1.15176 & 0 & 6 \\
\hline \multicolumn{6}{|c|}{ Other controls } \\
\hline Age & Age of irrigator (in years) & 41.76 & 12.11 & 16 & 85 \\
\hline Sex & $\begin{array}{l}\text { Gender of irrigator: } 1 \text { for men, } 0 \text { for } \\
\text { women }\end{array}$ & 0.614 & 0.488 & 0 & \\
\hline
\end{tabular}


Mean irrigated land size equals only 0.29 acres. Irrigation plots from small-scale irrigation schemes are generally small in Ghana. Land size may have either a positive or a negative impact on yields per acre. In regions where wages are low, as is the case in northern Ghana, an inverse relationship is usually observed (see e.g. Otsuka et al., 2016). The share of headenders in the sample equals 28 percent, while 27 percent of the surveyed households cultivate tail-end plots and 45 percent have plots that are located in the middle. Yields are expected to be highest among head-enders, given their relatively good access to irrigation water. Tomatoes are planted on 46 percent of the investigated plots, while onions and pepper are both planted on 27 percent of the plots. Different crops may have different yields, given that growing conditions and market prices may have been more favourable for specific crops and in specific irrigation schemes in the survey year.

Table 3.1 further shows that the majority of the interviewees i.e. 61.4 percent, are male. The mean age of irrigators is 41.8 years. The impact of sex and age on crop yields is indeterminate a priori. Standard inputs in the production function, like labour use, tools, seedlings, fertilizer and chemicals, are all expected to be positively associated with yields. All interviewed farmers use non-zero quantities of each of these inputs on their irrigated land. Not all farmers, however, were visited by extension agents during the year of observation. The number of extension visits ranged from 0 to 6 , with an average of 1.15. A negligible number of farmers (two farmers representing $0.54 \%$ of respondents) were not visited by extension agents in the reference period.

\subsection{Results and discussions}

Table 3.2 presents the main results of the regression analysis. The results of the model as specified in (4) are shown in column (1). The main focus of this study is on the relationship of yields with six WUA governance dimensions, as proxies of irrigated water use for which we do not have data. The results indicate that participation perceptions have a strongly significant positive association with crop yields of irrigated land. Estimated coefficients for the other dimensions are either insignificant or even negative. In other words, participation in the joint management of a scheme seems to be a crucial dimension in successful governance 
Table 3.2: Regression Results, Ordinary Least Squares

\begin{tabular}{|c|c|c|c|c|}
\hline Variables & (1) & (2) & (3) & (4) \\
\hline Participation & $\begin{array}{l}2.310 * * * \\
(0.778)\end{array}$ & $\begin{array}{l}1.393 * * * \\
(0.442)\end{array}$ & & \\
\hline Accountability & $\begin{array}{l}-0.638 \\
(0.619)\end{array}$ & & $\begin{array}{l}0.444 \\
(0.286)\end{array}$ & \\
\hline $\begin{array}{l}\text { Conflict } \\
\text { Management }\end{array}$ & $\begin{array}{l}-1.889 * \\
(1.039)\end{array}$ & $\begin{array}{l}-2.282 * * \\
(0.864)\end{array}$ & $\begin{array}{l}-1.612 * \\
(0.813)\end{array}$ & $\begin{array}{l}-1.685 \\
(1.007)\end{array}$ \\
\hline $\begin{array}{l}\text { Transparency } \\
\text { and cooperation }\end{array}$ & $\begin{array}{l}0.076 \\
(0.631)\end{array}$ & & & $\begin{array}{l}-0.355 \\
(0.359)\end{array}$ \\
\hline $\begin{array}{l}\text { Fairness and } \\
\text { Equity }\end{array}$ & $\begin{array}{l}0.081 \\
(0.491)\end{array}$ & & & \\
\hline $\begin{array}{l}\text { Sustainable } \\
\text { Use }\end{array}$ & $\begin{array}{l}0.264 \\
(0.372)\end{array}$ & & & \\
\hline Land & $\begin{array}{l}-0.612 * * * \\
(0.156)\end{array}$ & $\begin{array}{l}-0.589 * * * \\
(0.152)\end{array}$ & $\begin{array}{l}-0.584 * * * \\
(0.160)\end{array}$ & $\begin{array}{l}-0.606 * * * \\
(0.155)\end{array}$ \\
\hline Seed & $\begin{array}{l}0.044 \\
(0.082)\end{array}$ & $\begin{array}{l}0.045 \\
(0.074)\end{array}$ & $\begin{array}{l}0.051 \\
(0.074)\end{array}$ & $\begin{array}{l}0.047 \\
(0.074) \\
\end{array}$ \\
\hline Fertilizer & $\begin{array}{l}0.146 * * \\
(0.056)\end{array}$ & $\begin{array}{l}0.147 * * \\
(0.061)\end{array}$ & $\begin{array}{l}0.151 * * \\
(0.062)\end{array}$ & $\begin{array}{l}0.150 * * \\
(0.063)\end{array}$ \\
\hline Chemicals & $\begin{array}{l}0.274 * * * \\
(0.069)\end{array}$ & $\begin{array}{l}0.281 * * * \\
(0.070)\end{array}$ & $\begin{array}{l}0.282 * * * \\
(0.070)\end{array}$ & $\begin{array}{l}0.269 * * * \\
(0.073)\end{array}$ \\
\hline Labour & $\begin{array}{l}0.205 \\
(0.214) \\
\end{array}$ & $\begin{array}{l}0.189 \\
(0.220) \\
\end{array}$ & $\begin{array}{l}0.189 \\
(0.228) \\
\end{array}$ & $\begin{array}{l}0.242 \\
(0.225) \\
\end{array}$ \\
\hline $\begin{array}{l}\text { Head plot } \\
\text { Dummy }\end{array}$ & $\begin{array}{l}0.041 \\
(0.074)\end{array}$ & $\begin{array}{l}0.043 \\
(0.073)\end{array}$ & $\begin{array}{l}0.050 \\
(0.073)\end{array}$ & $\begin{array}{l}0.056 \\
(0.074)\end{array}$ \\
\hline $\begin{array}{l}\text { Tail plot } \\
\text { Dummy }\end{array}$ & $\begin{array}{l}0.072 \\
(0.076)\end{array}$ & $\begin{array}{l}0.077 \\
(0.075)\end{array}$ & $\begin{array}{l}0.089 \\
(0.076)\end{array}$ & $\begin{array}{l}0.091 \\
(0.076)\end{array}$ \\
\hline Tomato dummy & $\begin{array}{l}0.231 * \\
(0.133)\end{array}$ & $\begin{array}{l}0.225^{*} \\
(0.120)\end{array}$ & $\begin{array}{l}0.215^{*} \\
(0.127)\end{array}$ & $\begin{array}{l}0.230 * \\
(0.127)\end{array}$ \\
\hline Onion dummy & $\begin{array}{l}0.394 * * \\
(0.147)\end{array}$ & $\begin{array}{l}0.408 * * * \\
(0.124)\end{array}$ & $\begin{array}{l}0.439 * * * \\
(0.134)\end{array}$ & $\begin{array}{l}0.472 * * * \\
(0.133)\end{array}$ \\
\hline Tools & $\begin{array}{l}-0.248 \\
(0.194)\end{array}$ & $\begin{array}{l}-0.272 \\
(0.190)\end{array}$ & $\begin{array}{l}-0.251 \\
(0.198)\end{array}$ & $\begin{array}{l}-0.229 \\
(0.196)\end{array}$ \\
\hline Extension & $\begin{array}{l}0.172 * \\
(0.088) \\
\end{array}$ & $\begin{array}{l}0.169^{*} \\
(0.092)\end{array}$ & $\begin{array}{l}0.157^{*} \\
(0.090)\end{array}$ & $\begin{array}{l}0.147 \\
(0.090)\end{array}$ \\
\hline Age & $\begin{array}{l}-0.003 \\
(0.003)\end{array}$ & $\begin{array}{l}-0.003 \\
(0.003)\end{array}$ & $\begin{array}{l}-0.003 \\
(0.003)\end{array}$ & $\begin{array}{l}-0.003 \\
(0.003)\end{array}$ \\
\hline Sex & $\begin{array}{l}-0.005 \\
(0.068)\end{array}$ & $\begin{array}{l}-0.004 \\
(0.070)\end{array}$ & $\begin{array}{l}-0.000 \\
(0.070)\end{array}$ & $\begin{array}{l}-0.007 \\
(0.070)\end{array}$ \\
\hline Constant & $\begin{array}{l}5.500 * * \\
(2.691)\end{array}$ & $\begin{array}{l}6.941 * * * \\
(1.941)\end{array}$ & $\begin{array}{l}7.249 * * * \\
(2.121)\end{array}$ & $\begin{array}{l}7.927 * * * \\
(2.665)\end{array}$ \\
\hline Observations & 370 & 370 & 370 & 370 \\
\hline R-squared & 0.46 & 0.455 & 0.442 & 0.44 \\
\hline
\end{tabular}

Notes: $* * * \mathrm{p}<0.01,{ }^{* *} \mathrm{p}<0.05, * \mathrm{p}<0.1$; Robust cluster errors in brackets 
of irrigation schemes. Conflict management, on the other hand, has a significant negative association with crop yield. A potential explanation for this unanticipated finding is that rules and regulations put in place to avert conflicts contribute to freeriding and other anti-social behaviour by users exploring the limits of those rules and regulations. More research is needed to examine whether this result can also be found in jointly managed irrigation schemes located elsewhere and in other common pool resources, and to what extent the potential explanation that we offer can be substantiated. The insignificance of other governance dimensions may be affected by collinearity among those dimensions. Table 3.3 shows that correlation coefficients are highest (larger than 0.7) for three variables; participation, accountability, and transparency and cooperation. These three variables also have the highest Variance Inflation Factors (VIFs) in Table 3.4. In columns (2) - (4) of Table 3.2 we therefore present the regression results when only significant governance dimensions are included in the equation (column (2)) and when two seemingly correlated dimensions are included in the equation instead of participation (columns (3) and (4)). As can be seen from column (2), the estimated coefficients for participation and conflict management remain significant and have the same signs, but change somewhat in magnitude, when the insignificant dimensions are dropped. When participation is replaced by one of its correlated dimensions, those dimensions are found to have no significant association with yields (columns (3) and (4)). The latter result suggests that it is indeed participation, and not its correlated dimensions (accountability, transparency and cooperation) that associates with yields.

Table 3.3: Correlation matrix of governance dimensions

\begin{tabular}{|l|l|l|l|l|l|l|}
\hline & $\begin{array}{l}\text { Partici- } \\
\text { pation }\end{array}$ & $\begin{array}{l}\text { Accounta- } \\
\text { bility }\end{array}$ & $\begin{array}{l}\text { Conflict } \\
\text { management }\end{array}$ & $\begin{array}{l}\text { Transparency } \\
\text { and cooperation }\end{array}$ & $\begin{array}{l}\text { Fairness } \\
\text { and } \\
\text { equity }\end{array}$ & $\begin{array}{l}\text { Sustain- } \\
\text { able use }\end{array}$ \\
\hline Participation & 1.0000 & & & & & \\
\hline Accountability & 0.7534 & 1.0000 & & & & \\
\hline $\begin{array}{l}\text { Conflict } \\
\text { management }\end{array}$ & 0.5245 & 0.6063 & 1.0000 & & & \\
\hline $\begin{array}{l}\text { Transparency } \\
\text { and cooperation }\end{array}$ & 0.7120 & 0.8003 & 0.5807 & 1.0000 & & \\
\hline $\begin{array}{l}\text { Fairness and } \\
\text { equity }\end{array}$ & 0.4811 & 0.4778 & 0.4261 & 0.6365 & 1.0000 & \\
\hline Sustainable use & 0.2921 & 0.2748 & 0.3477 & 0.4106 & 0.5783 & 1.0000 \\
\hline
\end{tabular}


Table 3.4: VIFs of governance dimensions

\begin{tabular}{|l|l|l|}
\hline Variable & VIF & $1 /$ VIF \\
\hline Accountability & 3.74 & 0.2677 \\
\hline Transparency and cooperation & 3.72 & 0.2689 \\
\hline Participation & 2.44 & 0.4099 \\
\hline Fairness and equity & 2.10 & 0.4765 \\
\hline Conflict management & 1.74 & 0.5746 \\
\hline Sustainable use & 1.54 & 0.6487 \\
\hline
\end{tabular}

Note: VIF $>10$ signals severe collinearity

Table 3.2 also indicates that most estimates regarding conventional production function inputs are consistent with a priori expectations. The significant negative impact of irrigatedfarm size supports results of previous studies on the existence of an inverse land size productivity relationship in smallholder agriculture in different parts of the world (e.g. Cornia, 1985; Heltberg, 1998; Carletto et al., 2013; Otsuka et al., 2016). Use of fertilizer, other agro-chemicals, and extension services has significant positive effects on yields, with other chemicals having the highest elasticity $(0.27)$. The results suggest potential overuse of labour, seed, and tools, as their estimated coefficients (i.e. elasticities) do not differ significantly from zero. Productivity is significantly higher on tomato and (especially) onion plots, as compared to plots planted with pepper. As crop yields are measured in value terms, this finding may (partly) reflect favourable market prices for these two crops during the year of observation. The location of a plot does not significantly affect crop yields of the irrigators in the sample. The estimated coefficients for both head-end and tail-end plots do not significantly differ from zero, suggesting that access to irrigation water is not significantly affected by plot location. The two demographic factors that we include as explanatory variables - age and sex of the irrigator - do not have a significant effect on crop yields of the farmers that we interviewed. Male and female, and young and old, irrigators are thus found to have similar productivities when other inputs into production are controlled. 


\subsection{Conclusions and recommendations}

This study aimed at contributing to the discourse on the role of governance in sustaining communal resources. This was done by assessing the extent to which users' perceptions of different dimensions of irrigation governance relate to the performance of irrigation schemes in northern Ghana. We represent performance with irrigated crop yields per unit area, while the dimensions of governance assessed are participation, accountability, conflict management, fairness and equity, transparency and cooperation, and sustainable management. We applied a Cobb-Douglas production function to data collected among 370 farm households in 37 small-scale irrigation schemes in northern Ghana to estimate the strength of the associations of each dimension.

The results show that though governance generally has a positive association with irrigated yields, most dimensions of irrigation governance are not significant. Participation in particular influences yields positively. This confirms that participation in the joint management of irrigation resources or CPRs as advocated by scholars is crucial. Conflict management, however, associates negatively with irrigated yields. Rules and regulations for conflict resolutions in CPR user groups could be contributing to free riding.

To improve or develop the irrigation sector in northern Ghana, we make the following recommendations for policy consideration. These can be implemented by state institutions in charge of irrigation development or by NGOs and private sectors that focus on alleviating poverty whiles increasing rural incomes through dry-season farming.

1. In terms of governance, participation of users in joint management of irrigation resources seems to be a crucial dimension. It should be encouraged in schemes where participation perceptions are found to be low. This may include inclusive decision making and collective maintenance of irrigation facilities. 
2. There may be a need to break the negative link between conflict management perceptions and water use (and thus crop yields). Rules and regulations regarding conflict resolutions need to be reviewed and those that seem to encourage free riding should be eliminated.

3. Further research should be carried out to examine the effect of conflict management perceptions in jointly managed irrigation schemes located elsewhere and in other common pool resources, and to verify the potential explanation that we give. 


\title{
CHAPTER 4
}

\section{Sustaining small-scale irrigation systems: the role of users}

\begin{abstract}
Users' contributions in terms of labour towards irrigation resource maintenance are critical for long-term performance of the schem es. Users' contributions depend on $\mathrm{m}$ any factors, including users' perceptions of the governance of WUAs and users' cooperativeness, i.e. the willingness of users to cooperate in collective activities. In this paper we assess how users' governance perceptions and cooperativeness relate to users' contributions towards irrigation resource maintenance using survey and lab-in-the-field experimental data from 19 small-scale irrigation schemes in northern Ghana. We use household survey data to create indicators of a user's perception on six governance dim ensions, and estim ate his or her cooperativeness through lab-in-the-field experiments. We use two-stage least square regression for assessing the determinants of labour contributions and a tobit approach for assessing cooperativeness. We find that positive governance perceptions and cooperativeness generally increase a user's labour contribution towards maintenance. Sustainable use is the governance perception dimension that influences labour contributions. User perceptions of conflict management is found to have a negative impact on cooperativeness. We conclude that although better governance perceptions generally influence labour contributions to the maintenance of irrigation schemes in a positive way, different dimensions differ in their contributions.
\end{abstract}

Publication status: Akuriba, M.A, Haagsma R., Heerink N., and Dittoh S., 2018. Sustaining Small-Scale Irrigation Systems: The Role of Users. Paper presented at the $30^{\text {th }}$ International Conference of Agricultural Economists (ICAE), $28^{\text {th }} \mathrm{July}^{\text {to }} 2^{\text {nd }}$ August, 2018, Vancouver, Canada. 


\subsection{Introduction}

Irrigated agriculture is well advocated for improving food security, especially in developing countries in the wake of climate change. Irrigation particularly improves agricultural performance and rural livelihoods (Janaiah et al., 2000; Mengistie and Kidane, 2016; Namara et al., 2011; Oates et al., 2015). Over the years, governments in developing countries have invested in irrigation infrastructures aimed at increasing local agricultural production for food security. To ensure equity in the use of both natural and man-made resources among all social groups, the role of governments in infrastructure provision is paramount in enhancing usage and ensuring sustainability.

Large-scale irrigation schemes are however costly to build and maintain. This has led to many development agencies supporting the construction of small-scale schemes and including stakeholders in the planning and implementation of irrigation schemes. Inclusion of stakeholders inculcates a sense of ownership for the effective maintenance of schemes (Delaney, 2012; Yami, 2013). It also reduces burden on governments in terms of the daily management and maintenance of facilities. Ostrom $(2000,1990)$ emphasized the need for self-governance of common pool resources. Her central point is that users of a common resource can organize themselves into associations that effectively and sustainably manage the resource. The 'tragedy of the com m ons' is not unavoidable, and sustainability of com $\mathrm{m}$ on resources does not require authorities to intervene top-down (Wang et al., 2010). These insights led to the formation of Water User Associations (WUAs) for the governance of most small-scale schemes in developing countries.

Effective participatory governance of small-scale irrigation schemes depends on the cooperation among users in enforcing rules in the operation and maintenance of irrigation facilities. One way of assessing cooperation in self-governing user groups is the level of compliance in contributing towards the maintenance of facilities (Baerlein et al., 2015). Primary contributions from users can be in kind and in cash. Where collective action is key to achieving common goals, the tendency for some users to free-ride is however inevitable. The ability of a user group to succeed in managing irrigation resources thus lies in the cooperativeness of its members, that is, their willingness to act together for a mutual interest and to demonstrate their trust in the other members through their actions. Irrigation resources 
are common pools and users need to have confidence in each other by cooperating. As pointed out by Cardenas et al. (2011), "collective action in water $\mathrm{m}$ anagem ent requires that individuals overcome their individual incentives to free-ride and be willing to cooperate in the provision dilem $\mathrm{m}$ a".

A number of factors can explain why users may or may not be willing to contribute towards a common purpose, varying from socioeconomic reasons to factors that relate to the general governance of resources (Baerlein et al., 2015; Cardenas et al., 2011). When composing WUAs, heterogeneity in sex and age for instance is important for equity concerns, but this can influence the number of labour days contributed towards maintenance activities. The different roles played by men and women in households constrain their availability for communal activities. Experience between the young and old also varies and may reflect in their involvement in maintenance activities.

Fujiie et al. (2005) examined the conditions necessary for collective action in managing local commons using the Philippines as a case study. Using cross-sectional survey data on the activities of irrigator associations, their study found that availability of water, farm er's plot location, history of irrigated farming (experience in irrigation), and size of the user group, among others, influence users' collective action in the maintenance and operation of irrigation systems. Specifically, their results showed that collective action is difficult where water is abundant or extremely scarce, which is also the case of a farmer's location along a lateral. Experience in irrigation had a positive influence, while group size had a negative effect. Cardenas et al. (2011) on the other hand used behavioural experiments in assessing factors that affect collective action in watershed management in Colombia and Kenya. In their gam e settings, they estim ated farm ers' appropriation and provisioning decisions under different scenarios to ascertain the most effective way to increase cooperation. They concluded that allowing communication in groups increases cooperation significantly. Many other researchers have also pointed out the fact that an individual's willingness to cooperate for a common purpose is context-based and thus influenced by several factors (Anderies et al., 2011; Ostrom et al., 1994; Araral, 2009). A key factor is the institutional arrangements in governing the commons i.e., whether it is governed by governments or users, and the kind of institutions put in place to ensure compliance. The question that arises however is whether or not the perceptions of users regarding the governance structures of the commons also play a 
role in their levels of contributions in collective action. As explained by Kaufmann et al. (2004, 2009, 2011), perceptions matter in assessing governance because individuals and organisations base their decisions on perceived outcomes taking into consideration circumstances surrounding the decisions.

For user-managed resources, governance perceptions may also play an important part in collective action. The involvement of the individual may be influenced by how resources are governed. This goes beyond a simple distinction between government- or user-managed resources, focusing on the perceived style of governance. The level of contributions towards resource maintenance may be larger when users can testify that resources are well-governed in terms of accountability of leaders, transparency in dealings, fairness/equity in resource allocation, and other governance dimensions. The understanding of how these factors affect users' actions in collective action $\mathrm{m}$ ay help in advancing the debate on sustaining sm alscale irrigation resources.

It is also evident from the above that cooperativeness is vital in the maintenance of irrigation resources. Little is known however about the influence of cooperativeness on collective action in the operation and maintenance of small-scale irrigation schemes. Estimates of cooperation through behavioural experiments are often used to predict how individuals will behave when given a collective task. Factors that affect cooperation have been examined in $m$ any studies, but the associated effect of a user's willingness to cooperate on his/her actual contribution towards irrigation maintenance remains unanswered. This study therefore adds to knowledge on the commons by analysing how users' governance perceptions and cooperativeness relate to their contributions towards maintenance of small-scale irrigation systems. To achieve this, we used household survey data and results of a Voluntary Contribution Mechanism (VCM) experiment held among households in 19 gravity-flow small-scale irrigation schemes from northern Ghana to obtain more insights into these effects. Ghana is a lower-middle income country, with poverty being more pronounced in the northern part of the country. Rainfall is mono-modal in this part of the country, and surface irrigation from small reservoirs is used for dry-season gardening to complement rain-fed production. Insights from this particular case are expected to aid in understanding aspects of users of small-scale irrigation schemes that need more attention for developing sustainable irrigation systems. This is particularly relevant in establishing functional WUAs for effective 
governance of irrigation resources in economies under similar agro-ecological and socioeconomic conditions.

In Section 4.2 we present the theoretical background to the study, explaining the main factors that come to play in maintaining small-scale irrigation schemes, including the need for cooperation and good governance. Section 4.3 outlines the methods used for data collection and analysis. We present the empirical results in Section 4.4 and discuss them in Section 4.5. Concluding remarks are found in Section 4.6.

\subsection{Theoretical background}

\section{2.1 Management of small-scale irrigation systems}

Surface irrigation systems are interconnected systems involving many actors. All the actors play their roles in making the systems function. There are different types of these systems in terms of scale and technology. The most common irrigation systems in Ghana are small-scale irrigation schemes using gravity-flow reservoirs and involving many actors, including state institutions, the private sector, NGOs, and users. These are mostly constructed in rural communities for agricultural purposes. The main roles played by state institutions and NGOs are the funding of the construction of facilities and providing technical support to ensure that the systems function well. After construction, the providing agencies normally want the users of these systems to use them sustainably. Sustainability in this sense refers to the ability of systems to maintain their viability by using techniques that allow for continuity (Delaney, 2012).

For common pool resources (CPRs) like irrigation facilities, community ownership of facilities is vital in sustaining the systems. When communities are given a mandate to own and operate resources, they may manage the facilities by using local and communal experiences without waiting for prescribed rules. For a system to become sustainable, innovative ideas and technologies using traditional norms that are readily available are required. Gleick (2000) explains that water resources which are locally innovated and 
managed, including small-scale dams, are more cost-effective and environmentally-friendly to local communities due to the experiences of local communities with regard to traditional practices. The participation of local communities in irrigation governance may thus be sustainable because local stakeholders are often more familiar with peculiarities of local economic, social, cultural, and environmental situations (Tortajada, 2010). For these reasons, the practice of forming Water User Associations (WUAs), made up of local community members, to manage and control the use of communal irrigation resources has been commonplace in Ghana (and many other countries) for decades. This model of governance allows communities to own irrigation resources and take sole responsibility for managing the irrigation facilities through WUAs. The WUA concept incorporates acceptable local norms and rules in governing irrigation systems so that it becomes easier for users to comply with. The most common rules in WUAs in Ghana for instance are: compulsory participation of users in communal labour for maintenance; and avoidance of upstream-farming to minimise siltation of reservoirs. The communal labour concept is indigenous and is thus accepted for the sustenance of irrigation facilities.

Rules and regulations are required to maintain order among a group of users. This is particularly important in the management of CPRs to avoid over-exploitation of resources and negative externalities that pose a threat to the sustainability of CPRs. The existence of rules is a step towards achieving sustainability. However, the enforcement of such rules and regulations by ensuring that users who do not obey the agreed rules are punished accordingly is important for the sustenance of resources. Sanctions serve as deterrents to other users, and are also indications of unbiasedness in the management of CPRs. In Agrawal (2003), graduated sanctions are recommended for the sustainable governance of CPRs.

In addition to the enforcem ent of rules, sustainable use largely depends on users' willingness to contribute in maintaining the facilities, and the use of water-saving technologies such as drip irrigation. However, irrigation technologies from small-scale reservoirs hardly differ in northern Ghana, so the focus is on maintenance. As illustrated in Figure 1, the individual's involvement in maintenance activities forms the foundation of sustainable irrigation. Though other actors are important in sustaining irrigation systems, the individual's actions determine the system's survival for posterity. 
Although contributions in kind through labour are required from individuals and their communities for maintaining irrigation facilities in Ghana, cash contributions through levies for water use and voluntary contributions are also taken for minor repairs of facilities. Thus, the individual's willingness to offer these contributions in kind and/or in cash is vital in sustaining small-scale irrigation schemes. A user's willingness to contribute towards maintenance may however be affected by inherent elements such as the characteristics of a user as well as the characteristics of the irrigation scheme and user group.

In Agrawal's sustainable governance fram ework (Agrawal 2003), the characteristics of users and resources affect the sustainability of commons. The amount of provisioning for resource maintenance depends on the attributes of the users in question. The characteristics of the resource determines to what extent it serves users. Users may avail themselves to sustaining a resource if they consider it has prospects. Knowledge on the influence of these factors is necessary in the formation and monitoring of WUAs in sustaining small-scale irrigation schemes. That is, by knowing these associated effects, appropriate criteria can be established for better management of irrigation resources. The expected influence of the main factors affecting users' contributions towards irrigation m aintenance as illustrated in Figure 4.1 are discussed in the following sections.

\subsubsection{User characteristics}

In this section we discuss some of the characteristics of users that may influence their contribution towards the collective maintenance of small-scale irrigation schemes and general cooperativeness of users in irrigation management. We start by discussing governance perceptions and its major dimensions, followed by a discussion of other more common explanatory variables used in studies of collective action. 


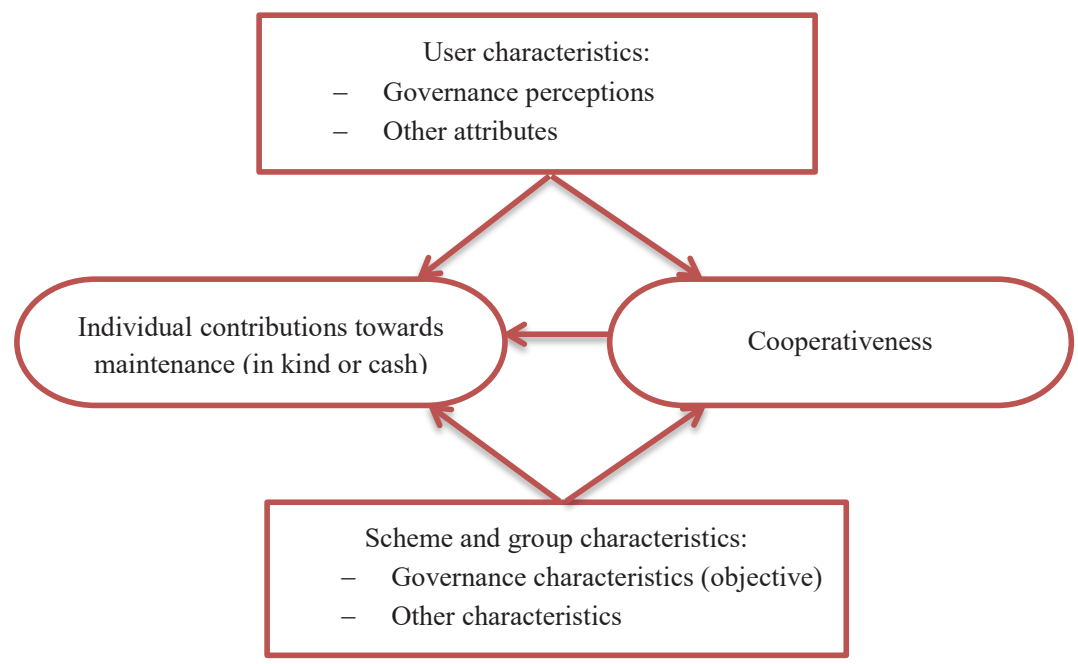

Figure 4.1: Factors affecting maintenance of small-scale irrigation schemes

\section{Governance perceptions}

The style of governance of a resource $m$ ay be one factor that determ ines users' contributions to CPRs. For self-governing irrigation schemes, good governance is key to ensuring trust in users. The manner in which an irrigation facility is handled by users and their leaders with respect to enforcement of rules and regulations can have dire consequences on user participation. Leaders of WUAs need to guide resource use in an unbiased manner. Equitable allocation of resources may for instance attract equitable contributions from users. Governance can be assessed objectively (Index, 2013) as well as subjectively through perceptions-based measures (Kaufmann et al., 2011). For the involvement of users in maintaining common property, user perceptions of governance are likely to determine contribution levels, because users have the greatest stake in the sustainable use of resources (Abernethy, 2010). The description and measurement of six major governance dimensions considered in this study are presented in Chapter 2. 


\section{Other user attributes}

Several other user attributes may also influence their participation in maintaining common pool resources.

Age: Age is said to generally associate positively with cooperation in collective action (De Janvry and Sadoulet, 2016: p. 587). In terms of labour contributions, older users may be involved more in maintenance activities than younger ones. Older users tend to have more experience in irrigation activities, and knowing what benefits accrue from collective action propels them to be more committed than younger ones. Likewise, cooperating in any activity in the management of irrigation resources may be cherished more by relatively older users.

Sex: As explained earlier, the different roles of sexes in local communities may influence collective action. In rural areas in Ghana, wom en's role in agriculture is relatively less laborious, such as planting, watering, harvesting, and agro-processing, while men are involved in the laborious activities including clearing of lands and soil tilling (ADF, 2008). It is not strange though to see some women outperform men on some maintenance-related activities such as covering gullies with stones and sand, which is arduous, but that is not the norm. For hardcore activities like clearing weeds around irrigation facilities and desilting canals, among others, men are expected to be involved more. As farming, and for that matter irrigation, is a male-dominated activity in Africa and many other places, women are likely to cooperate less in irrigation management. On the other hand, getting the opportunity to take part in irrigation activities may motivate women to cooperate more. Sex can thus have any directional effect on user cooperativeness.

Education: The educational level of users can influence collective action positively. Education generally stimulates critical thinking and analysis to distinguish right from wrong for continuity. For CPRs in local communities, the use of local norms is prevalent. Users of such CPRs who have acquired formal education have an added advantage of integrating local norms and acquired knowledge for a sustainable governance of CPRs and may be involved more in activities towards the sustainability of CPRs. Cooperation in irrigation management in particular is high in users with relatively higher levels of education. Cardenas et al. (2011) 
empirically confirmed this in their study on collective action for watershed management in Colombia and Kenya.

Household labour force: Households with a large number of labourers have an advantage over households with a small number of labourers and may thus contribute more to maintenance. Urgent matters can hinder small labourer households from partaking in maintenance activities, but large labourer households have the opportunity to delegate other household members to take part in irrigation maintenance activities. Cooperativeness in the management of irrigation resources may generally be better in households with a large labour force due to the advantage of size.

Training: Access to irrigation-related training is said to improve collective activities in irrigation management (Muchara et al., 2014). Training offers users improved skills in efficient water management for enhanced production. This motivates users and increases their interest in irrigation. The increased desire may influence user participation in maintaining irrigation facilities for sustainable production.

Plot location: For irrigation systems, plot location is important as this determines the timeliness of water accessibility. The location of users along the canals of mainstream irrigation is a good way to measure water availability to users (Meinzen-Dick et al., 2002). Cooperation in collective action is assumed to be more difficult when a resource is either abundant or extremely scarce (Bardhan, 1993; Nagrah et al., 2016). For small-scale irrigation, extremities may not exist among users in terms of their plot locations since canals in such schemes are relatively short. That notwithstanding, users may have preferences for plots. Some well-located users may feel reluctant to cooperate and/or take part in maintenance activities due to their easy access to water. Tail-end users may therefore cooperate more in the management of irrigation facilities, perhaps contributing more in terms of labour to ensure canals and laterals are well-maintained for a guaranteed access to water. 


\subsubsection{Cooperativeness}

In common pool resources (CPRs) where resources are used by several individuals and communities, cooperation among users is the key to sustaining resources. It involves working together in terms of decisions and actions for a mutual benefit. Hardin's (1968) predictions on the tragedy of the commons pointed out free riding as one of the factors hindering collective action. To ensure the sustainable management of common pools, he highlighted the need for mutual coercing such as enforcing rules and regulations to prevent free riding on CPRs amidst population growth. Users who are cooperative abide by agreed-on rules and willingly contribute for com mon interests. For a continuous and sustainable "appropriation", there is need for "provisioning" in term s of good maintenance of the resource which requires cooperation. Cooperativeness is thus needed for mutual benefits. It is generally aided by altruism (Akresh et al., 2016). Altruistic users are selfless and more concerned about issues of common interest and may willingly contribute more towards resource maintenance. Hence, cooperators $\mathrm{m}$ ay associate positively with user's contributions in irrigation $\mathrm{m}$ aintenance activities.

\subsubsection{Scheme and group characteristics}

The attributes of irrigation schemes such as CPRs have potential effects on users' attitudes towards irrigation sustenance. The nature of groups using CPRs can also affect how resources are managed and, consequently, whether users are willing to contribute in maintaining such resources or not. In this section we discuss some of the characteristics of irrigation schemes and user groups that can potentially influence the contributions of users in maintaining irrigation resources such as commons.

\section{Governance characteristics}

The outcomes resulting from the style of governance can influence collective action in irrigation maintenance. However, as discussed in Kaufmann et al. (2011), the absence of data (lack of records) makes it difficult to quantify some governance outcomes. In the case of 
CPRs, governance directly involves the enforcement of rules and regulations to ensure the sustainability of resources. We will now discuss aspects of objective governance that can affect the management of CPRs and for that matter irrigation maintenance.

Leadership type: Leadership is essential in resource governance to ensure that users abide by rules and regulations in sustaining resources (Nagrah et al., 2016). In self-governing CPRs, the mode by which leaders are selected can either encourage or discourage user participation in resource maintenance. In groups where users are free to choose their leaders, the tendency to obey instructions from such leadership is high. Leaders elected democratically often have the qualities desired by the majority for effective governance. In cases where group leaders are imposed by community heads, governments, and/or NGOs, among others, users may not be enthused by the qualities of such leaders and may decide to ignore orders from them, thereby cooperating less and possibly contributing less to resource maintenance.

Other aspects of objective governance that may be relevant in contributions to maintenance could not be measured and are thus captured under user perceptions.

\section{Other scheme and group characteristics}

Scheme size: CPRs that are small are relatively easy to manage sustainably (Agrawal, 2003). This is because fewer resources are required in maintenance, and monitoring is more effective if the CPR is small. In this study, we represent scheme size with the amount of developed land in an irrigation scheme. In relatively smaller irrigation schemes, land may be limited. Users of relatively smaller schemes may be more committed to maintenance activities to avoid losing allocated land to other users. User cooperativeness may however be negatively influenced if the size of a developed area is small and not compliant with user demands.

Group size: Smaller user groups are said to be easily manageable in terms of organization for collective action (Fujiie et al., 2005). As groups get larger, the tendency to free-ride increases because each user looks to the other to offer services. Contention in that manner hinders 
collective action and in such cases leaders may have to use compelling tactics to get maximum participation in maintaining resources. Smaller user groups are also likely to function well in terms of general cooperativeness, because the social interlinkages in such groups are greater (Olson, 1965).

Age of scheme: As an irrigation scheme gets older (in terms of number of years of existence), it deteriorates, making it unable to perform well as before. That is, older schemes require more maintenance; the amount of maintenance that is needed $m$ ay negatively affect users' willingness to contribute. On the other hand, the fact that more maintenance is needed may have a direct positive effect on the contributions of individuals. Hence, the impact can be positive as well as negative on both labour contribution and user cooperativeness.

Market access: Market accessibility brings opportunities for trade and income generation. Irrigation sites closer to markets have better incentives for effective irrigation since such communities are likely to be more commercially oriented (Meinzen-Dick et al., 2002). Proximity to markets may therefore offer a better opportunity in increasing returns to irrigated produce, which can be an incentive for users to partake in sustaining irrigation facilities. On the other hand, proximity of irrigation facilities to market centres can be a disincentive to cooperation because market proximity loosens traditional social ties that bind farmers into mutual dependencies, thereby making enforcement difficult (Araral, 2009). Thus, market accessibility can play either role in collective action.

Dependence on resource: Users who depend more on a resource are more likely to devote more time and energy in maintaining it for their livelihood. Those who have varied sources of income will normally have to divide their time and capital between these sources and may end up contributing less to each of the resources on which they depend on for their livelihoods. Dietz et al. (2003) considers this as one of the main conditions for collective action in CPRs, and explained that users must depend to a large extent on a resource to be willing to devote their time to its sustenance. In the maintenance of irrigation resources, users who depend less on irrigation may contribute less labour and generally cooperate less in irrigation management. 
Main crop: The main crop grown at a scheme is decided at the scheme level, and can thus be considered exogenous to the labour contributions of users. The crop grown in a scheme may influence the availability of water for irrigation in a season (depending on water demands of crops). Irrigation dams can run dry if water-demanding crops are grown, which may be a disincentive for user participation in maintenance. The economic value of a crop can influence participation in maintenance positively. The net impact of the main cop grown in a scheme on user involvement in maintaining irrigation schemes is indeterminate.

\subsection{Methodology}

\subsubsection{Data collection}

A Voluntary Contribution Mechanism (VCM) experiment was performed in 19 small-scale irrigation schemes in the study area (using dams with canals) from November 2014 to April 2015 to elicit the willingness of users to contribute towards irrigation resource maintenance. This experiment aimed at estimating the cooperative nature of users, which is used as a variable to check if being cooperative or altruistic plays a role in users' involvem ent in maintenance activities. As acknowledged by De Janvry and Sadoulet (2016 pp 585), though difficult and expensive to run, lab-in-the-field experiments have the advantage of addressing issues that lab experiments may be unable to. Student populations in the case of lab experiments may not be sensitive to or knowledgeable about the subject under study. Experimenting with stakeholders gives a better prediction of reality.

We complemented the VCM experiment with a household survey using questionnaires. The amount of labour contributed towards irrigation resource maintenance was captured in the household questionnaire aimed at measuring contributions in kind by users (our measure of collective action), among other useful information needed for the study. A simple random approach using the lottery method was used to sample respondents from a list of WUA members. Fifteen (15) respondents were sampled from each WUA of the 19 small-scale irrigation schemes, giving a total of 285 participants for the VCM experiment. A total of 190 respondents (10 from each scheme) were however considered for the household interview. 
The depth of the household questionnaire took a lot of time so we had to limit the number of respondents to 10 per scheme. For each scheme, one of the three crops considered dominant in the scheme was chosen. Only users who grew the dominant crop took part in the sampling process. Non-growers of these crops were however allowed to take part in the focus group discussions. Detailed description of the household survey is presented in Chapter 2.

\section{Estimating governance perceptions}

The main relationships of interest in this study concern the influence of governance arrangements on collective action. The Cronbach alpha test results in Table 4.1 indicates that the set of items included in each governance dimension (described in Chapter 2) are closely related as a group (for the 19 schemes considered for this paper).

Table 4.1: Cronbach alpha test of irrigation governance dimensions scales

\begin{tabular}{|l|c|c|c|}
\hline $\begin{array}{l}\text { Irrigation Governance } \\
\text { Dimension }\end{array}$ & $\begin{array}{c}\text { Number of } \\
\text { Components }\end{array}$ & $\begin{array}{c}\text { Average Interim } \\
\text { Covariance }\end{array}$ & $\begin{array}{c}\text { Scale Reliability } \\
\text { Coefficient }(\alpha)\end{array}$ \\
\hline Participation & 5 & 0.3757 & 0.78 \\
\hline Accountability & 5 & 0.6177 & 0.85 \\
\hline Conflict management & 4 & 0.1763 & 0.71 \\
\hline Transparency/cooperation & 14 & 0.3688 & 0.88 \\
\hline Fairness and equity & 7 & 0.2682 & 0.71 \\
\hline Sustainable use & 11 & 0.2589 & 0.72 \\
\hline Overall governance & 6 & 0.2398 & 0.87 \\
\hline
\end{tabular}

Note: $\alpha \geq 0.7$ is acceptable 


\section{Measuring cooperativeness}

In studying cooperation in CPR use, behavioural experiments have often been used to assess the willingness of users to cooperate in resource governance (Anderies et al., 2011; De Janvry and Sadoulet, 2016: p. 584). Economic experiments aid in predicting the behaviour of users in their appropriation of resources and/or contributions to their sustenance. Ostrom et al. (1994) performed CPR experiments in the context of fisheries, irrigation systems, forests, and groundwater basins to understand how individuals behave in CPRs. Their experiments were formulated in such a way as to assess how participants allocate given tokens (initial endowments) between two markets, with one market yielding fixed returns, and the other market (representing a CPR) yielding a return dependent on investments of other participants into the CPR. Cardenas et al. (2011), and Baerlein et al. (2015) also used experiments to understand actions in the management of irrigation systems. Experiments on willingness to cooperate estimate the individual's cooperative will. Individuals who contribute more in such games are regarded as being cooperative and may cooperate better in real life. In this study, we used a VCM experiment to estimate cooperativeness as explained in the following section.

\section{VCM experimental design}

A standard VCM game was framed in the context of irrigation management, asking participants to assume that contributions to the public fund are for the maintenance of their irrigation facility (see Appendix 1 for details of instructions). Participants were randomly placed in anonymous groups of five, each person not knowing which group others belonged to, and played for a total of 10 rounds. Three groups were formed and they were all made to sit far apart from each other so that they did not see their neighbours' decisions.

In each round of play, participants were given 25 tokens as their endowments and asked to decide how many tokens they would invest in a private account for their own benefit and to a public account towards the maintenance of their dam. A token invested in a private account yielded the participant a token without interest. Earnings from the public account however 
depended on what other members of the group contributed. The total of the contributions by a group to the public account was multiplied by 2 and then divided equally among all group members at the end of each round. The earnings of participant $i\left(E_{i}\right)$ were given by

$$
E_{i}=25-C_{i}+0.4 \sum_{j=1}^{5} C_{j}
$$

where $C_{i}$ is $i$ 's contribution to the public account, and the summation is taken over all members of the group.

The only information given to participants in each round was the total contribution by their group and the amount each group member received from the public fund. Real payments were made to incentivise participants to take the experiment seriously and make choices as they would have made in real situations. These payments were based on a random draw from the ten rounds. Each group member was paid according to his or her choice made in this round of play. Cash payments were 30 pesewas per token (an average of US\$ 0.10 at the time of the experiment).

The variable cooperativeness is measured by the average contribution of a user to the public fund in the ten rounds of play. An average is taken because, in a standard repeated number of VCM games, contributions normally start at a high level and gradually decrease (Ledyard, 1995). Though stakes are high in the first instance, they carry no further repercussions and may be weak indicators of cooperativeness. For finite games, contributions in the last round can be predictable and may also be weak estimates of cooperativeness. The essence of repetition is to control for reciprocity. Since reciprocal behaviour affects collective action (Fehr and Fischbacher, 2002), it is expected that cooperation unravels overtime in finitely repeated games (Ibid). An average of the repeated contributions is thus a better measure for cooperativeness instead of relying on the first or last round of play. 


\subsubsection{Empirical approach}

Labour contribution towards irrigation maintenance was estimated by the number of days a plot owner took part in maintenance activities at an irrigation scheme in the previous year. Some users did not take part in physical activities themselves but were represented by other household members, which we counted as contribution by the user. We therefore consider labour contribution to be household labour, and hypothesize that the amount of labour a household contributes towards the maintenance of the irrigation scheme depends on user characteristics (governance perceptions of the user, and other attributes of the user), the cooperative nature of the user, and scheme/group characteristics. Our regression equation is

$$
L_{i j}=f\left(G_{i j}, U_{i j}, C_{i j}, S_{j}\right)+e_{i j}
$$

where;

$$
\begin{aligned}
L_{i j} & =\text { Household labour contribution by user } i \text { of scheme } j \\
G_{i j} & =\text { Governance perceptions of user } i \text { of scheme } j \\
U_{i j} & =\text { Other attributes of user } i \text { of scheme } j \\
C_{i j} & =\text { Cooperativeness of user } i \text { of scheme } j \\
S_{j} & =\text { Scheme and group characteristics of scheme } \mathrm{j} \\
e_{i j} & =\text { error term }
\end{aligned}
$$

Table 4.2 summarizes the definitions of the variables in our estimated model, their measurements, and the expected influence on labour contribution (see column 1).

Cooperativeness is advocated by several scholars as being required for user involvement in collective action in CPRs. As explained by Anderies et al. (2011), in common pool resource dilemmas, the incentives are such that each individual becomes better off if everyone else cooperated. Nonetheless, a number of factors influence individual decisions, yielding different levels of cooperation among users. Cárdenas and Ostrom (2004) hypothesized three layers of information that likely influence decisions that players take in experimental settings. They include: the characteristics of each player; the composition of the group of players; and the material payoffs from the game. The characteristics of players (in this case, users) are 
varied, including the perceptions they hold about irrigation governance as explained earlier. Players in the VCM game were composed of only members of a WUA but no one knew who was in which group. Therefore, factors that likely affect a player's decision in this case are the characteristics of the group and/or the scheme.

In terms of material payoffs, participants were paid in real monetary terms to incentivise them to take real decisions. So, we assume equal likely effect of this on all players for a simplified analysis. The cooperativeness of users can thus be affected by user characteristics and the nature of the resource at hand. To obtain more insight into the factors affecting cooperativeness of irrigation system users, we also estimated the relationship:

$$
C_{i j}=g\left(G_{i j}, U_{i j}, S_{j}\right)+u_{i j}
$$

where $u_{i j}$ is an error term.

A Tobit model is used to estimate (2) since observations are censored; subjects in the VCM experiment cannot contribute less than 0 or more than 25 . Table 4.2 also presents the variables used in this regression (see column 2). Cooperativeness may be an endogenous variable, as it may be affected by labour contributions to maintenance while there may also exist omitted variables, like personal characteristics, that simultaneously affect both variables. We therefore use a two-stage least square regression with education and age (two statistically significant determinants of cooperativeness) as instrumental variables for cooperativeness in the labour contribution equation. The correlation matrix and Variance Inflation Factors (VIF) are used to check for potential (multi)collinearity. 
Table 4.2: Definition of variables and expected influence

\begin{tabular}{|c|c|c|c|}
\hline Variable & Definition & Eq. 1 & Eq. 2 \\
\hline \multicolumn{4}{|c|}{ Dependent variables } \\
\hline Labour contribution (1) & $\begin{array}{l}\text { Number of days a user household took part in maintenance } \\
\text { activities }\end{array}$ & & \\
\hline Cooperativeness (2) & $\begin{array}{l}\text { Average contribution in the VCM experiment on irrigation } \\
\text { management }\end{array}$ & + & \\
\hline \multicolumn{4}{|c|}{ User characteristics } \\
\hline \multicolumn{4}{|l|}{ Governance perceptions } \\
\hline Participation & Mean rank of participation indicators in a 1-to-5 Likert scale & + & + \\
\hline Accountability & Mean rank of accountability indicators in a 1-to-5 Likert scale & + & + \\
\hline Conflict management & $\begin{array}{l}\text { Mean rank of conflict management indicators in a 1-to-5 Likert } \\
\text { scale }\end{array}$ & + & + \\
\hline $\begin{array}{l}\text { Transparency and } \\
\text { cooperation }\end{array}$ & $\begin{array}{l}\text { Mean rank of transparency and cooperation indicators in a } 1 \text { to } 5 \\
\text { Likert scale }\end{array}$ & + & + \\
\hline Equity and fairness & $\begin{array}{l}\text { Mean rank of equity and fairness indicators in a 1-to-5 Likert } \\
\text { scale }\end{array}$ & + & + \\
\hline Sustainable use & Mean rank of sustainable use indicators in a 1-to-5 Likert scale & + & + \\
\hline $\begin{array}{l}\text { Overall governance } \\
\text { perception }\end{array}$ & $\begin{array}{l}\text { Mean rank of all governance dimensions in a 1-to-5 Likert scale, } \\
\text { with all dimensions having equal weight }\end{array}$ & + & + \\
\hline \multicolumn{4}{|l|}{ Other user attributes } \\
\hline Age & Age of user in years & + & + \\
\hline Sex & A dummy that takes a value of 1 if the user is male & + & $-/+$ \\
\hline Educational level & Number of years of formal education & + & + \\
\hline Household labour force & Number of people in the household that are 15 years or older & + & + \\
\hline Training & $\begin{array}{l}\text { A dummy that takes a value of } 1 \text { if user has attended any } \\
\text { irrigation-related training or workshop }\end{array}$ & + & + \\
\hline Head-end plot & A dummy that takes a value of 1 if plot location is at head-end & - & - \\
\hline Tail-end plot & A dummy that takes a value of 1 if plot location is at tail-end & + & + \\
\hline \multicolumn{4}{|c|}{ Scheme and group characteristics } \\
\hline Leadership type & $\begin{array}{l}\text { A dummy that takes a value of } 1 \text { if the chairman of the group } \\
\text { was elected }\end{array}$ & + & + \\
\hline Scheme size & Developed irrigable area of a scheme in acres & - & + \\
\hline Group size & Number of users in a WUA & - & - \\
\hline Age of scheme & The number of years a scheme has existed & $-/+$ & $-/+$ \\
\hline Local market & $\begin{array}{l}\text { A dummy that takes a value of } 1 \text { if there is a market in the } \\
\text { community (a proxy for proximity to markets) }\end{array}$ & $-/+$ & $-/+$ \\
\hline Absence & $\begin{array}{l}\text { Mean number of days users stayed away from the community in } \\
\text { a WUA }\end{array}$ & - & - \\
\hline Tomatoes & A dummy that takes a value of 1 if main crop is tomatoes & $-/+$ & $-/ /+$ \\
\hline Onions & A dummy that takes a value of 1 if main crop is onions & $-/+$ & $-/+$ \\
\hline
\end{tabular}




\subsection{Results}

\subsubsection{Summary statistics}

In Table 4.3 we present summary statistics of the variables for 190 survey respondents. Labour contributions towards maintenance activities per user vary from 2 to 11 days per irrigation season with a mean of 5.2 days. The coefficient of variation equals 0.34 , indicating a substantial variation in labour contributions among users. The mean contribution from the VCM experiment, our measure of cooperativeness, is 8.63 tokens, with minimum and maximum contributions of 2.5 and 20.6 tokens. The coefficient of variation equals 0.45 , indicating that the variation in cooperativeness exceeds that of the labour contributions to irrigation maintenance. It might be that because participation in maintenance is visible to anyone while contributions in the game are not, social pressures motivated by equity considerations particularly reduce the variability of labour contributions.

Figures 4.2 and 4.3 provide more information on the cooperativeness variable. The average contributions from all three groups in the VCM experiment (Figure 4.2) is consistent with results from experimental games where contributions start at a high percentage of endowments and decline with repetition (Ledyard, 1995; Levitt and List, 2007; McGinty and Milam, 2013). The decline in contribution is a result of inequity aversion when contributors realize others are not cooperating (Fehr and Schmidt, 1999). Figure 4.3 plots the cooperativeness and labour contribution variables. As expected, it shows a positive relationship: users who are cooperative tend to contribute more towards collective action such as maintenance activities.

Continuing with Table 4.3, the mean of overall governance perceptions is 3.72 , with minimum and maximum ratings of 2.1 and 4.79. This implies that the overall perception of users about irrigation governance is fairly good (i.e. larger than 3.0) in northern Ghana. Its standard deviation (0.52) is $14 \%$ of the mean, which is relatively low compared to most of the individual governance dimensions. This suggests that there is more agreement in the overall rating of irrigation governance than in its dimensions. Among the latter, accountability perceptions have the highest variation $(23 \%$ of the mean), while conflict management 
perceptions have the lowest variation (12\% of mean). So there appears to be more agreement on conflict management than on the other dimensions, with accountability having the most varied opinions. Conflict management also has the highest mean score (4.13), while perceptions about sustainable use have the lowest mean score (3.29).

Table 4.3: Summary statistics

\begin{tabular}{|c|c|c|c|c|c|}
\hline Variable & Mean & Std. Dev. & Min. & Max. & $\begin{array}{l}\text { Coefficient } \\
\text { of Variation }\end{array}$ \\
\hline \multicolumn{6}{|c|}{ Dependent variables } \\
\hline Labour contribution & 5.179 & 1.764 & 2 & 11 & 0.341 \\
\hline Cooperativeness & 8.633 & 3.847 & 2.5 & 20.6 & 0.446 \\
\hline \multicolumn{6}{|c|}{ User characteristics } \\
\hline \multicolumn{6}{|l|}{ Governance perceptions } \\
\hline Participation & 3.977 & 0.692 & 1.8 & 5 & 0.174 \\
\hline Accountability & 3.626 & 0.852 & 1.2 & 5 & 0.235 \\
\hline Conflict management & 4.133 & 0.499 & 1 & 5 & 0.121 \\
\hline $\begin{array}{l}\text { Transparency and } \\
\text { cooperation }\end{array}$ & 3.709 & 0.652 & 1.6 & 5 & 0.176 \\
\hline Equity and fairness & 3.574 & 0.597 & 1.857 & 5 & 0.167 \\
\hline Sustainable use & 3.286 & 0.598 & 1.909 & 4.727 & 0.182 \\
\hline $\begin{array}{l}\text { Overall governance } \\
\text { perception }\end{array}$ & 3.717 & 0.522 & 2.1 & 4.793 & 0.140 \\
\hline \multicolumn{6}{|l|}{ Other user attributes } \\
\hline Age (years) & 40.116 & 12.007 & 16 & 70 & \\
\hline Sex & 0.605 & 0.49 & 0 & 1 & \\
\hline Education (years) & 3.695 & 4.898 & 0 & 16 & \\
\hline Household labour force & 9.3 & 3.522 & 3 & 18 & \\
\hline Training & 0.689 & 0.464 & 0 & 1 & \\
\hline Head-end plot & 0.3 & 0.46 & 0 & 1 & \\
\hline Tail-end plot & 0.321 & 0.468 & 0 & 1 & \\
\hline \multicolumn{6}{|c|}{ Scheme and group characteristics } \\
\hline Leadership type & 0.684 & 0.466 & 0 & 1 & \\
\hline Scheme size & 35.158 & 21.703 & 6 & 84 & \\
\hline Group size & 81.158 & 42.794 & 30 & 200 & \\
\hline Age of scheme & 44.053 & 15.166 & 10 & 57 & \\
\hline Local market & 0.374 & 0.485 & 0 & 1 & \\
\hline Absence (days) & 2.184 & 2.067 & 0 & 6.6 & \\
\hline Tomatoes & 0.579 & 0.495 & 0 & 1 & \\
\hline Onions & 0.211 & 0.409 & 0 & 1 & \\
\hline
\end{tabular}




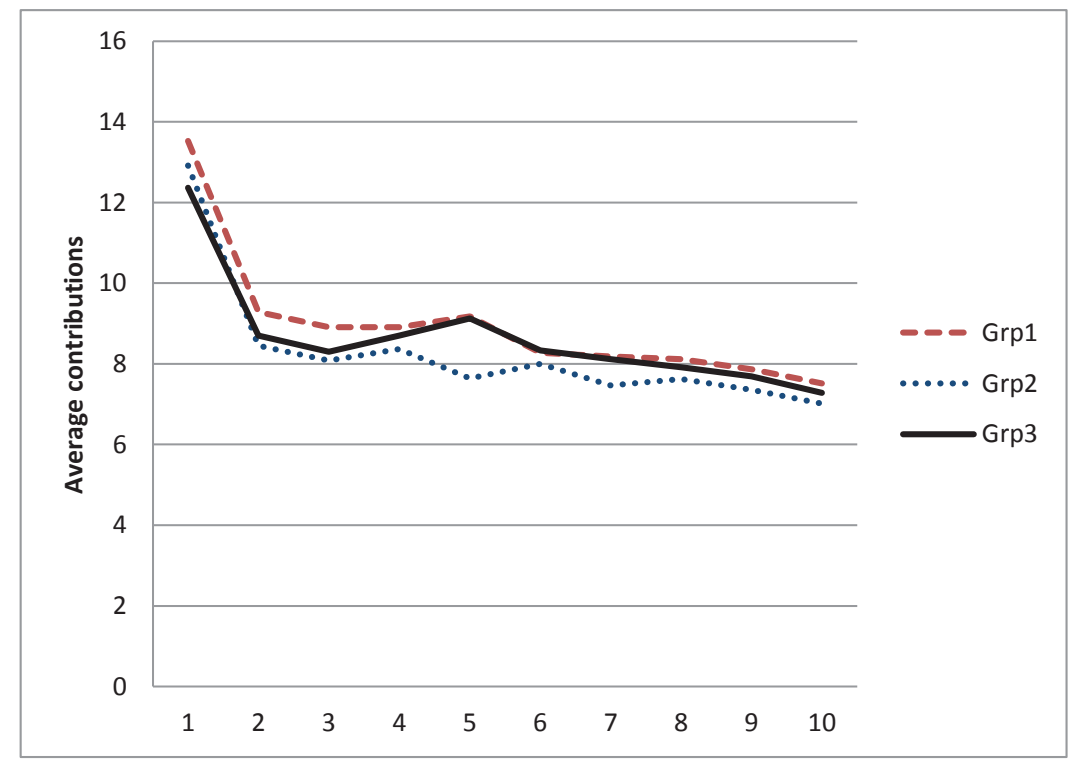

Figure 4.2: Average contributions from VCM experiment

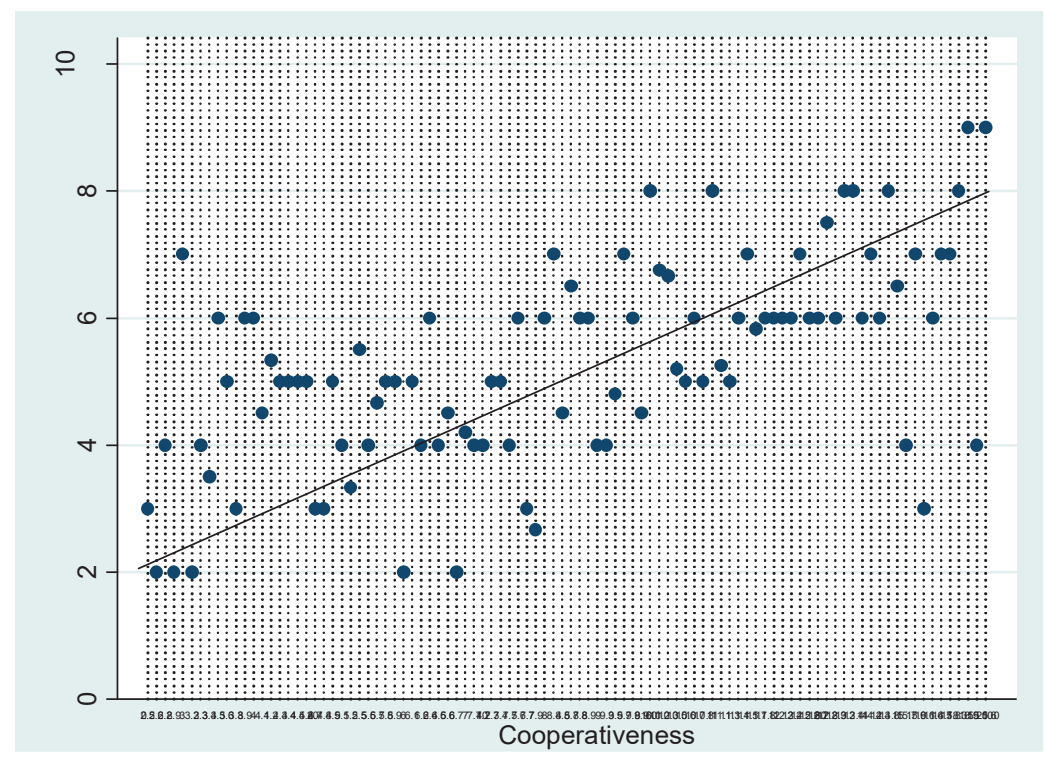

Figure 4.3: Scatter plot of cooperativeness and labour contribution 
Users are mostly middle-aged with a mean of 40 years, with a minimum of 16 and a maximum of 70 years. The representation of gender in our sample is fairly balanced: about $60 \%$ of the respondents are men and $40 \%$ are women. Though some users do not have any formal education, others have up to 16 years of formal education. The mean education is 3 years, indicating that most users have low levels of formal education. The size of the household labour force ranges from 3 to 18, with a mean of 9 persons. Households in northern Ghana are mostly extended in nature and are thus mostly large, as shown here. The distribution of respondents over plot locations is fairly uniform, with $30 \%$ of the respondents having head-end plots, $32 \%$ having tail-end plots, and 38\% being located in the middle.

The results also indicate a wide variation in scheme size. The schemes range from a minimum of 6 to a maximum of 84 acres of developed areas with a mean size of 35 acres (14 hectares). The oldest scheme is about 57 years old and the youngest is about 10 years old. The mean age of schemes is 44 years, which indicates that most of the schemes are relatively old. The average number of days users have stayed out of the community (absence) in a WUA is about 2 days, and the maximum absence is 6.6 days.

\subsubsection{Regression results}

\section{Cooperativeness of users}

Regression results of the Tobit model of factors associated with user cooperativeness (equation 2) are presented at the left-hand side of Table 4.4. The first regression (column (1)) includes overall governance perception as an explanatory variable, while the second regression (column 2) includes the six specific dimensions of governance that we distinguish in this study. 
Table 4.4: Regression results for cooperativeness (Tobit) and labour contribution (OLS)

\begin{tabular}{|c|c|c|c|c|}
\hline \multirow[t]{2}{*}{ Variables } & \multicolumn{2}{|c|}{ Cooperativeness } & \multirow{2}{*}{$\begin{array}{c}\text { Labour contribution } \\
(3)\end{array}$} & \multirow[b]{2}{*}{ (4) } \\
\hline & (1) & $(2)$ & & \\
\hline \multicolumn{5}{|c|}{ User characteristics } \\
\hline \multicolumn{5}{|c|}{ Governance perceptions } \\
\hline Participation & & $\begin{array}{l}0.379 \\
{[0.847]}\end{array}$ & & $\begin{array}{l}0.014 \\
{[0.257]}\end{array}$ \\
\hline Accountability & & $\begin{array}{l}1.245^{*} \\
{[0.708]}\end{array}$ & & $\begin{array}{l}0.267 \\
{[0.214]}\end{array}$ \\
\hline $\begin{array}{l}\text { Conflict } \\
\text { Management }\end{array}$ & & $\begin{array}{l}-1.533^{* * *} \\
{[0.588]}\end{array}$ & & $\begin{array}{l}-0.031 \\
{[0.121]}\end{array}$ \\
\hline $\begin{array}{l}\text { Transparency and } \\
\text { Cooperation }\end{array}$ & & $\begin{array}{l}0.223 \\
{[0.441]}\end{array}$ & & $\begin{array}{l}0.578^{*} \\
{[0.302]}\end{array}$ \\
\hline Equity and fairness & & $\begin{array}{l}0.561 \\
{[0.508]}\end{array}$ & & $\begin{array}{l}0.043 \\
{[0.255]}\end{array}$ \\
\hline Sustainable use & & $\begin{array}{l}0.729 \\
{[0.460]}\end{array}$ & & $\begin{array}{l}0.422^{* *} \\
{[0.199]}\end{array}$ \\
\hline $\begin{array}{l}\text { Overall governance } \\
\text { Perception }\end{array}$ & $\begin{array}{l}0.502 \\
{[0.612]}\end{array}$ & & $\begin{array}{l}1.381 * * * \\
{[0.193]}\end{array}$ & \\
\hline Age & $\begin{array}{l}0.242 * * * \\
{[0.026]}\end{array}$ & $\begin{array}{l}0.235^{* * *} \\
{[0.026]}\end{array}$ & $\begin{array}{l}0.015 \\
{[0.009]}\end{array}$ & $\begin{array}{l}0.015 \\
{[0.010]} \\
\end{array}$ \\
\hline Sex & $\begin{array}{l}0.467 \\
{[0.420]}\end{array}$ & $\begin{array}{l}0.553 \\
{[0.410]}\end{array}$ & $\begin{array}{l}0.353^{* *} \\
{[0.139]}\end{array}$ & $\begin{array}{l}0.321^{* *} \\
{[0.147]}\end{array}$ \\
\hline Education & $\begin{array}{l}0.096^{* *} \\
{[0.043]}\end{array}$ & $\begin{array}{l}0.086^{*} \\
{[0.045]}\end{array}$ & $\begin{array}{l}0.003 \\
{[0.016]}\end{array}$ & $\begin{array}{l}0.008 \\
{[0.018]}\end{array}$ \\
\hline $\begin{array}{l}\text { Household labour } \\
\text { Force }\end{array}$ & $\begin{array}{l}-0.001 \\
{[0.055]}\end{array}$ & $\begin{array}{l}0.024 \\
{[0.050]}\end{array}$ & $\begin{array}{l}0.060 * * \\
{[0.023]}\end{array}$ & $\begin{array}{l}0.061^{* *} \\
{[0.022]}\end{array}$ \\
\hline Training & $\begin{array}{l}0.988 \\
{[1.004]}\end{array}$ & $\begin{array}{l}0.948 \\
{[0.891]}\end{array}$ & $\begin{array}{l}0.613 * * * \\
{[0.200]}\end{array}$ & $\begin{array}{l}0.557^{* *} \\
{[0.199]}\end{array}$ \\
\hline Head-end plot & $\begin{array}{l}0.237 \\
{[0.297]}\end{array}$ & $\begin{array}{l}0.449^{*} \\
{[0.262]}\end{array}$ & $\begin{array}{l}0.086 \\
{[0.195]}\end{array}$ & $\begin{array}{l}0.148 \\
{[0.192]}\end{array}$ \\
\hline Tail-end plot & $\begin{array}{l}0.050 \\
{[0.412]}\end{array}$ & $\begin{array}{l}0.188 \\
{[0.396]}\end{array}$ & $\begin{array}{l}0.410^{* *} \\
{[0.190]}\end{array}$ & $\begin{array}{l}0.446^{* *} \\
{[0.184]}\end{array}$ \\
\hline \multicolumn{5}{|c|}{ Cooperativeness } \\
\hline Cooperativeness & & & $\begin{array}{l}0.182 * * * \\
{[0.041]}\end{array}$ & $\begin{array}{l}0.180 * * * \\
{[0.042]}\end{array}$ \\
\hline \multicolumn{5}{|c|}{ Scheme and group characteristics } \\
\hline Leadership type & $\begin{array}{l}-0.542 \\
{[0.796]}\end{array}$ & $\begin{array}{l}-0.909 \\
{[0.553]}\end{array}$ & $\begin{array}{l}0.485^{* *} \\
{[0.175]} \\
\end{array}$ & $\begin{array}{l}0.434 * * \\
{[0.184]}\end{array}$ \\
\hline Scheme size & $\begin{array}{l}-0.027 \\
{[0.024]}\end{array}$ & $\begin{array}{l}-0.022 \\
{[0.022]}\end{array}$ & $\begin{array}{l}-0.013^{* * *} \\
{[0.004]}\end{array}$ & $\begin{array}{l}-0.013 * * * \\
{[0.004]}\end{array}$ \\
\hline Group size & $\begin{array}{l}0.009 \\
{[0.016]}\end{array}$ & $\begin{array}{l}0.003 \\
{[0.014]}\end{array}$ & $\begin{array}{l}-0.001 \\
{[0.002]}\end{array}$ & $\begin{array}{l}-0.001 \\
{[0.003]}\end{array}$ \\
\hline Age of scheme & $\begin{array}{l}-0.022 \\
{[0.026]}\end{array}$ & $\begin{array}{l}-0.014 \\
{[0.025]}\end{array}$ & $\begin{array}{l}-0.007 \\
{[0.006]}\end{array}$ & $\begin{array}{l}-0.010 \\
{[0.008]}\end{array}$ \\
\hline Local market & $\begin{array}{l}1.388 \\
{[0.934]}\end{array}$ & $\begin{array}{l}1.414^{*} \\
{[0.825]}\end{array}$ & $\begin{array}{l}0.878 * * * \\
{[0.146]}\end{array}$ & $\begin{array}{l}0.992 * * * \\
{[0.188]}\end{array}$ \\
\hline Absence & $\begin{array}{l}0.159 \\
{[0.187]}\end{array}$ & $\begin{array}{l}0.091 \\
{[0.157]}\end{array}$ & $\begin{array}{l}-0.051^{*} \\
{[0.026]}\end{array}$ & $\begin{array}{l}-0.059 * \\
{[0.029]}\end{array}$ \\
\hline Tomatoes & $\begin{array}{l}0.728 \\
{[1.041]}\end{array}$ & $\begin{array}{l}0.281 \\
{[0.987]} \\
\end{array}$ & $\begin{array}{l}0.230 \\
{[0.188]} \\
\end{array}$ & $\begin{array}{l}0.227 \\
{[0.214]} \\
\end{array}$ \\
\hline Onions & $\begin{array}{l}0.818 \\
{[0.901]}\end{array}$ & $\begin{array}{l}0.011 \\
{[1.050]}\end{array}$ & $\begin{array}{l}-0.076 \\
{[0.245]}\end{array}$ & $\begin{array}{l}0.023 \\
{[0.225]}\end{array}$ \\
\hline Constant & $\begin{array}{l}-2.377 \\
{[1.783]}\end{array}$ & $\begin{array}{l}-3.956 \\
{[7.542]}\end{array}$ & $\begin{array}{l}-3.234 * * \\
{[1.137]}\end{array}$ & $\begin{array}{l}-2.526 \\
{[1.475]}\end{array}$ \\
\hline Observations & 190 & 190 & 190 & 190 \\
\hline R-squared & & & 0.570 & 0.578 \\
\hline
\end{tabular}


The results indicate that the overall governance perceptions do not matter in user cooperativeness while some specific dimensions do. Governance dimensions that are statistically significant are accountability and conflict management. While accountability relates positively as expected, conflict management has a significant negative association with cooperativeness. A unit increase in the perceptions of accountability (on a 1-5 scale) increases a user's expected contribution by 1.245 . On the other hand, a unit increase in a user's perception of conflict $\mathrm{m}$ anagem ent decreases expected contributions by 1.53 tokens.

This unexpected result seems to suggest that rules and regulations put in place to avert conflicts contribute to freeriding and other anti-social behaviour by users, and thus, decreases user cooperativeness. As indicated in Chapter 3, correlations among some governance dimensions may make their association with cooperativeness insignificant. In Table 4.6, we iterated seemingly correlated governance dimensions (participation, accountability and transparency and cooperation) with the most significant governance dimension (conflict management) to check which dimensions truly associate with cooperativeness. The results from columns (1) to (3) indicate that accountability and conflict management are indeed the governance dimensions that relate to cooperativeness.

Other user characteristics found to have relations with cooperativeness are age, educational level and being allocated a head-end plot. These variables have positive associations with cooperativeness as anticipated and are all statistically significant. The expected contribution of a one-year older user is 0.235 tokens higher. Similarly, a user with one more year education is expected to contribute 0.086 tokens higher than users without formal education and the expected contribution of a user allocated at the head-ends is 0.449 higher than users in the middle plots. This implies that older and more educated users are more willing to cooperate. 


\section{Labour contribution to maintenance}

Two-stage least square (2SLS) regression results for labour contribution to maintenance (equation (1)), with age and education as instruments for cooperativeness, are presented in Table 4.5. The first regression (column 1) includes overall governance perception as an explanatory variable, while the second regression (column 2) includes the six specific dimensions of governance that we distinguish in this study. Both regressions provide support for the hypothesis that governance perceptions of users matter. The estimated association with overall governance perception is positive and statistically significant. A unit increase in overall perceived governance (on a scale of 1 to 5 ) is associated with an increase of about 1.49 labour days for maintenance.

Though the estimated coefficient for overall irrigation governance perception is statistically significant, this does not hold for each governance dimension. The only governance dimension that has a statistically significant coefficient is sustainable use. A unit increase in the perceived rating of sustainable use is associated with a 0.422 increase in labour days. The estimated coefficient for transparency and cooperation, which was significant at a $10 \%$ testing level in Table 4.4, does not differ significantly from zero in the two-stage least squares approach. Estimated coefficients for the other governance dimensions do not differ significantly from zero in both the OLS and the 2SLS approach.

Other user characteristics that are statistically significant are sex, household labour force, training, and plot location. Their signs conform to what we expected. Male users contribute about 0.403 labour days (2.418 hours) more than female users. Further, households with a larger labour force tend to provide higher labour contributions. One labour force more increases labour contribution by about 0.372 working hours (0.062 days). As expected, users who have had the opportunity to attend irrigation-related trainings or demonstrations contribute more, about 0.411 labour days. Also, tail-end users contribute more labour towards maintenance (about 0.499 days); the relation for head-enders is not statistically significant. 
Table 4.5: 2SLS regression results for labour contributions

\begin{tabular}{|c|c|c|}
\hline Variables & \multicolumn{2}{|c|}{ Labour contribution } \\
\hline & (1) & (2) \\
\hline \multicolumn{3}{|c|}{ User characteristics } \\
\hline Participation & & $\begin{array}{l}0.215 \\
(0.238)\end{array}$ \\
\hline Accountability & & $\begin{array}{l}0.197 \\
(0.143) \\
\end{array}$ \\
\hline Conflict management & & $\begin{array}{l}0.176 \\
(0.123)\end{array}$ \\
\hline Transparency and cooperation & & $\begin{array}{l}0.258 \\
(0.255)\end{array}$ \\
\hline Equity and fairness & & $\begin{array}{l}0.249 \\
(0.156) \\
\end{array}$ \\
\hline Sustainable use & & $\begin{array}{l}0.422 * * \\
(0.180)\end{array}$ \\
\hline Overall governance perception & $\begin{array}{l}1.490 * * * \\
(0.169)\end{array}$ & \\
\hline \multicolumn{3}{|l|}{ Age } \\
\hline Sex & $\begin{array}{l}0.398^{* *} \\
(0.155) \\
\end{array}$ & $\begin{array}{l}0.403^{* *} \\
(0.159) \\
\end{array}$ \\
\hline \multicolumn{3}{|l|}{ Education } \\
\hline Household labour force & $\begin{array}{l}0.064 * * * \\
(0.022)\end{array}$ & $\begin{array}{l}0.062 * * * \\
(0.022)\end{array}$ \\
\hline Training & $\begin{array}{l}0.437 * * * \\
(0.163) \\
\end{array}$ & $\begin{array}{l}0.411 * * * \\
(0.157) \\
\end{array}$ \\
\hline Head-end plot & $\begin{array}{l}0.173 \\
(0.204) \\
\end{array}$ & $\begin{array}{l}0.189 \\
(0.206) \\
\end{array}$ \\
\hline Tail-end plot & $\begin{array}{l}0.484 * * \\
(0.194)\end{array}$ & $\begin{array}{l}0.499 * * * \\
(0.188)\end{array}$ \\
\hline Cooperativeness & $\begin{array}{l}0.245 * * * \\
(0.037) \\
\end{array}$ & $\begin{array}{l}0.247 * * * \\
(0.037) \\
\end{array}$ \\
\hline \multicolumn{3}{|c|}{ Scheme and group characteristics } \\
\hline Leadership type & $\begin{array}{l}0.477 * * * \\
(0.150) \\
\end{array}$ & $\begin{array}{l}0.448 * * * \\
(0.139) \\
\end{array}$ \\
\hline Scheme size & $\begin{array}{l}-0.015^{* * *} \\
(0.005)\end{array}$ & $\begin{array}{l}-0.015^{* * *} \\
(0.005)\end{array}$ \\
\hline Group size & $\begin{array}{l}0.001 \\
(0.003)\end{array}$ & $\begin{array}{l}0.002 \\
(0.003)\end{array}$ \\
\hline Age of scheme & $\begin{array}{l}-0.007 \\
(0.005) \\
\end{array}$ & $\begin{array}{l}-0.007 \\
(0.007) \\
\end{array}$ \\
\hline Local market & $\begin{array}{l}0.958 * * * \\
(0.137)\end{array}$ & $\begin{array}{l}1.013 * * * \\
(0.159)\end{array}$ \\
\hline Absence & $\begin{array}{l}0.023 \\
(0.046)\end{array}$ & $\begin{array}{l}0.030 \\
(0.043)\end{array}$ \\
\hline Tomatoes & $\begin{array}{l}0.192 \\
(0.184) \\
\end{array}$ & $\begin{array}{l}0.265 \\
(0.164) \\
\end{array}$ \\
\hline Onions & $\begin{array}{l}-0.025 \\
(0.242) \\
\end{array}$ & $\begin{array}{l}0.129 \\
(0.191)\end{array}$ \\
\hline Constant & $\begin{array}{l}-3.916^{* * *} \\
(0.962)\end{array}$ & $\begin{array}{l}-4.014 * * * \\
(0.965)\end{array}$ \\
\hline Observations & 190 & 190 \\
\hline R-squared & 0.534 & 0.537 \\
\hline
\end{tabular}


Table 4.5 further shows that, as expected, user cooperativeness has a significant, positive effect on labour contribution. A unit increase in cooperativeness (as instrumented by age and education) leads to a 0.247 increase in labour days (1.482 hours).

Scheme and group characteristics that have significant relations are leadership type, scheme size, and availability of local markets. As expected, leadership type relates positively with labour contribution, indicating that users from schemes where leaders are elected by users themselves contribute more labour (about 0.448 days) than those from schemes where leadership is imposed. Scheme size has a significant negative association with labour contribution as expected.

The availability of markets in irrigation communities has a significant positive relationship with labour contribution. Users in communities with local markets contribute on average 1.013 more labour days towards maintenance as compared with communities without local markets.

\section{Multicollinearity}

In Table 4.6, regression results are presented when the only significant governance dimension (conflict management in the cooperativeness equation; sustainable use in the labour contribution equation) is combined with each of three highly correlated dimensions, respectively. In the cooperativeness equation, accountability is found to have a significant positive association (at a 5\% testing level) while the estimated coefficients for participation and transparency and cooperation do not differ significantly from zero. This finding confirms that user perceptions of accountability are positively related to cooperativeness, while the two dimensions that are highly correlated with it (participation, transparency and cooperation) are not (see column (2) in Table 4.4). In the labour contribution equation (estimated with 2SLS), the estimated coefficients for participation, accountability and transparency and cooperation are statistically significant, even though they were not significantly different from zero when they were jointly included in the regression (Table 4.5). This means that, due to the high correlations between these three dimensions, our data set cannot adequately distinguish the separate relationships of each dimension with labour contributions to maintenance. 
Table 4.6: Regression results when seemingly correlated dimensions are iterated

\begin{tabular}{|c|c|c|c|c|c|c|}
\hline \multirow[t]{2}{*}{ Variables } & \multicolumn{3}{|c|}{ Cooperativeness (Tobit) } & \multicolumn{3}{|c|}{ Labour contributions (2SLS) } \\
\hline & $(1)$ & $(2)$ & (3) & (4) & $(5)$ & (6) \\
\hline \multicolumn{7}{|c|}{ User characteristics } \\
\hline \multirow[t]{2}{*}{ Participation } & & 0.394 & & $0.651 * * *$ & & \\
\hline & & $(0.511)$ & & $(0.109)$ & & \\
\hline \multirow[t]{2}{*}{ Accountability } & $0.958 * *$ & & & & $0.561 * * *$ & \\
\hline & $(0.382)$ & & & & $(0.079)$ & \\
\hline Conflict & $-1.770 * * *$ & $-1.260 *$ & $-1.190 * *$ & & & \\
\hline Management & $(0.575)$ & $(0.639)$ & $(0.546)$ & & & \\
\hline Transparency and & & & 0.311 & & & $0.741^{* * *}$ \\
\hline Cooperation & & & $(0.327)$ & & & $(0.125)$ \\
\hline \multirow[t]{2}{*}{ Sustainable use } & & & & $0.671 * * *$ & $0.715 * * *$ & $0.494 * * *$ \\
\hline & & & & $(0.133)$ & $(0.118)$ & $(0.141)$ \\
\hline \multirow[t]{2}{*}{ Age } & $0.236^{* * *}$ & $0.236 * * *$ & $0.237 * * *$ & & & \\
\hline & $(0.026)$ & $(0.026)$ & $(0.025)$ & & & \\
\hline \multirow[t]{2}{*}{ Sex } & 0.527 & 0.490 & 0.478 & $0.395 * *$ & $0.392 * *$ & $0.382 * *$ \\
\hline & $(0.403)$ & $(0.417)$ & $(0.411)$ & $(0.164)$ & $(0.164)$ & $(0.161)$ \\
\hline \multirow[t]{2}{*}{ Education } & $0.096^{* *}$ & $0.100 * *$ & $0.103 * *$ & & & \\
\hline & $(0.043)$ & $(0.043)$ & $(0.042)$ & & & \\
\hline Household labour & 0.020 & 0.011 & 0.010 & $0.058 * *$ & $0.055 * *$ & $0.063 * * *$ \\
\hline Force & $(0.049)$ & $(0.052)$ & $(0.054)$ & $(0.024)$ & $(0.023)$ & $(0.020)$ \\
\hline \multirow[t]{2}{*}{ Training } & 0.745 & 0.972 & 0.975 & $0.418^{* * *}$ & $0.307^{*}$ & $0.454 * * *$ \\
\hline & $(0.987)$ & $(0.992)$ & $(1.008)$ & $(0.148)$ & $(0.180)$ & $(0.128)$ \\
\hline \multirow[t]{2}{*}{ Head-end plot } & $0.515^{*}$ & 0.387 & 0.410 & 0.187 & 0.238 & 0.237 \\
\hline & $(0.267)$ & $(0.339)$ & $(0.351)$ & $(0.209)$ & $(0.214)$ & $(0.216)$ \\
\hline \multirow[t]{2}{*}{ Tail-end plot } & 0.207 & 0.161 & 0.186 & $0.485 * *$ & $0.497 * * *$ & $0.546^{* * *}$ \\
\hline & $(0.378)$ & $(0.405)$ & $(0.422)$ & $(0.195)$ & $(0.191)$ & $(0.197)$ \\
\hline \multirow[t]{2}{*}{ Cooperativeness } & & & & $0.241 * * *$ & $0.248 * * *$ & $0.245^{* * *}$ \\
\hline & & & & $(0.034)$ & $(0.034)$ & $(0.035)$ \\
\hline \multicolumn{7}{|c|}{ Scheme and group characteristics } \\
\hline \multirow[t]{2}{*}{ Leadership type } & -0.897 & -0.612 & -0.662 & $0.577 * * *$ & $0.412 * * *$ & $0.513 * * *$ \\
\hline & $(0.634)$ & $(0.781)$ & $(0.809)$ & $(0.129)$ & $(0.153)$ & $(0.133)$ \\
\hline \multirow[t]{2}{*}{ Scheme size } & -0.022 & -0.024 & -0.025 & $-0.013 * * *$ & $-0.013 * * *$ & $-0.015 * * *$ \\
\hline & $(0.022)$ & $(0.023)$ & $(0.023)$ & $(0.004)$ & $(0.005)$ & $(0.005)$ \\
\hline \multirow[t]{2}{*}{ Group size } & 0.002 & 0.004 & 0.006 & 0.001 & 0.001 & 0.002 \\
\hline & $(0.014)$ & $(0.016)$ & $(0.015)$ & $(0.003)$ & $(0.003)$ & $(0.003)$ \\
\hline \multirow[t]{2}{*}{ Age of scheme } & -0.015 & -0.017 & -0.021 & -0.007 & -0.009 & $-0.013^{* * *}$ \\
\hline & $(0.023)$ & $(0.026)$ & $(0.025)$ & $(0.006)$ & $(0.006)$ & $(0.005)$ \\
\hline \multirow[t]{2}{*}{ Local market } & $1.567^{*}$ & $1.502^{*}$ & $1.547^{*}$ & $1.046^{* * *}$ & $1.109 * * *$ & $1.077 * * *$ \\
\hline & $(0.834)$ & $(0.887)$ & $(0.888)$ & $(0.167)$ & $(0.160)$ & $(0.146)$ \\
\hline \multirow[t]{2}{*}{ Absence } & 0.095 & 0.147 & 0.149 & 0.031 & 0.005 & 0.022 \\
\hline & $(0.177)$ & $(0.184)$ & $(0.183)$ & $(0.050)$ & $(0.051)$ & $(0.046)$ \\
\hline Tomatoes & 0.389 & 0.639 & 0.648 & $0.348^{* *}$ & 0.287 & 0.268 \\
\hline & $(1.061)$ & $(1.029)$ & $(1.026)$ & $(0.172)$ & $(0.195)$ & $(0.1700$ \\
\hline Onions & 0.180 & 0.697 & 0.811 & 0.271 & 0.223 & $0.299 *$ \\
\hline & $(1.105)$ & $(0.923)$ & $(0.884)$ & $(0.225)$ & $(0.194)$ & $(0.154)$ \\
\hline Constant & 3.339 & 2.560 & 2.690 & $-3.360 * * *$ & $-2.739 * * *$ & $-2.770 * * *$ \\
\hline & $(2.806)$ & $(2.924)$ & $(2.839)$ & $(1.096)$ & $(0.953)$ & $(0.851)$ \\
\hline Observations & 190 & 190 & 190 & 190 & 190 & 190 \\
\hline R-squared & & & & 0.524 & 0.524 & 0.525 \\
\hline
\end{tabular}

Notes: ${ }^{* * *} \mathrm{p}<0.01,{ }^{* *} \mathrm{p}<0.05,{ }^{*} \mathrm{p}<0.1$; Robust standard errors in parentheses 


\subsection{Discussion}

The results agree with our expectation that users who perceive irrigation governance to be good contribute more in the maintenance of irrigation resources. Sustainable use of resources appear to be particularly essential in motivating users to partake in the maintenance of irrigation facilities. Sustainable use is critical to resource sustainability (UNESCO, 2015). Users who see prospects in the survival of irrigation resources for posterity contribute more to maintaining the resources. The availability of water, soil suitability, and output levels, among other indicators, may indicate whether a resource is sustainable or not. These structures motivate investments by users and thus influence their participation in maintaining irrigation resources.

We further find that user perceptions of participation, accountability and/or transparency and cooperation are positively related to labour contributions to maintenance, but our data set unfortunately cannot adequately distinguish the separate relationships of each dimension due to the high correlations between them. User perceptions of conflict management and equity and fairness are not significantly related to individual labour contributions. From the sample means presented in Table 4.3 it can be inferred that these dimensions are perceived as 'good', especially with regards to conflict management (with a mean value of 4.1 on a scale of 1-5). This could mean that these two aspects of governance are thought to be well handled by users are seen as norm al practices and $\mathrm{m}$ ay not necessarily influence users' labour contributions significantly.

Household labour force, training, and plot location are the other user attributes that have significant influence on labour contributions. For household labour force, our results are positive and consistent with findings in Wang et al. (2016). This suggests that if the eagerness to participate in maintenance exists, then households with a large labour force contribute more labour. Larger households are able to trade responsibilities to be able to take part in communal activities whenever the need arises, hence affecting maintenance positively.

As explained above, training embodies the transfer or sharing of knowledge that improves skills of users. It is thus an avenue that empowers users on irrigation techniques and boosts their interests in irrigation. The interests and skills acquired motivate users for wanting to 
contribute more to sustain irrigation resources for sustainable production. Our focus group discussions revealed that some NGOs, particularly World Vision and the Association of Church Development Program (ACDEP), organise sensitization workshops on livelihoods activities including irrigation, for which some users have been privileged to take part. This, they say, gives them insights into how to improve irrigation. Our results therefore suggest that training incentivises users to partake in irrigation maintenance. As posited by Muchara et al. (2014), access to irrigation-related training improves collective activities.

Our finding regarding plot location is similar with Nagrah et al. (2016), who found that in Pakistan watercourse communities located at the tail reaches of irrigation systems contributed more labour to maintenance than users at other locations. Our focus group discussions disclosed that tail-enders sometimes voluntarily desilt blocked canals and laterals outside communal work days, so as to access water to their plots, thus making their labour contribution significantly higher than users in preferred locations. In this case, water scarcity may not be a challenge, and a disincentive to collective action, as indicated by Fujiie et al. (2005). Rather, conditions of access channels, such as canals that sometimes make water flow to the tail-end difficult, do matter in labour contribution. Users at such locations therefore have to put in more labour in maintenance for effective production.

As expected, user cooperativeness is found to positively influence labour contributions (see 2SLS results presented in Tables 4.5 and 4.6). Cooperativeness is an inherent characteristic of individuals and, depending on circumstances surrounding an individual, he or she decides either to cooperate or not. It is observed that CPRs in northern Ghana are generally seen as community assets that bind indigenes through communal efforts. Here, preserving CPRs is a collective task that safeguards the heritage of communities. Users who are cooperative generally may want to give more towards this achievement.

Perceptions on accountability and conflict management, age and education are factors that significantly associate with a user's cooperativeness. The association of these factors are positive and consistent with our hypotheses, except in the case of conflict management. For instance, regarding age, older users in WUAs cooperate more probably due to their longer experience in irrigation (De Janvry and Sadoulet (2016: p. 587)). Regarding education, 
schooling helps in properly analysing issues and improving decision making, so that, since cooperation is desired in CPRs, users with more years of formal education tend to cooperate better in irrigation management (Cardenas et al., 2011). Since our different dimensions of irrigation governance are generally expected to relate to cooperation positively, the negative association of conflict management comes somewhat as a surprise. Maybe it is a result of selfish desires, where users take the opportunity to free-ride in their contributions when they observe a congenial environment in their group with good management of conflicts. Users who perceive conflict management to be good may cooperate less when they expect that disagreements will probably be well handled.

Scheme and group characteristics that are reported to have significant relationship with labour contribution are leadership type, scheme size, and availability of local markets. As expected, larger schemes showed lower labour contributions towards maintenance. Apart from the fact that large schemes are difficult to manage in terms of effective monitoring, thus allowing for low individual contributions, large schemes also provide a disincentive for labour contributions because users have access to abundant resources. In schemes where the developed area is relatively large, users seem not to put in much effort towards maintenance, especially when land allocation is not competed for. This is also consistent with the study of Fujiie et al. (2005), where irrigation associations are found to be more active in the operation and maintenance of irrigation facilities when the service area is smaller.

The availability of local markets had a positive association with labour contributions, supporting the view that the presence of markets increases the scope of cooperation. According to Meinzen-Dick et al. (2002), market proximity brings commercialization, which is an incentive for effective irrigation. Thus, access to markets creates an avenue for farmers to sell their surpluses, thereby making them interested in higher production and improved performance of their schemes. Market accessibility is therefore seen as an incentive for users to cooperate more in irrigation maintenance for sustainable and higher production for income generation. 


\subsection{Conclusion}

This paper assessed the determ inants of water users' contributions in term s of labour towards the maintenance of small-scale irrigation systems using survey and lab-in-the-field experimental data from 19 schemes in northern Ghana. We explained that the participation of users in maintenance relates to a range of factors including users' perceptions on the governance of WUAs and their levels of cooperativeness. The paper specifically addressed the role of the perceptions users have on the general governance of their irrigation scheme and the role of their individual willingness to cooperate in collective activities that allow for free riding. We therefore created indicators of a user's perception on governance and of his or her willingness to cooperate, and set out to analyse their effects on individual labour contributions towards irrigation maintenance. We used a two-stage least square approach for assessing the determinants of labour contributions and a tobit regression for cooperativeness.

Our results confirm that positive governance perceptions and cooperativeness indeed increase a user's labour contribution towards $m$ aintenance. Users who perceive irrigation governance as relatively good participate more in maintenance activities. We tested the influence of six different dimensions of governance perceptions. Sustainable use is the governance dimension that significantly relates to labour contributions. Users who are more cooperative also contribute more labour. Accountability relates positively to cooperativeness while perceived conflict management has an unexpected negative relationship with cooperativeness. This indicates that good perceptions on conflict management influences free riding among users. Other factors that significantly associate with cooperativeness are age and education.

Our results also highlight the relations of some other user and scheme characteristics to labour contributions. In addition to cooperativeness, user characteristics that relate to labour contribution are household labour force size, irrigation-related training, and plot location. Thus users with larger households, with more training, and with plots located at the tail-end of the canals participate more in maintenance activities. 
Scheme characteristics that significantly associate with labour contributions include leadership type, scheme size, and availability of local markets. Labour contributions are higher in schemes where group leaders are elected, as opposed to imposed leadership. Larger schemes attract lower labour contributions. Users of irrigation schemes with markets in the community contribute on average more labour in maintenance.

All in all, the study confirms the key role users' perceptions on the governance of WUAs and their levels of cooperativeness have in sustaining small-scale irrigation schemes as commons. Users need to be well organized in governance arrangements, and be cooperative in communal activities towards maintenance of schemes for continued production. In line with this, we believe that leaders of WUAs and WUA members have to know that good governance is essential in obtaining maximum participation from users in maintenance. For sustainable management of irrigation facilities, WUAs should aspire to offer accountable and transparent governance. More importantly, resources should be used sustainably by adhering to recommended and acceptable practices, as rules and regulations help in ensuring that public resources are used judiciously and in a fair manner. For the unexpected effect of perceived conflict management on cooperation, water users should understand that serenity is a result of the collective action of all users, which should encourage more cooperation than free riding. Also, our findings suggest that relatively old users and those with a higher education are more cooperative. Age and education may however have different effects on other important aspects of WUAs, like setting irrigations schedules, enforcing fee payments or avoiding water theft. It is important then to consider age and educational levels of water users and their intended effects when assigning responsibilities for the organisation and maintenance of irrigation facilities. 


\section{Appendices}

\section{Appendix 4.1: Experimental design to measure "willingness to cooperate"}

\section{Instructions:}

You are invited here to take part in an economic activity for academic purposes and for possible policy interventions. You can earn money depending on your decisions. It is therefore important that you understand the instructions. Each of you will be assigned to one of us to help in record keeping but your decisions are solely your responsibility. You are not allowed to communicate with other participants during the activity. If you do, you will have to quit and forfeit (lose) all earnings. If you have any questions please ask us.

During the task, your earnings will be calculated in points rather than Ghana Cedis. The amount of points you earn will then be converted to Ghana Cedis for you at the end of the task at the following rate:

$$
1 \text { point }=30 \text { pesewas }
$$

You will be put in groups of five to perform the task for twenty rounds; nobody knows who is in which group except us, the experimenters.

\section{The decision situation}

As stated earlier, you will be a member of a group of five participants. Each member has to decide how to allocate 25 tokens during each round of the task. You can put these 25 tokens into a private account or invest them fully or partially in a public fund towards the maintenance of your dam. Each token you do not invest in the public fund will automatically be transferred to your private account.

For each token you put in your private account, you will earn exactly one point. For example, if you put twenty-five tokens in your private account (which implies that you do not invest anything in the project) you will earn exactly twenty-five points from the private account. If 
you put five tokens into your private account, you will earn five points from your private account. You are the only person who can earn anything from your private account.

At the end of each round, the total contributions to the public fund made by the five members of the group will be doubled and immediately distributed in equal shares to all members of the group. The only information that will be given to all of you in each round is the total contributions by the group and the amount each member receives from the public fund.

Thus for each group member, the income from the public fund for each round will be determined as follows:

Income from public fund $=\underline{\text { sum of contributions to the public fund } * 2}$

5

For example, if all the five group members contribute a total of 10 tokens to the fund, each member receives: $10 * 2 / 5=4$ tokens each as payoffs from the public fund.

Sample calculations:

If all five group members contribute a total of 15 tokens to the fund, how many tokens will each member receive as payoff from the public fund? Ans: 6

If all five group members contribute a total of 30 tokens to the fund, how many tokens will each member receive as payoff from the public fund? Ans: 12

If all the five group members contribute a total of 50 tokens to the fund, how many tokens will each member receive as payoff from the public fund? Ans: 20

And so on.

Your total income for each round is the result of the summation of your income from the private account and your income from the public fund.

\section{Total earnings}

After the ten (10) rounds of the task, two numbers will be randomly drawn as decisions that count. Each member of the group will be paid from choices that were made in these rounds. 
If 6 and 2 are drawn for instance, then the decisions that count will be decisions made in the $6^{\text {th }}$ and $2^{\text {nd }}$ rounds respectively. Each member of the group will thus receive what they earned in the $6^{\text {th }}$ and $2^{\text {nd }}$ rounds of the task. Your total earning (take-home) is then a sum of your earnings from the two draws. Every decision you make can be a decision-that-counts, so please take every round of play serious.

Table 4.1.A: Payoffs table:

\begin{tabular}{|c|l|l|l|}
\hline $\begin{array}{l}\text { Rounds of } \\
\text { play }\end{array}$ & Public fund & Private account & $\begin{array}{l}\text { Payoff from public } \\
\text { fund }\end{array}$ \\
\hline 1. & & & \\
\hline 2. & & & \\
\hline 3. & & & \\
\hline 4. & & & \\
\hline 5. & & & \\
\hline 6. & & & \\
\hline 7. & & & \\
\hline 8. & & & \\
\hline 9. & & & \\
\hline 10. & & & \\
\hline Decisions & & & \\
\hline
\end{tabular}

Total pay $($ draw $1+$ draw 2$)=$ 


\title{
CHAPTER 5
}

\section{Governance, time preference, and collective maintenance: the case of small-scale irrigation in northern Ghana}

\begin{abstract}
Small-scale irrigation schemes in northern Ghana are managed by Water User Groups (WUAs). Maintenance of these schemes is a collective effort by WUA members. We argue that the individual labour contributions to maintenance depend on perceptions of the prevailing governance strategies of WUAs. Moreover, as labour contributions can be seen as investments that provide future returns, the individual labour contributions depend also on time preferences. We empirically estimate these relationships using household survey data collected in 18 small-scale irrigation schemes and data obtained from a field experiment from which time preferences have been elicited. We find that governance perceptions of conflict management and equity and fairness positively associate with labour contributions, while the (negative) association of time preferences is not statistically significant. We further find that time preferences in their turn are negatively associated with household wealth, as found in previous studies. Farmers with plots in the head-ends, and farmers growing tomatoes or onions tend to have relatively high time preferences.
\end{abstract}

Publication status: Akuriba, M.A, Haagsma R., and Heerink N., 2018. Governance, time preference, and collective maintenance: the case of small-scale irrigation in northern

Ghana. Working paper. 


\subsection{Introduction}

For poor rural populations that depend to a large extent on agriculture for their livelihoods, increased productivity is critical in reducing poverty. Irrigated agriculture is commonly regarded as a major way to increase agricultural productivity (Namara et al., 2011; Dittoh et al., 2013a; Mengistie and Kidane, 2016). Given the low prevalence of irrigated agriculture in Africa, investments in irrigation infrastructure geared towards poverty reduction and improved food security are urgently needed (e.g. Oates et al., 2015; Svendsen et al., 2009).

Irrigation schemes can be considered as so-called common pool resources (CPRs) (Bravo and Marelli, 2008; Ostrom, 2000; Yu et al., 2016), which are mostly used by groups of people or communities. Small-scale irrigation schemes in Africa and elsewhere are increasingly managed by these users themselves, often in the form of Water User Associations (WUAs) or irrigation management committees (Mutambara et al., 2016). The daily activities of these user groups play a critical role in the sustainability of the schemes. The underperformance and unsustainability of most irrigation facilities in Africa has partly to do with the poor operation and maintenance by user groups (Mutambara et al., 2016; Namara et al., 2011; Lamptey et al., 2011).

Proper maintenance requires governance strategies that curtail free riding among those who have to partake in maintenance, and governance strategies that ensure optimum and equitable use of limited water resources. A well-governed resource ensures equity in the distribution of costs and benefits to its users (Wiek and Larson, 2012). When there is transparency and fairness in the allocation of tasks and benefits, users are more likely to see it as their responsibility to partake in maintaining resources. Active involvement of farmers in contributions towards the establishment and maintenance of their irrigation schemes is therefore recommended for the sustainability of smallholder irrigation schemes in Africa (Mutambara et al., 2016). Governance strategies that curtail free riding are crucial in this respect. Unlike private investments, where the investor is solely responsible for any future returns, the yields from putting effort into maintaining irrigation schemes (and CPRs in general) are dependent on the collective effort of all users. The governing strategies of WUAs may be assumed to influence the collective action of users, including their willingness to 
invest in maintenance. But to our knowledge, empirical research on this issue is missing so far.

Another factor that influences willingness to take part in maintenance activities is individual time preference. Devoting working time to maintenance is an investment with future returns. Users with less time preference (more patience) are more likely to invest in maintenance, other things being equal. People's level of time preference may be shaped by their past experiences. Holden et al. (1998) found that poverty in the past tends to create high rates of time preference. Although there is an increasing body of research on factors affecting time preferences, as far as we know, the role of time preference and its determinants in decisions regarding maintenance of small-scale irrigation systems has not yet been examined.

This paper therefore examines two questions: (1) To what extent does a farm er's labour contribution to general irrigation maintenance depend on his or her perception of local governance performance and on his or her time preference? (2) What factors can explain time preferences in farmers? To answer these research questions, we collected field data in northern Ghana.

The most common irrigation facilities in Ghana are small-scale reservoirs, mostly found in the Savannah Zone in the north. These schemes were constructed by the government with funding from development partners or by NGOs (Namara et al., 2011). Since their construction (or renovation), the daily management of the schemes has been handled by WUAs. The government is currently enrolling a policy in the agricultural sector to help fight poverty, dubbed "planting for food and jobs". The aim is to construct $m$ ore dam $\mathrm{s}$ in farm ing communities to boost agriculture. This study may help to identify which aspects of the governance of WUAs need attention for achieving sustainable production, and thus provide support for the "planting for food and jobs" agenda. The results $\mathrm{m}$ ay also help im provea WUA's general operation and $\mathrm{m}$ anagem ent of sm ał\$cale irrigation.

This paper is structured as follows. In Section 5.2 we present a conceptual framework of the relationships between poverty, time preferences, governance of irrigation resources, and maintenance of irrigation resources. Section 5.3 presents the research methodology. The 
presentation and discussion of results and our final conclusions are outlined in Sections 5.4 and 5.5 , respectively.

\subsection{Conceptual framework}

\subsubsection{Governing irrigation resources as commons}

Common pool resources are resources characterized by rivalry in consumption and nonexclusiveness. Their open-access nature can lead to overuse of the resource by some individuals, thereby creating negative externalities for others in the short or long run (Birner et al., 2005; Ostrom and Gardner, 1993; Ostrom, 2000). In such cases, regulating its use and ensuring due diligence is encouraged. Without proper governance, small-scale irrigation schemes and other common pool resources are likely to suffer from the "tragedy of the com m ons'(GWP, 2009; Ostrom, 2000; Tortajada, 2010).

Following Herrera et al. (2014), we define irrigation governance as the rules and regulations that determine the use and management of irrigation resources by local users. Several dimensions of governance can be ascertained. While some rules encourage user participation in the operation and management of the facilities, others aim to ensure transparency, accountability, equity, sustainable management, and control of corruption (GWP, 2009; Lautze et al., 2011; Mansungu, 2004; Tortajada, 2010).

In northern Ghana, Water User Associations (WUAs) are responsible for the general operation and maintenance of irrigation facilities, the allocation of land and water, and the collection of water fees (Mul et al., 2015; Namara et al., 2011; van Edig et al., 2003). Governance strategies of WUAs can have a major impact on the livelihoods of their members and communities at large. It is expected that good governance contributes to higher yields and lower poverty levels among irrigated-farm households. 
Maintenance of irrigation facilities is important for irrigation sustenance and requires the participation of all users. The active involvement of users inculcates a sense of ownership, making them feel the need for sustainable management of irrigation resources (Mutambara et al., 2016). Major maintenance activities of irrigation facilities in northern Ghana take place during the dry season (also called the irrigation season), the period in which rain-fed farming is not possible. The opportunity cost of participating in maintenance can be high because during this season farmers may engage in off-farm activities, such as trading, small-scale mining (galamsey) and artisanry, or may migrate to the south for menial jobs. Opportunity costs may differ between farmers due to their differences in education, social capital, and other factors driving off-farm employment and temporary migration.

\subsubsection{Governance perceptions}

Outcomes from governing strategies may not satisfy all users equally and can affect the enthusiasm of users' participation in resource maintenance. Users who perceive governance as being good may likely contribute more labour towards maintenance. Though the perceived quality of governance may generally affect users' contributions, different dim ensions can have different effects on the willingness of users to contribute. A detailed description and measurement of six governance dimensions considered in this study is presented in Chapter 2.

\subsubsection{Time preferences and farmer investments}

A person's rate of tim e preference m easures the am ount of future consum ption he or she is willing to sacrifice for being able to consume one unit more in the present time. Becker and Mullingan (1997) described it as an index of the intertemporal marginal rate of substitution at all points in the current-future consumption plane. Persons with high rates of time preference are often impatient with respect to future benefits. Since time preference is a psychological disposition shaped by past experiences such as poverty, it may vary from person to person. 
A farm er's willingness to invest is affected by his or her tim e preference. Tim e preference is an integral part of farm ers' decisions regarding production activities including participation in conservation practices (Duquette et al., 2011; Shiferaw et al., 2009). In a study on time preferences of farm households in Ethiopia, Yesuf (2004) found that high time preferences significantly reduced adoption of soil conservation technologies. Similarly in Kenya, Duflo et al. (2011) found that impatient farmers failed to invest profitably in fertilizer purchases. For long-term investments Godoy et al. (1998) found that patient people find it more attractive to invest in clearing old-growth forests and wait for their returns.

Hence, we may expect that the time preferences among water users will influence the amount of labour they are willing to invest for the maintenance of their irrigation scheme. Time preferences may be even more relevant than in the case of private investments because returns in public irrigation works generally show up later. Users with low time preferences may participate more in maintaining irrigation resources and may consequently contribute more labour to that effect.

A number of studies have tried to explain the level of time preferences among farmers. Holden et al. (1998) found that current liquidity as well as past wealth of households influenced rates of time preference. They showed that poor people were less likely to invest in environmental conservation. Recent studies provide support for the positive effect of poverty on time preferences. Living in a wealthy environment such as a household or village decreases one's tim e preference (Tanaka and Munro, 2012; Yesuf, 2004), as does higher wealth per capita (Wang et al., 2016). Access or proximity to economic factors such as good land and markets generally also decreases one's tim e preference(Holden et al., 1998).

Tanaka and Munro (2012) found that individuals with more schooling are more patient in investing in community infrastructures. Education enlightens individuals on the benefits of investing to maintain group assets. Broadly, education can have any direction of effect on time preference. Yesuf (2004) explained that educated people may be forward-looking and therefore have a low time preference on the one hand, but may also have access to better investment opportunities, leading to high rates of time preference on the other. Probably, as 
stated by Becker and Mullingan (1997), "educated people should be m ore productive at reducing the rem oteness of future pleasures".

Other personal characteristics such as age and gender of individuals are also found to influence time preferences (Becker and Mullingan, 1997; Wang et al., 2011; Yesuf, 2004). The effect of age is however ambiguous and can have any direction. Becker and Mullingan (1997) explained that young people tend to invest relatively much because they have more years remaining to harvest the returns, while older people invest less because fewer years remain. Children generally have short time horizons, which explains their impatience and unwillingness to invest. The future may therefore be discounted heavily at both young and old ages. In terms of sex, females are found to be more patient in investments (Silverman, 2003).

Differences in time preference may also be explained by cultural differences and socioeconomic factors (Holden et al., 1998; Wang et al., 2016). The beliefs of people inform their perceptions and decisions. Investment decisions may thus be affected by cultural environment.

\subsubsection{Framework used in this study}

Figure 5.1 illustrates the relationships between governance, time preferences, and labour contributions to irrigation maintenance. In our framework, good governance perceptions might have a direct effect where it increases the expected returns to labour investment in maintenance by reducing free-rider problems. Governance strategies may not affect users equally, hence labour contributions to maintenance may not be equal. Labour contributions here refer to the number of man-days a household contributes towards maintenance activities.

The individual contributions towards maintenance are a matter of choice even though key to the realisation of collective action. The benefits of contributing may not be realised immediately. Users who contribute more towards maintenance may therefore be those with much patience and enthusiasm for the sustainability of their scheme. Thus, time preference $\mathrm{m}$ ay influence a user's contribution to irrigation $\mathrm{m}$ aintenance. 
Poverty is said to influence an individual's tim e preference. The patience to wait for the fruition of an investment is high when poverty is relatively low. For labour contribution, relatively poor users may prefer investing their time and effort into ventures that will bring instant returns as compared to investing in a common resource. We use the value of household farm lands and livestock as proxy for poverty.

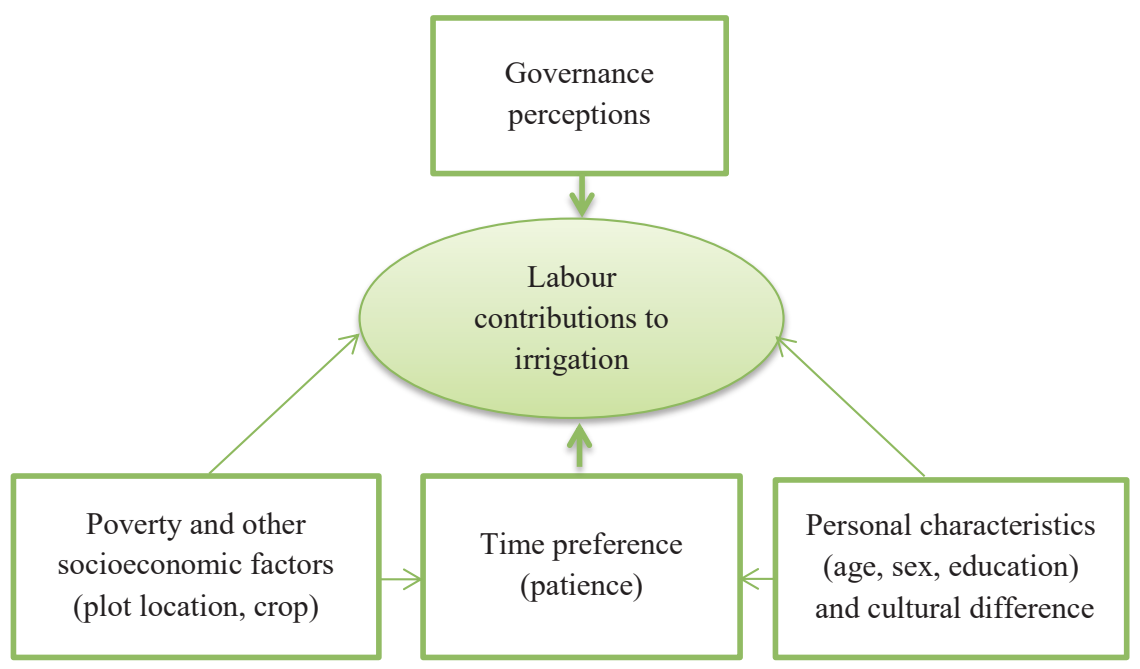

Figure 5.1: Time preference and governance perception as determinants of irrigation maintenance $^{3}$

Other socioeconomic factors peculiar to irrigation are plot location and the crop grown. Plots at the tail-ends are often least preferred. Users located at these ends may be termed as resource-poor. Resource-poor farmers mostly have short planning horizons and thus face difficulties in adopting a long-term view (Holden et al. 1998).

Several factors affect a schem e's choice for a particular crop. These may include history of diseases, water challenges, and relative output and input prices for various crops. The main crop grown in a scheme may therefore also affect one's tim e preference, because "if farm ers

\footnotetext{
${ }^{3}$ The relationship between poverty and labour contribution is not assessed in this study
} 
are able to recognize indirect costs, they will be factored into their consideration of investm ent strategies"(Shiferaw et al., 2009).

Personal characteristics such as number of years in formal education, and age and sex of water users may also influence time preference. The study area has many ethnic groups with varied cultural practices. The regions in which schemes, and thus users, are located may therefore influence time preference.

\subsection{Methodology}

\subsubsection{Data collection}

Data from a household survey of 18 smallholder irrigation schemes in northern Ghana was used (details presented in Chapter 2). This was complemented with a field experiment to estimate time preferences of irrigators. Ten (10) respondents were sampled from each WUA of the 18 schemes, giving a total of 180 participants in both the survey and experiment. Labour contributions towards maintenance were measured in terms of man-days (each manday being equivalent to six hours of labour). Irrigation plots are household assets but there is always one household member using the plot or leading in decisions regarding farming on the plot. Respondents in this study are the main farmers (using the household irrigation plots).

\section{Estimating time preferences}

Two main approaches have been used to estimate time preferences in the past: through consumption data, where discount rates are inferred from real-life decisions (Cagetti, 2003; Dreyfus and Viscusi, 1995; Hausman, 1979), and through experimental data (Andersen et al., 2008; Frederick et al., 2002; Tanaka et al., 2010). Recently, experiments have been the favoured approach, with multiple price list (MPL) methods being the most commonly used (Andersen et al., 2008; Andreoni and Sprenger, 2012; Tanaka et al., 2010). The MPL method 
employs multiple questions asked to individuals to choose between smaller payment amounts closer to the present, and relatively larger payments in the future, with interest rates increasing monotonically in a price list. Discount rates using standard methods like MPL are however said to be upward-biased, and thus too high on average, due to the linear preferences in their design (Andreoni et al., 2013; Andreoni and Sprenger, 2012). To minimize this, Andreoni and Sprenger (2010, 2012) proposed the so-called Convex Time Budget (CTB) method. The advantage of the CTB method over standard elicitation methods is its ability to identify discounting and utility function curvature (risk aversion) and its ability to test for present biases, at both the individual and aggregate level (Ibid). Following Andreoni and Sprenger (2012), we used a CTB design in estimating time preferences of irrigators. Appendix 5.A describes the experimental design and estimation results.

\subsubsection{Empirical approach}

We estimate two relationships. First, labour contributions to maintenance $(L C)$ are considered to be a function of governance perceptions $(G P)$, time preference $(T P)$, and other factors $(O F)$ :

$$
L C_{i j}=f\left(G P_{i j}, T P_{i j}, O F_{i j}\right)+e_{i j} \quad \text { for } i=1, \ldots, 180, \quad j=1, \ldots, 18
$$

Where:

$$
\begin{array}{ll}
L C_{i j} & =\text { Household labour contribution by user } i \text { in scheme } j \\
G P_{i j} & =\text { Governance perceptions of user } i \text { in scheme } j \\
T P_{i j} & =\text { Time preference of user } i \text { in scheme } j \\
O F_{i j} & =\text { Other factors of user } i \text { in scheme } j \\
e_{i j} & =\text { Error term }
\end{array}
$$

Second, time preference rates of users $(T P)$ are thought to be a function of wealth $(W)$, socioeconomic properties of a scheme $(S F)$, such as plot size, group size, age of the scheme, plot location and crop grown, personal characteristics $(P C)$, including age, sex, education and household labour force, and cultural background $(C B)$ : 


$$
T P_{i j}=g\left(W_{i j}, S F_{i j}, P C_{i j}, C B_{i j}\right)+u_{i j} \quad \text { for } i=1, \ldots, 180, \quad j=1, \ldots, 18
$$

Where:

$T P_{i j} \quad=$ Time preference of user $i$ in scheme $j$

$W_{i j} \quad=$ Wealth of user $i$ in scheme $j$

$S F_{i j} \quad=$ Socioeconomic properties of user $i$ in scheme $j$

$P C_{i j} \quad=$ Personal characteristics of user $i$ in scheme $j$

$C B_{i j} \quad=$ Cultural background of user $i$ in scheme $j$

$u_{i j} \quad=$ Error term

Equation (1) is estimated using a Tobit approach while equation (2) is estimated with Ordinary Least Squares (OLS). We used Tobit because a linear model would ignore the zero lower bound and not take into account that a user may not participate in maintenance activities. The Tobit approach does take this into account and therefore improves standard linear estimates. We also employ Generalized Linear Model (GLM) and OLS regressions to test the robustness of the results. The GLM method is able to estimate regressions with arbitrary and/or skewed continuous distributions in a consistent manner compared to standard methods like OLS (McCulloch, 2000). Because the error terms may be correlated for households living within the same irrigation scheme, we apply the "Robust-Clustered" errors approach (at scheme level) in both estimation procedures.

Table 5.1 presents definitions of the variables used in the regression equations and the signs of their expected influence. In addition to the effects of governance and time preferences, which have been described in our framework above, many other factors can influence labour contributions and time preferences We describe the most important ones below.

Plot size: Farmers with large plots may contribute more labour to maintenance, because they will be the most affected in the event of a collapse of the facility.

Group size: Farmers in large WUAs are more likely to free-ride than farmers in schemes with sm all WUAs. Moreover, a sm aller group m eans that one's returmon labour contribution is 
greater. Farmers in large WUAs are therefore likely to contribute less labour and be less patient in their investments.

Plot location: The location of a farm er's plot along the waterway determ ines how readily accessible water is to him or her. The closer the farmer is to the water reservoir, the more likely he or she would have adequate access to water and the more reluctant he or she may feel in maintaining resources since the water needs are readily met. Farmers farther away and at the tail-end of the facility are normally the most affected by water shortages, especially in the event that a facility runs dry. Tail-end farmers may thus get more involved in maintenance to ensure that water supply is sustained (Nagrah et al., 2016). The proximity of head-enders to water supply gives an assurance of high yields, so that having a head-end plot may correspond with low time preferences. By contrast, tail-enders may be impatient and have high time preferences.

Crop: The dominant crop grown at a facility depends on the value placed on the crop or environmental conditions surrounding the facility. Crop type can therefore have any direction of effect on labour contributions, depending on agro-climatic and market circumstances.

Household labour force: The larger the workforce, the more resources the household has in contributing labour (Wang et al., 2016). 
Table 5.1: Definition of variables and expected influence

\begin{tabular}{|c|c|c|c|}
\hline Variable & Definition & Labour & $\begin{array}{l}\text { Time } \\
\text { pref. }\end{array}$ \\
\hline \multicolumn{4}{|c|}{ Dependent variables } \\
\hline $\begin{array}{l}\text { Labour } \\
\text { contribution }\end{array}$ & $\begin{array}{l}\text { Number of days a user household took part in maintenance } \\
\text { activities of public spaces not directly bordering the household's } \\
\text { plot in the past year }\end{array}$ & & \\
\hline Time preference & $\begin{array}{l}\text { Daily time preference rate ( }=\text { inverse of daily discount rate, minus } \\
\text { one) obtained from Convex Time Budget (CTB) experiment }\end{array}$ & - & \\
\hline \multicolumn{4}{|c|}{ Governance perceptions } \\
\hline Participation & Mean rank of participation indicators in a 1-to-5 Likert scale & + & \\
\hline Accountability & Mean rank of accountability indicators in a 1-to-5 Likert scale & + & \\
\hline $\begin{array}{l}\text { Conflict } \\
\text { management }\end{array}$ & $\begin{array}{l}\text { Mean rank of conflict management indicators in a 1-to-5 Likert } \\
\text { scale }\end{array}$ & + & \\
\hline $\begin{array}{l}\text { Transparency and } \\
\text { cooperation }\end{array}$ & $\begin{array}{l}\text { Mean rank of transparency and cooperation indicators in a 1-to-5 } \\
\text { Likert scale }\end{array}$ & + & \\
\hline Equity and fairness & $\begin{array}{l}\text { Mean rank of equity and fairness indicators in a 1-to-5 Likert } \\
\text { scale }\end{array}$ & + & \\
\hline Sustainable use & Mean rank of sustainable use indicators in a 1-to-5 Likert scale & + & \\
\hline $\begin{array}{l}\text { Overall } \\
\text { governance } \\
\text { perception }\end{array}$ & $\begin{array}{l}\text { Mean rank of all governance dimensions in a 1-to-5 Likert scale, } \\
\text { with all dimensions having equal weight }\end{array}$ & + & \\
\hline \multicolumn{4}{|c|}{ Other factors } \\
\hline \multicolumn{4}{|l|}{ Wealth } \\
\hline Household wealth & $\begin{array}{l}\text { Value of household farm lands and livestock in Ghana Cedis } \\
\text { (expressed in GHC ’000) }\end{array}$ & & - \\
\hline Wealth per capita & $\begin{array}{l}\text { Household wealth per person in Ghana Cedis (expressed in GHC } \\
\text { '000) }\end{array}$ & & - \\
\hline \multicolumn{4}{|c|}{ Socioeconomic properties } \\
\hline Plot size & Size of plot allocated to a household in acres & + & \\
\hline Group size & Number of users in a WUA & - & + \\
\hline Age of scheme & The number of years a scheme has existed & $-/+$ & $-/+$ \\
\hline Head-end plot & A dummy that takes a value of 1 if plot location is at head-end & - & - \\
\hline Tail-end plot & A dummy that takes a value of 1 if plot location is at tail-end & + & + \\
\hline Tomatoes & A dummy that takes a value of 1 if main crop is tomatoes & $-/+$ & $-/+$ \\
\hline Onions & A dummy that takes a value of 1 if main crop is onions & $-/+$ & $-/+$ \\
\hline \multicolumn{4}{|c|}{ Personal characteristics } \\
\hline Age & Age of user in years & + & - \\
\hline Sex & A dummy that takes a value of 1 if the user is male & + & $-/+$ \\
\hline Educational level & $\begin{array}{l}\text { Number of years of formal education (also an indicator of } \\
\text { opportunity cost) }\end{array}$ & $-/+$ & $-/+$ \\
\hline $\begin{array}{l}\text { Household labour } \\
\text { force }\end{array}$ & Number of people in the household that are 15 years or older & + & \\
\hline \multicolumn{4}{|c|}{ Cultural background } \\
\hline Upper East Region & A dummy that takes a value of 1 if region is Upper East & $-/+$ & $-/+$ \\
\hline $\begin{array}{l}\text { Upper West } \\
\text { Region }\end{array}$ & A dummy that takes a value of 1 if region is Upper West & $-/+$ & $-/+$ \\
\hline
\end{tabular}




\subsection{Results and discussion}

\subsubsection{Summary statistics}

In Table 5.2, we present the summary statistics of variables included in our analysis for 107 observations out of the 180 sampled participants. Time preferences could be estimated for 107 subjects only. Of the remaining 73 subjects, 52 subjects switched multiple times, while 21 subjects had no variation in their choices. This may be due to subject confusion following the elaborate nature of the CTB design. An attrition check using a Probit regression (see Appendix 5.C) indicates that the probability of a participant being included in the 107 observations sample is significantly influenced by household wealth (1000 GHC) and mobility (= number of times the irrigator migrated last season), whereas age, sex, education and religion do not play a significant role. The negative estimated coefficient for wealth may be explained by the fact that small changes in income are much less important for wealthier persons than they are for poorer persons. Hence, the amount of money used for playing the game has a different meaning for them. Less wealthy farmers are more likely to take the game serious. On the other hand farmers who frequently migrated during the previous season are more likely to be involved in the market economy than those who remain at home. They are probably more aware of the value of money as compared to (semi-subsistence) farmers. These results suggest that the sample of 107 observations is not just a random sub-sample of the 180 irrigators who played the game, and that the results that we obtain in this chapter apply in particular to those irrigators who have relatively low wealth and more migration experience.

Inconsistent choices is a common problem in standard multiple price list experiments. Depending on the subject pool, about $10-75 \%$ of the subjects make inconsistent choices (Charness and Viceisza, 2011; Meier and Sprenger, 2010; Jacobson and Petrie, 2009). This is assumed to be slightly lower with the CTB approach (Andreoni and Sprenger, 2012, p 3345). 
Table 5.2: Summary statistics, 107 observations

\begin{tabular}{|c|c|c|c|c|c|}
\hline Variable & Mean & Std. Dev. & Min & Max & $\mathrm{CV}$ \\
\hline \multicolumn{6}{|c|}{ Dependent variables } \\
\hline Labour contribution (days) & 2.477 & 1.679 & 0 & 8 & 0.678 \\
\hline Daily discount factor & 0.984 & 0.018 & 0.890 & 1.012 & 0.018 \\
\hline Daily time preference rate & 0.017 & 0.0194 & -0.012 & 0.123 & 1.141 \\
\hline \multicolumn{6}{|c|}{ Governance perceptions } \\
\hline Overall gov. perception & 3.836 & 0.459 & 1.681 & 4.560 & 0.120 \\
\hline Participation & 4.062 & 0.472 & 2.8 & 5 & 0.116 \\
\hline Accountability & 3.660 & 0.762 & 1.2 & 4.8 & 0.208 \\
\hline Conflict management & 4.287 & 0.615 & 1 & 5 & 0.143 \\
\hline $\begin{array}{l}\text { Transparency and } \\
\text { cooperation }\end{array}$ & 3.860 & 0.686 & 1.067 & 4.933333 & 0.178 \\
\hline Equity and fairness & 3.650 & 0.563 & 2 & 4.857 & 0.154 \\
\hline Sustainable use & 3.494 & 0.533 & 1.818 & 4.545 & 0.153 \\
\hline \multicolumn{6}{|c|}{ Other factors } \\
\hline \multicolumn{6}{|l|}{ Wealth } \\
\hline $\begin{array}{l}\text { Household wealth (1000 } \\
\text { GHC) }\end{array}$ & 9.170 & 5.723 & 1.750 & 27.775 & 0.624 \\
\hline $\begin{array}{l}\text { Wealth per capita (1000 } \\
\text { GHC) }\end{array}$ & 1.393 & 0.965 & 0.165 & 5.265 & 0.693 \\
\hline \multicolumn{6}{|l|}{ Socioeconomic properties } \\
\hline Plot size (acres) & 0.226 & 0.142 & 0.056 & 0.5 & 0.628 \\
\hline Group size & 71.561 & 34.182 & 17 & 125 & 0.478 \\
\hline Age of scheme (years) & 44.523 & 18.248 & 16 & 81 & 0.410 \\
\hline Head-end plot & 0.271 & 0.447 & 0 & 1 & 1.649 \\
\hline Tail-end plot & 0.234 & 0.425 & 0 & 1 & 1.816 \\
\hline Tomatoes & 0.299 & 0.460 & 0 & 1 & 1.538 \\
\hline Onions & 0.364 & 0.484 & 0 & 1 & 1.330 \\
\hline \multicolumn{6}{|l|}{ Personal characteristics } \\
\hline Age (years) & 43.607 & 12.119 & 18 & 85 & 0.278 \\
\hline Sex $($ male $=1)$ & 0.626 & 0.486 & 0 & 1 & 0.776 \\
\hline Education (years) & 3.776 & 4.853 & 0 & 16 & 1.285 \\
\hline Household labour force & 7.262 & 2.575 & 3 & 15 & 0.355 \\
\hline \multicolumn{6}{|l|}{ Cultural background } \\
\hline Upper East Region & 0.692 & 0.464 & 0 & 1 & 0.671 \\
\hline Upper West Region & 0.028 & 0.166 & 0 & 1 & 5.929 \\
\hline
\end{tabular}

The mean contribution of labour to irrigation maintenance is 2.5 days, with a minimum of zero days and a maximum of 8 days. Daily discount factors of users range between 0.89 and 1.012. The mean discount factor is 0.984 , while the median equals 0.988 . The estimated median is lower than the one estimated for American university students by Andreoni and Sprenger (2012), who obtained a median estimate of 0.9991 . The mean daily time preference rate is $1.7 \%$ with minimum and maximum of about $-1.2 \%$ and $12.3 \%$ respectively, while the 
median daily time preference rate is $1.2 \%$. In the experiment of Andreoni and Sprenger (2012), the estimated median daily time preference rate equals $0.09 \%$. The relatively high time preferences estimated from our experiment may not only reflect differences in wealth between American university students and Ghanaian smallholders (see also regression results for wealth in time preferences equation presented below), but also from the fact that the CTB experiment estimates nominal instead of real time preferences. Year-on-year inflation in Ghana stood at ca. 17 percent during the months when we carried out the experiments (November 2014 - April 2015). The interest rates that we used in the CTB experiment reflect the rapid price increases and corresponding depreciation of the Ghanaian Cedi (see Appendix 5.A).

The mean overall governance perception is 3.8 , with a minimum of 1.7 and a maximum of 4.6. The mean rating is fairly above the average (3), indicating a relatively positive perceived governance in the study area. The coefficient of variation (CV) is 0.12 , indicating that the variation in perceptions is relatively small compared to its mean value. The lowest ranked governance dimension is sustainable use, with a mean value of 3.5. Conflict management had the highest mean of 4.3 , and is thus perceived as relatively good, while sustainable use is considered problematic. The other four governance dimensions have mean values ranging between 3.7 and 4.1, and hence are perceived as positive on average by the scheme users. Accountability perceptions has the highest coefficient of variation $(0.21)$, implying that there is relatively much variation in the opinions about this dimension compared to the other governance dimensions. The correlation coefficients among the governance dimensions, presented in Table 5.3, show that they are not very large except for the correlation between accountability and transparency and cooperation (which equals 0.82 ).

Table 5.2 further indicates that household wealth status of respondents varied from a low of 1.75 to a high of 27.78 thousand Ghana Cedis worth of farmlands and livestock. The mean wealth is 9.17 , with a standard deviation of 5.72 thousand Ghana Cedis and a coefficient of variation of $62 \%$. The variation is even wider when wealth per capita is considered. The mean wealth per capita in a household is about 1.39 thousand Ghana Cedis with 0.17 and 5.27 thousand Ghana Cedis as minimum and maximum wealth per capita respectively. The standard deviation of wealth per capita is $69 \%$ of the mean. 
Table 5.3: Correlation coefficients among governance dimensions

\begin{tabular}{|l|l|l|l|l|l|l|}
\hline & $\begin{array}{l}\text { Partici- } \\
\text { pation }\end{array}$ & $\begin{array}{l}\text { Account- } \\
\text { ability }\end{array}$ & $\begin{array}{l}\text { Conflict } \\
\text { manage- } \\
\text { ment }\end{array}$ & $\begin{array}{l}\text { Transparency } \\
\text { and } \\
\text { cooperation }\end{array}$ & $\begin{array}{l}\text { Fairness } \\
\text { and equity }\end{array}$ & $\begin{array}{l}\text { Sustainable } \\
\text { use }\end{array}$ \\
\hline Participation & 1.0000 & & & & & \\
\hline Accountability & 0.5592 & 1.0000 & & & & \\
\hline $\begin{array}{l}\text { Conflict } \\
\text { management }\end{array}$ & 0.4338 & 0.6635 & 1.0000 & & 1.0000 & \\
\hline $\begin{array}{l}\text { Transparency } \\
\text { and } \\
\text { cooperation }\end{array}$ & 0.5814 & 0.8231 & 0.6121 & & & \\
\hline $\begin{array}{l}\text { Fairness and } \\
\text { equity }\end{array}$ & 0.5385 & 0.5541 & 0.4850 & 0.6626 & 1.0000 & \\
\hline $\begin{array}{l}\text { Sustainable } \\
\text { use }\end{array}$ & 0.1054 & 0.0858 & 0.2975 & 0.1757 & 0.4151 & 1.0000 \\
\hline
\end{tabular}

Plots allocated to households by management range from 0.056 to 0.5 acres with a mean size of 0.229 acres. The standard deviation of plot size is 0.142 . Several factors are considered during the allocation of plots to households including proportion of the household's farm land that was confiscated or destroyed in the process of constructing reservoirs which may explain the variability in plot sizes. The irrigation schemes have a mean user group size of 72 farmers, with the smallest user group size being 17 farmers and the largest group size 125 farmers. The mean age of these schemes is 45 years, the minimum is 16 years and the maximum is 81 years. About $27 \%$ and $23 \%$ of respondents were allocated head-end and tailend plots, respectively. Hence, $50 \%$ of the farmers have plots located in the middle of the scheme. The sampled crops (tomatoes, onions, pepper) had about 30\%, 36\% and 34\% respective representation in the respondents.

Most of the respondents were middle-aged with a mean age of 43.6 years. The minimum age recorded is 18 years and the maximum 85 years. The sample had about $63 \%$ males and $37 \%$ females. Farming in northern Ghana is generally male-dominated, which is reflected in our study sample. Farmers on average spent 3.8 years on formal education. While some spent up to 16 years on schooling, some farmers did not have any level of formal education. The mean household labour force size is 7.26 with a minimum of 3 persons and a maximum of 15 . 
In terms of location, about $69 \%$ of respondents are from the Upper East Region, 3\% from the Upper West Region and 28\% from the Northern Region. Most small-scale irrigation facilities are located in the Upper East Region.

\subsubsection{Regression results}

\section{Labour contributions to maintenance}

Table 5.4 presents results of our regression analysis for labour contributions to maintenance using a Tobit approach. The first regression (column 1) estimates determinants of labour contributions using overall governance perception as one of the explanatory variables, and column 2 presents the estimation results when governance is split into its six dimensions. The table also presents estimates when only significant governance dimensions are considered (column (3)) and when seemingly correlated dimensions (accountability and transparency and cooperation as indicated in Table 5.3) are iterated with the two significant dimensions (columns (4) and (5)).

The estimated relation of the overall governance perception to labour contributions is positive and highly significant. An increase of one unit in governance perception (on a 1-5 scale) relates to about 1.1 increase in the expected number of labour days contributed towards maintenance. The results presented in the second column suggest that perceptions about conflict management and equity and fairness are the governance dimensions that are of most importance to the sampled farmers. An increase of one unit in conflict management perceptions associates with an increase in expected labour contribution by 0.79 days, while a similar increase in perceptions on equity and fairness increases the expected contribution by 0.71 days. The significant associations of conflict management and equity and fairness with labour contribution can be related to the fact that most people like to associate with the best in terms of serenity and respect for rights. Investments stride well in peaceful environments where obstructions are less. Equity and fairness is an assurance that returns from investments will not be infringed upon. Farmers are motivated by these which explains the significant relations of these variables to labour contributions. 
Table 5.4: Tobit regression results for labour contributions

\begin{tabular}{|c|c|c|c|c|c|}
\hline Variables & (1) & (2) & (3) & (4) & (5) \\
\hline $\begin{array}{l}\text { Overall governance } \\
\text { Perception }\end{array}$ & $\begin{array}{l}1.100 * * * \\
(0.357)\end{array}$ & & & & \\
\hline Participation & & $\begin{array}{l}0.011 \\
(0.354)\end{array}$ & & & \\
\hline Accountability & & $\begin{array}{l}0.102 \\
(0.344)\end{array}$ & & $\begin{array}{l}0.307 \\
(0.273)\end{array}$ & \\
\hline $\begin{array}{l}\text { Conflict } \\
\text { Management }\end{array}$ & & $\begin{array}{l}0.785 * * \\
(0.366)\end{array}$ & $\begin{array}{l}1.043 * * * \\
(0.298)\end{array}$ & $\begin{array}{l}0.853 * * \\
(0.364)\end{array}$ & $\begin{array}{l}0.872 * * \\
(0.341)\end{array}$ \\
\hline $\begin{array}{l}\text { Transparency and } \\
\text { Cooperation }\end{array}$ & & $\begin{array}{l}0.392 \\
(0.428)\end{array}$ & & & $\begin{array}{l}0.433 \\
(0.345)\end{array}$ \\
\hline Equity and fairness & & $\begin{array}{l}0.709 * * \\
(0.269)\end{array}$ & $\begin{array}{l}0.427 * * \\
(0.203)\end{array}$ & $\begin{array}{l}0.460 * * \\
(0.206)\end{array}$ & $\begin{array}{l}0.579 * * \\
(0.237)\end{array}$ \\
\hline Sustainable use & & $\begin{array}{l}0.263 \\
(0.268)\end{array}$ & & & \\
\hline $\begin{array}{l}\text { Daily time } \\
\text { Preference }\end{array}$ & $\begin{array}{l}-4.045 \\
(4.641)\end{array}$ & $\begin{array}{l}-4.947 \\
(4.745)\end{array}$ & $\begin{array}{l}-3.567 \\
(5.046)\end{array}$ & $\begin{array}{l}-3.984 \\
(4.852)\end{array}$ & $\begin{array}{l}-4.094 \\
(5.006)\end{array}$ \\
\hline Age & $\begin{array}{l}-0.021 * * \\
(0.009)\end{array}$ & $\begin{array}{l}-0.024 * * \\
(0.009)\end{array}$ & $\begin{array}{l}-0.024 * * \\
(0.009)\end{array}$ & $\begin{array}{l}-0.024 * * * \\
(0.009)\end{array}$ & $\begin{array}{l}-0.025 * * * \\
(0.009)\end{array}$ \\
\hline Sex & $\begin{array}{l}-0.333 \\
(0.223)\end{array}$ & $\begin{array}{l}-0.329 \\
(0.224)\end{array}$ & $\begin{array}{l}-0.289 \\
(0.221)\end{array}$ & $\begin{array}{l}-0.303 \\
(0.214)\end{array}$ & $\begin{array}{l}-0.350 \\
(0.231)\end{array}$ \\
\hline Education & $\begin{array}{l}-0.074 * * * \\
(0.022)\end{array}$ & $\begin{array}{l}-0.076 * * * \\
(0.021)\end{array}$ & $\begin{array}{l}-0.081 * * * \\
(0.023)\end{array}$ & $\begin{array}{l}-0.079 * * * \\
(0.023)\end{array}$ & $\begin{array}{l}-0.077 * * * \\
(0.022)\end{array}$ \\
\hline $\begin{array}{l}\text { Household labour } \\
\text { Force }\end{array}$ & $\begin{array}{l}-0.008 \\
(0.051)\end{array}$ & $\begin{array}{l}0.002 \\
(0.060)\end{array}$ & $\begin{array}{l}-0.008 \\
(0.053)\end{array}$ & $\begin{array}{l}-0.003 \\
(0.055)\end{array}$ & $\begin{array}{l}-0.011 \\
(0.052)\end{array}$ \\
\hline Plot size & $\begin{array}{l}1.696 \\
(1.054) \\
\end{array}$ & $\begin{array}{l}1.938 * \\
(1.016)\end{array}$ & $\begin{array}{l}2.003 * * \\
(0.839)\end{array}$ & $\begin{array}{l}1.979 * * \\
(0.894)\end{array}$ & $\begin{array}{l}1.716^{*} \\
(0.889)\end{array}$ \\
\hline Group size & $\begin{array}{l}0.005 \\
(0.005)\end{array}$ & $\begin{array}{l}0.007 \\
(0.005)\end{array}$ & $\begin{array}{l}0.007 \\
(0.005)\end{array}$ & $\begin{array}{l}0.007 \\
(0.005)\end{array}$ & $\begin{array}{l}0.008 \\
(0.005)\end{array}$ \\
\hline Age of scheme & $\begin{array}{l}0.011 * \\
(0.007)\end{array}$ & $\begin{array}{l}0.007 \\
(0.007)\end{array}$ & $\begin{array}{l}0.009 \\
(0.006)\end{array}$ & $\begin{array}{l}0.008 \\
(0.007)\end{array}$ & $\begin{array}{l}0.006 \\
(0.008)\end{array}$ \\
\hline Head-end plot & $\begin{array}{l}-1.324 * * * \\
(0.281)\end{array}$ & $\begin{array}{l}-1.260 * * * \\
(0.224)\end{array}$ & $\begin{array}{l}-1.400 * * * \\
(0.250)\end{array}$ & $\begin{array}{l}-1.380 * * * \\
(0.228)\end{array}$ & $\begin{array}{l}-1.325 * * * \\
(0.235)\end{array}$ \\
\hline Tail-end plot & $\begin{array}{l}0.120 \\
(0.367)\end{array}$ & $\begin{array}{l}0.087 \\
(0.361)\end{array}$ & $\begin{array}{l}0.106 \\
(0.379)\end{array}$ & $\begin{array}{l}0.079 \\
(0.376)\end{array}$ & $\begin{array}{l}0.051 \\
(0.358)\end{array}$ \\
\hline Tomatoes & $\begin{array}{l}1.994 * * * \\
(0.259)\end{array}$ & $\begin{array}{l}2.102 * * * \\
(0.245)\end{array}$ & $\begin{array}{l}2.156^{* * * *} \\
(0.215)\end{array}$ & $\begin{array}{l}2.062 * * * \\
(0.247)\end{array}$ & $\begin{array}{l}2.101 * * * \\
(0.234)\end{array}$ \\
\hline Onions & $\begin{array}{l}1.313 * * * \\
(0.319)\end{array}$ & $\begin{array}{l}1.315 * * * \\
(0.353)\end{array}$ & $\begin{array}{l}1.213 * * * \\
(0.284)\end{array}$ & $\begin{array}{l}1.129 * * * \\
(0.322)\end{array}$ & $\begin{array}{l}1.282 * * * \\
(0.283)\end{array}$ \\
\hline Upper East & $\begin{array}{l}-1.368 * * * \\
(0.293)\end{array}$ & $\begin{array}{l}-1.015 * * * \\
(0.313)\end{array}$ & $\begin{array}{l}-0.879 * * * \\
(0.213)\end{array}$ & $\begin{array}{l}-1.052 * * * \\
(0.254)\end{array}$ & $\begin{array}{l}-1.091 * * * \\
(0.258)\end{array}$ \\
\hline Upper West & $\begin{array}{l}0.969 * * \\
(0.473)\end{array}$ & $\begin{array}{l}1.427 * * * \\
(0.501)\end{array}$ & $\begin{array}{l}1.804 * * * \\
(0.287)\end{array}$ & $\begin{array}{l}1.410 * * * \\
(0.505)\end{array}$ & $\begin{array}{l}1.449 * * * \\
(0.456)\end{array}$ \\
\hline Constant & $\begin{array}{l}-1.297 \\
(1.377)\end{array}$ & $\begin{array}{l}-5.210^{*} \\
(2.717)\end{array}$ & $\begin{array}{l}-2.916 \\
(1.799)\end{array}$ & $\begin{array}{l}-3.093 \\
(1.917)\end{array}$ & $\begin{array}{l}-3.837^{*} \\
(2.0250\end{array}$ \\
\hline Observations & 107 & 107 & 107 & 107 & 107 \\
\hline Pseudo R-squared & 0.1517 & 0.1801 & 0.1739 & 0.1579 & 0.1527 \\
\hline
\end{tabular}

Notes: ${ }^{* * *} \mathrm{p}<0.01,{ }^{* *} \mathrm{p}<0.05,{ }^{*} \mathrm{p}<0.1$; Cluster robust standard errors in parentheses 
The estimated coefficient for perceptions of conflict management becomes even more significant when included in the equation with equity and fairness as the only governance dimensions (column (3)). The insignificance of other governance dimensions may be affected by collinearity among those dimensions, and therefore should be interpreted with care. In columns (4) and (5) we present the regressions results when conflict management and equity and fairness are both combined with accountability and transparency and cooperation respectively. As can be seen from the results, the estimated coefficients for the seemingly correlated dimensions (accountability and transparency and cooperation) are still not significantly different from zero. This means that conflict management and equity and fairness are the governance dimensions that play significant roles in labour contributions to irrigation maintenance in this sample. The results further provide some evidence that time preference has a negative association with labour contributions, as we posited. However, the estimated coefficient is not significantly different from zero.

Other factors that are significantly related to labour contributions to irrigation maintenance include age, education, plot size, plot location, main crop, and regional difference. An increase in the age of a farmer by a year decreases his expected labour contributions by 0.024 labour days. An additional year of formal education of a farmer decreases his expected labour contributions by 0.076 labour days. Plot size has a significant positive relationship with labour contributions. A 0.1 acre increase in the land allocated to a household is associated with a 0.194 days increase in the expected contributions to maintenance. Households with large irrigated plots have the advantage of gaining more when the resource is wellmaintained.

As we hypothesized, plot location relates to the amount of labour a farmer contributes to maintenance. The influence of being allocated a head-end plot is negative and significant, which is consistent with findings in Nagrah et al. (2016). The associated influence of having a tail-end plot is not significantly different from zero. The estimated coefficient for the headend dummy indicates that, controlling for other factors, farmers with plots at the head-end are expected to contribute on average 1.26 labour days less than farmers with plots in the middle. 
The dominant crop grown in a scheme is also found to have a significant relation to maintenance contributions. Tomato farmers are expected to contribute on average 2.1 days more than pepper farmers, and onion farmers 1.32 days more (when other factors affecting labour contributions are controlled). The regional differences of farmers also influence their labour contributions. Farmers located in the Upper East Region are expected to contribute on average 1.02 labour days less than farmers in the Northern Region while farmers in the Upper West Region are expected to contribute 1.43 labour days more than those in the Northern Region. Variabilities in the regions such as culture, temperatures, and alternative livelihood activities among others may account for this. Poverty is more pronounced in the Upper East Region. Farmers tin the region involve in different economic activities at a time thereby dividing their labour days among the lot. This may explain why farmers in the Upper East Region contribute less labour than farmers in the Northern Region.

Additionally, we estimated the same two equations by OLS and GLM as robustness checks. The results are presented in Appendix 5B. The main conclusions that can be derived from these results are similar to the ones we drew from the Tobit regression results.

\section{Time preferences}

In Table 5.5, we present the OLS regression results for the daily time preference rates. Two different equations were estimated, one with total household wealth (column 1) and one with per capita wealth (column 2) among the explanatory variables.

The relationship between wealth and time preference is negative, as expected. However, only household wealth is found to have a statistically significant relation; the estimated coefficient for per capita wealth does not differ significantly from zero. A GHC 1,000 increase in the wealth of a farm household is associated with a 0.1 percentage points decline in a user's daily time preference rate. This finding is consistent with Tanaka and Munro (2012), and Yesuf (2004), who found that household wealth correlates with low rates of time preferences and thus patience. It may be that poor households are concerned about the present needs of their families due to inadequacies and will therefore be too impatient to plan long-term 
investments. Relatively wealthy farmers can sell or rent out part of their assets when the need arises and therefore have lower time preferences. But the estimated relationship may also reflect that households with low time preferences tend to accumulate more wealth.

Table 5.5: OLS regression results for daily time preference rates

\begin{tabular}{|c|c|c|}
\hline Variable & (1) & (2) \\
\hline Household wealth & $\begin{array}{l}-0.001 \text { *** } \\
(0.000)\end{array}$ & \\
\hline Wealth per capita & & $\begin{array}{l}-0.002 \\
(0.002)\end{array}$ \\
\hline Group size & $\begin{array}{l}-0.000 \\
(0.000)\end{array}$ & $\begin{array}{l}-0.000 \\
(0.000)\end{array}$ \\
\hline Age of scheme & $\begin{array}{l}0.000 \\
(0.000)\end{array}$ & $\begin{array}{l}-0.000 \\
(0.000)\end{array}$ \\
\hline Head-end plot & $\begin{array}{l}0.008^{*} \\
(0.004)\end{array}$ & $\begin{array}{l}0.009 * * \\
(0.004)\end{array}$ \\
\hline Tail-end plot & $\begin{array}{l}0.000 \\
(0.005)\end{array}$ & $\begin{array}{l}0.001 \\
(0.005)\end{array}$ \\
\hline Tomatoes & $\begin{array}{l}0.010 * * * \\
(0.002)\end{array}$ & $\begin{array}{l}0.011 * * * \\
(0.003)\end{array}$ \\
\hline Onions & $\begin{array}{l}0.017 * * * \\
(0.005)\end{array}$ & $\begin{array}{l}0.017 * * * \\
(0.005)\end{array}$ \\
\hline Age & $\begin{array}{l}0.000 \\
(0.000)\end{array}$ & $\begin{array}{l}0.000 \\
(0.000)\end{array}$ \\
\hline Sex & $\begin{array}{l}-0.001 \\
(0.003)\end{array}$ & $\begin{array}{l}-0.001 \\
(0.003)\end{array}$ \\
\hline Education & $\begin{array}{l}0.001 \\
(0.000)\end{array}$ & $\begin{array}{l}0.000 \\
(0.000)\end{array}$ \\
\hline Upper East Region & $\begin{array}{l}-0.015^{* * *} \\
(0.005)\end{array}$ & $\begin{array}{l}-0.018^{* * *} \\
(0.005)\end{array}$ \\
\hline Upper West Region & $\begin{array}{l}-0.004 \\
(0.007)\end{array}$ & $\begin{array}{l}-0.004 \\
(0.007)\end{array}$ \\
\hline Constant & $\begin{array}{l}0.018^{*} \\
(0.008)\end{array}$ & $\begin{array}{l}0.015^{*} \\
(0.008)\end{array}$ \\
\hline Observations & 107 & 107 \\
\hline R-squared & 0.166 & 0.0127 \\
\hline
\end{tabular}

Notes: ${ }^{* * *} \mathrm{p}<0.01,{ }^{* *} \mathrm{p}<0.05,{ }^{*} \mathrm{p}<0.1$; Cluster robust standard errors in parentheses

Other significant variables that correlate with time preference in our model are plot location, main crop, and regional location. Being allocated to a head-end plot has a significant positive association with time preference of farmers. Controlling for other factors relating to time 
preferences, head-enders' time preferences are on average 0.9 percentage points higher than those of farmers with plots located elsewhere in the scheme. Head-end plots are economically advantaged in terms of water access and quality of infrastructure, as they are mostly the first to be allocated water for irrigation. It therefore takes less surveillance to ensure timely supply of water for effective production and one would have wished that farmers allocated to such plots will have more patience but this is contrary to that. Farmers at the tail-end plots have the expected positive association but insignificant in determining time preferences.

Main type of crop grown in a scheme is also found to have a significant association with time preference. The results indicate that, assuming other factors remain constant, time preferences of tomatoes and onions farmers are 1.0 and 1.7 respective percentage points higher than pepper farmers in the surveyed schemes. Vegetable farmers (particularly tomatoes farmers) face a lot of marketing challenges in northern Ghana due to a lack of functional processing and storage facilities in the area. The farm ers $m$ ostly rely on " $m$ arket queens" ( $m$ iddle $m$ en) to sell their produce. Farmers in most schemes visited expressed the frustration they go through to sell their produce and the low prices they often receive due to the perishable nature of most vegetables.

The regional location of schemes is also found to affect time preferences. Farmers located in the Upper East Region have significantly lower time preferences, controlling for other factors, than farmers located in the other two regions. The estimated mean difference is 1.5 percentage points. Many cultural differences exist between different regions in Ghana, and this may affect time preference, as discussed in Wang et al. (2016). We did not examine the impact of these cultural dimensions in more detail in this study.

\subsection{Conclusion}

In northern Ghana, small-scale irrigation schemes have been constructed as a measure to reduce poverty. These schemes are mostly managed by Water User Associations (WUAs), and proper maintenance of these schemes is important for sustainable production. Being a common pool resource, the maintenance of these schemes is a collective effort by WUA 
members. We argue that the labour contributions of users to this effect are related to how positive the governing strategies of WUAs are perceived by the users. We also explain that labour contribution is a form of investment with expected future returns and, therefore, is related to the time preference of a user. We explore these correlations using cross-section data from a survey, and data from a field experiment that elicits time preferences of irrigation farmers in northern Ghana. The analysis and conclusion is drawn from 107 observations (59\% of the sample) which reflect consistent choices in the time preference experiment (see Appendix 5.A).

We find that governance perceptions relate to labour contributions towards maintenance. Irrigation farmers who perceive governance to be good are found to participate more in maintenance activities than those who perceive otherwise. Though the associated influence of governance is generally regarded as positive, as indicated by the overall governance perception, different dimensions of governance score differently. Six governance dimensions have been studied. Among these, conflict management and equity and fairness dimensions are found to have positive and significant associations with labour contributions. In other words, users who perceive that governing strategies on conflict management and equity and fairness are carried out well generally contribute more to maintaining irrigation resources.

The link between time preference and labour contribution is negative. Impatient farmers (i.e., those with high time preferences) on average contribute less to irrigation maintenance but this is not statistically significant from zero. We also examined factors associated with differences in time preferences as obtained from the field experiment. Our findings confirm a negative and significant correlation between household wealth and time preferences. They also suggests that farmers with plots in the head-ends and farmers growing tomatoes or onions tend to have relatively high time preferences while farmers located in the Upper East Region have low time preferences.

Our results also highlight other factors that associate with labour contributions, in addition to governance perceptions. We find that age, education, head-end plots, and being located in the Upper East Region have significant, negative relations to labour contributions. Plot size, and growing tomatoes or onions as main crops associate positively with labour contribution. 
We conclude that it is important for WUAs to note that their governing principles, regarding conflict management and equity and fairness in particular, influence how much labour each member willingly contributes to maintenance. Ensuring that conflicts are resolved to the satisfaction of all parties involved and being unbiased in the distribution of irrigation resources should therefore be encouraged. It is also important that WUAs observe and encourage activities that can improve water availability to minimise water related conflicts whiles ensuring equity and fairness. An example can be to resort to ground water use. A lot of water is wasted through the canal systems due to seepage. Farmers can be assisted to construct ground water structures where surface water reservoirs only serve as recharging facilities. This makes the irrigation facilities semi-communal thereby reducing water related conflicts while motivating high labour investments to maintain irrigation systems.

In terms of research recommendations, the fact that 73 observations ( $41 \%$ of the sample) in the time preferences experiment had to be dropped, as they made implausible choices, may to a certain extent have affected the results. Results of a Probit analysis exploring the underlying factors (see Appendix 5.C) indicate that farmers with relatively high household wealth and low mobility are significantly more likely to show irrational behaviour in the experiment. Future studies using Convex Time Budget (CTB) games for soliciting time preferences, like we used, are therefore advised to explore ways in which the high drop-out rates of farmers with relatively high wealth and low mobility can be reduced. 


\section{Appendix 5.A: Convex Time Budget (CTB) design}

The experimental design had 15 convex budgets in which participants had to make choices over how to allocate 50 tokens between two points in time, one time being earlier, $t$, and the other being later, $t+k$. The later points in time varied across decisions to allow for time discounting. A (1x3) design approach was used by crossing the earlier payment date, $t=7$ with three delay periods, $k=(21,49,77)$. In all, there were three $(t, t+k)$ cells, with each cell having five CTB choices, making a total of 15 choices per subject (Table 5.A.1). Unlike in Andreoni and Sprenger $(2010,2012)$, the earliest time to receive payments in our experiment was seven (7) days from the day of the experiment. This was to avoid present bias and to simplify the estimation methods since our interest was in discount rates. To avoid differential weekday effects, $t$ and $k$ were both multiples of 7 . Tokens allocated to earlier and later payments had values of $\mathrm{a}_{t}$ and $\mathrm{a}_{t+k}$ respectively. Values of $\mathrm{a}_{t}$ varied from GHC0.10 to GHC0.30, while $\mathrm{a}_{t+k}$ had a value of GHC0.40 in all cases (making the future-value budget, $m$, GHC20.00). The gross interest rate over $k$ days was $\mathrm{a}_{t+k} / \mathrm{a}_{t}=1+r$, so that the standardized daily net interest rate was $(1+r)^{1 / k}-1$. Table 5.A.1 presents details of the choice sets that were used.

Table 5.A.1: Convex Time Budget choice sets

\begin{tabular}{cccccccc}
\hline $\begin{array}{c}\mathrm{t} \\
\text { (earlier date) }\end{array}$ & $\begin{array}{c}\mathrm{k} \\
\text { (delay) }\end{array}$ & Tokens & $\mathrm{a}_{t}$ & $\mathrm{a}_{t+k}$ & $(1+r)$ & $\begin{array}{c}\text { Daily net } \\
\text { interest rates } \\
\text { (percent) }\end{array}$ & $\begin{array}{c}\text { Quarterly } \\
\text { compounded annual } \\
\text { rate (percent) }\end{array}$ \\
\hline 7 & 21 & 50 & 0.30 & 0.4 & 1.33 & 1.38 & 2502.5 \\
7 & 21 & 50 & 0.25 & 0.4 & 1.60 & 2.26 & 8728.6 \\
7 & 21 & 50 & 0.20 & 0.4 & 2.00 & 3.36 & 27128.4 \\
7 & 21 & 50 & 0.15 & 0.4 & 2.67 & 4.78 & 82626.0 \\
7 & 21 & 50 & 0.10 & 0.4 & 4.00 & 6.82 & 272700.6 \\
7 & 49 & 50 & 0.30 & 0.4 & 1.33 & 0.59 & 458.5 \\
7 & 49 & 50 & 0.25 & 0.4 & 1.60 & 0.96 & 1147.8 \\
7 & 49 & 50 & 0.20 & 0.4 & 2.00 & 1.42 & 2698.3 \\
7 & 49 & 50 & 0.15 & 0.4 & 2.67 & 2.02 & 6450.8 \\
7 & 49 & 50 & 0.10 & 0.4 & 4.00 & 2.87 & 17043.8 \\
7 & 77 & 50 & 0.30 & 0.4 & 1.33 & 0.37 & 223.9 \\
7 & 77 & 50 & 0.25 & 0.4 & 1.60 & 0.61 & 490.3 \\
7 & 77 & 50 & 0.20 & 0.4 & 2.00 & 0.90 & 1009.6 \\
7 & 77 & 50 & 0.15 & 0.4 & 2.67 & 1.28 & 2116.5 \\
7 & 77 & 50 & 0.10 & 0.4 & 4.00 & 1.82 & 4889.3 \\
\hline
\end{tabular}


The game was repeated for $t=14,28$ days giving a total of 45 choices per farmer. Unfortunately, only $t=7$ can be used in the analysis due to an error in the design when all 45 choices are considered. When all 45 decisions had been made, we randomly selected one of the 45 decisions to determine actual earnings of participants. Subjects were assigned to research assistants to help in record keeping but decisions were solely the responsibility of the subjects. Time was allowed for participants to ask questions for clarification before the experim ent was perform ed. Each participant was given GHC3.00 at the end as a "thank you" for taking part in the study.

The values of $\mathrm{a}_{t}$ and $\mathrm{a}_{t+k}$ were chosen to accommodate the fact that interest rates in Ghana are relatively high due to the rapid inflation and the resultant depreciation of the Ghana Cedi. To make the game understandable and realistic in terms of market value, the chosen daily and annual interest rates were higher than those used by Andreoni and Sprenger (2012).

Following Andreoni and Sprenger (2012), we estimated the discount factor from the data set obtained through the experiment. From the experimental design, the future-value budget constraint is

$$
(1+r) c_{t}+c_{t+k}=m
$$

Where

$c_{t} \quad=$ experimental earnings at earlier time, $t$

$c_{t+k}=$ experimental earnings at a later time, $t+k$

$(1+r)=$ experimental gross interest rate

$m \quad$ = experimental budget

We posit a time separable constant relative risk aversion (CRRA) utility function discounted by the quasi-hyperbolic $\delta$ discounting function

$$
U\left(c_{t}, c_{t+k}\right)=\left(c_{t}-w_{1}\right)^{\alpha} / \alpha+\delta^{k}\left(c_{t+k}-w_{2}\right)^{\alpha} / \alpha
$$


Where

$\delta \quad=$ daily discount factor

$\alpha \quad=$ CRRA curvature parameter

$w_{1}, w_{2}=$ background consumption

Maximizing (2) subject to the budget constraint (1) gives the tangency condition

$$
\frac{c_{t}-w_{1}}{c_{t+k}-w_{2}}=\left(\delta^{k}(1+r)\right)^{\frac{1}{\alpha-1}}, \quad \text { if } t>0
$$

and an intertemporal formulation of a Stone-Geary linear demand for $C_{t}$,

$C_{t}=\left[\frac{1}{1+(1+r)\left(\delta^{k}(1+r)\right)^{\left(\frac{1}{\alpha-1}\right)}}\right] W_{1}+\left[\frac{\left(\delta^{k}(1+r)^{\left(\frac{1}{\alpha-1}\right)}\right.}{1+(1+r)\left(\delta^{k}(1+r)\right)^{\left(\frac{1}{\alpha-1}\right)}}\right]\left(m-w_{2}\right)$

Equation (4) and the parameters $\delta, \alpha, w_{1}$, and $w_{2}$ are estimated using nonlinear least squares.

Also, linearizing (3) gives

$$
\ln \left(\frac{c_{t}-w_{1}}{c_{t+k}-w_{2}}\right)=\left(\frac{\ln \delta}{\alpha-1}\right) \cdot k+\left(\frac{1}{\alpha-1}\right) \cdot \ln (1+r) \quad \text { if } t>0
$$

which can be written as

$$
\ln \left(\frac{c_{t}-w_{1}}{c_{t+k}-w_{2}}\right)=\gamma_{1} k+\gamma_{2} \ln (1+r) \quad \text { if } t>0
$$

Given an additive error structure and projected background consumption, equation (6) can be estimated using a two-limit censored Tobit regression to take care of the censoring nature of the data. 
From (5) and (6),

$$
\alpha=\frac{1}{\gamma_{2}}+1, \quad \text { and } \quad \delta=\exp \left(\frac{\gamma_{1}}{\gamma_{2}}\right) \text { is the daily discount factor }
$$

The daily rate of time preference, denoted by $\theta$, follows from the daily discount factor:

$$
\theta=\frac{1}{\delta}-1
$$

From GLSS 6 (2014, p 136), the mean annual household expenditure for both food and nonfood in the three regions are: Northern $(\mathbb{C} 7,153)$, Upper East $(\mathbb{C} 6,210)$, and Upper West $(\mathbb{C} 5,991)$, giving an average of $\mathbb{C} 6,451.33$ for the study area. This implies a daily household consum ption of $\mathbb{C} 17.67$. We therefore use $\mathbb{C} 18.00$ (an equivalent of about $\$ 7.65$ as at January 2014) as the background consumption in the Tobit estimates. Thus $w_{1}=w_{2}=-18$. Table 5.A.2 presents the aggregate estimates using NLS and two-limit Tobit regressions (for $w_{1}=$ $w_{2}=-0.01$ and $\left.w_{1}=w_{2}=-18\right)$. Aggregate estimation results are sensitive to the estimation methods and the assumption about the background parameters as indicate in the table. Table 5.A.3 summarizes the individual discounting and curvature parameter estimates from the NLS approach (with $w_{1}=w_{2}=0$ ). 
Table 5.A.2: Aggregate estimates from sub-sample of no multiple switching and with valid individual level estimates (107 participants)

\begin{tabular}{lcccccc}
\hline & $(1)$ & $(2)$ & $(3)$ & $(4)$ & $(5)$ & $(6)$ \\
& NLS & NLS & NLS & Tobit & NLS & Tobit \\
\hline CRRA curvature: $\alpha$ & $0.649^{* * * *}$ & $0.644^{* * *}$ & $0.661^{* * * *}$ & $0.945^{* * * *}$ & $-0.436^{* * * *}$ & $0.390^{* * * *}$ \\
& $(0.0271)$ & $(0.0487)$ & $(0.0216)$ & $(0.00745)$ & $(0.0603)$ & $(0.0730)$ \\
Annual discount rate & $3.873^{* * *}$ & $46.03^{* * *}$ & $45.97^{* * *}$ & $203.4^{* * *}$ & $47.80^{* * *}$ & $122.5^{* * *}$ \\
& $(1.583)$ & $(12.24)$ & $(12.14)$ & $(72.31)$ & $(12.08)$ & $(39.78)$ \\
$w_{1}$ & 0.102 & -0.248 & & & \\
$w_{2}$ & $(0.264)$ & $(0.453)$ & & & & \\
$w_{1}=w_{2}$ & $-9.770^{* * *}$ & & & & \\
Daily discount factor: $\delta$ & $(2.105)$ & - & & & & -18 \\
& $0.996^{* * *}$ & $0.990^{* * *}$ & $0.990^{* * *}$ & $0.986^{* * *}$ & $0.989^{* * *}$ & $0.987^{* * *}$ \\
\hline Observations & $(0.000886)$ & $(0.000706)$ & $(0.000701)$ & $(0.000955)$ & $(0.000671)$ & $(0.000871)$ \\
\hline
\end{tabular}

Standard errors in parentheses

${ }^{*} p<0.10,{ }^{* *} p<0.05,{ }^{* * *} p<0.01$

Table 5.A.3: Individual discounting and curvature parameter estimates

\begin{tabular}{|l|l|l|l|l|l|l|}
\hline & $\mathrm{N}$ & Median & $\begin{array}{l}5^{\text {th }} \\
\text { percentile }\end{array}$ & $\begin{array}{l}95^{\text {th }} \\
\text { percentile }\end{array}$ & Min & Max \\
\hline $\begin{array}{l}\text { Daily discount } \\
\text { factor: delta }\end{array}$ & 107 & 0.9879 & 0.9468 & 1.0072 & 0.8904 & 1.0125 \\
\hline $\begin{array}{l}\text { Curvature: } \\
\text { alpha }\end{array}$ & 107 & 0.8478 & -0.6429 & 0.9977 & -2.6579 & 0.9990 \\
\hline
\end{tabular}

Notes: Estimated with non-linear least squares (NLS) with $w_{1}=w_{2}=0$. 
Appendix 5.B: OLS and GLM regression results for labour contributions

\begin{tabular}{|c|c|c|c|c|}
\hline & $\begin{array}{l}\text { 1. OLS overall } \\
\text { governance }\end{array}$ & $\begin{array}{l}\text { 2. OLS gov. } \\
\text { dimensions }\end{array}$ & $\begin{array}{l}\text { 3. GLM overall } \\
\text { governance }\end{array}$ & $\begin{array}{l}\text { 4. GLM gov. } \\
\text { dimensions }\end{array}$ \\
\hline $\begin{array}{l}\text { Overall governance } \\
\text { Perception }\end{array}$ & $\begin{array}{l}1.116^{* * *} \\
(0.385) \\
\end{array}$ & & $\begin{array}{l}1.116 * * * \\
(0.357)\end{array}$ & \\
\hline Participation & & $\begin{array}{l}0.043 \\
(0.378) \\
\end{array}$ & & $\begin{array}{l}0.043 \\
(0.341) \\
\end{array}$ \\
\hline Accountability & & $\begin{array}{l}0.058 \\
(0.361) \\
\end{array}$ & & $\begin{array}{l}0.058 \\
(0.325) \\
\end{array}$ \\
\hline $\begin{array}{l}\text { Conflict } \\
\text { Management }\end{array}$ & & $\begin{array}{l}0.731 * \\
(0.398)\end{array}$ & & $\begin{array}{l}0.731 * * \\
(0.358)\end{array}$ \\
\hline $\begin{array}{l}\text { Transparency and } \\
\text { Cooperation }\end{array}$ & & $\begin{array}{l}0.427 \\
(0.474)\end{array}$ & & $\begin{array}{l}0.427 \\
(0.427)\end{array}$ \\
\hline Equity and fairness & & $\begin{array}{l}0.660^{* *} \\
(0.287)\end{array}$ & & $\begin{array}{l}0.660 * * \\
(0.258) \\
\end{array}$ \\
\hline Sustainable use & & $\begin{array}{l}0.306 \\
(0.296)\end{array}$ & & $\begin{array}{l}0.306 \\
(0.266)\end{array}$ \\
\hline Time preference & $\begin{array}{l}-4.326 \\
(5.072)\end{array}$ & $\begin{array}{l}-5.295 \\
(5.261) \\
\end{array}$ & $\begin{array}{l}-4.326 \\
(4.699)\end{array}$ & $\begin{array}{l}-5.295 \\
(4.739) \\
\end{array}$ \\
\hline Age & $\begin{array}{l}-0.022 * * \\
(0.010)\end{array}$ & $\begin{array}{l}-0.024 * * \\
(0.010)\end{array}$ & $\begin{array}{l}-0.022 * * \\
(0.009)\end{array}$ & $\begin{array}{l}-0.024 * * * \\
(0.009)\end{array}$ \\
\hline Sex & $\begin{array}{l}-0.349 \\
(0.242)\end{array}$ & $\begin{array}{l}-0.345 \\
(0.249) \\
\end{array}$ & $\begin{array}{l}-0.349 \\
(0.224)\end{array}$ & $\begin{array}{l}-0.345 \\
(0.225) \\
\end{array}$ \\
\hline Education & $\begin{array}{l}-0.073 * * * \\
(0.023)\end{array}$ & $\begin{array}{l}-0.074 * * * \\
(0.024)\end{array}$ & $\begin{array}{l}-0.073 * * * \\
(0.021)\end{array}$ & $\begin{array}{l}-0.074 * * * \\
(0.022)\end{array}$ \\
\hline $\begin{array}{l}\text { Household labour } \\
\text { Force }\end{array}$ & $\begin{array}{l}-0.008 \\
(0.054)\end{array}$ & $\begin{array}{l}0.001 \\
(0.064)\end{array}$ & $\begin{array}{l}-0.008 \\
(0.050)\end{array}$ & $\begin{array}{l}0.001 \\
(0.058)\end{array}$ \\
\hline Plot size & $\begin{array}{l}1.573 \\
(1.160)\end{array}$ & $\begin{array}{l}1.786 \\
(1.162) \\
\end{array}$ & $\begin{array}{l}1.573 \\
(1.075)\end{array}$ & $\begin{array}{l}1.786 * \\
(1.047) \\
\end{array}$ \\
\hline Group size & $\begin{array}{l}0.006 \\
(0.005) \\
\end{array}$ & $\begin{array}{l}0.007 \\
(0.005) \\
\end{array}$ & $\begin{array}{l}0.006 \\
(0.005) \\
\end{array}$ & $\begin{array}{l}0.007 \\
(0.005) \\
\end{array}$ \\
\hline Age of scheme & $\begin{array}{l}0.011 \\
(0.007) \\
\end{array}$ & $\begin{array}{l}0.007 \\
(0.008) \\
\end{array}$ & $\begin{array}{l}0.011 \\
(0.007) \\
\end{array}$ & $\begin{array}{l}0.007 \\
(0.008) \\
\end{array}$ \\
\hline Head-end plot & $\begin{array}{l}-1.275^{* * *} \\
(0.285)\end{array}$ & $\begin{array}{l}-1.189 * * * \\
(0.227)\end{array}$ & $\begin{array}{l}-1.275^{* * * *} \\
(0.264)\end{array}$ & $\begin{array}{l}-1.189 * * * \\
(0.204)\end{array}$ \\
\hline Tail-end plot & $\begin{array}{l}0.120 \\
(0.396)\end{array}$ & $\begin{array}{l}0.096 \\
(0.399)\end{array}$ & $\begin{array}{l}0.120 \\
(0.367)\end{array}$ & $\begin{array}{l}0.096 \\
(0.359)\end{array}$ \\
\hline Tomatoes & $\begin{array}{l}1.988 * * * \\
(0.282) \\
\end{array}$ & $\begin{array}{l}2.101 * * * \\
(0.274) \\
\end{array}$ & $\begin{array}{l}1.988 * * * \\
(0.262) \\
\end{array}$ & $\begin{array}{l}2.101 * * * \\
(0.247) \\
\end{array}$ \\
\hline Onions & $\begin{array}{l}1.313 * * * \\
(0.337) \\
\end{array}$ & $\begin{array}{l}1.358 * * * \\
(0.363) \\
\end{array}$ & $\begin{array}{l}1.313 * * * \\
(0.312)\end{array}$ & $\begin{array}{l}1.358 * * * \\
(0.327) \\
\end{array}$ \\
\hline Upper East & $\begin{array}{l}-1.394 * * * \\
(0.317)\end{array}$ & $\begin{array}{l}-1.054 * * * \\
(0.359)\end{array}$ & $\begin{array}{l}-1.394 * * * \\
(0.293)\end{array}$ & $\begin{array}{l}-1.054 * * * \\
(0.323)\end{array}$ \\
\hline Upper West & $\begin{array}{l}0.923 * \\
(0.512)\end{array}$ & $\begin{array}{l}1.366^{* *} \\
(0.577)\end{array}$ & $\begin{array}{l}0.923 * \\
(0.475)\end{array}$ & $\begin{array}{l}1.366^{* * * *} \\
(0.519)\end{array}$ \\
\hline Constant & $\begin{array}{l}-1.290 \\
(1.479) \\
\end{array}$ & $\begin{array}{l}-5.056 \\
(2.968) \\
\end{array}$ & $\begin{array}{l}-1.290 \\
(1.370)\end{array}$ & $\begin{array}{l}-5.056^{*} \\
(2.673)\end{array}$ \\
\hline Observations & 107 & 107 & 107 & 107 \\
\hline R-squared & 0.444 & 0.495 & & \\
\hline
\end{tabular}

Notes: $* * * \mathrm{p}<0.01, * * \mathrm{p}<0.05, * \mathrm{p}<0.1$; Robust standard errors in parenthesis 
Appendix 5.C: Probit regression results of being included in the sample of 107 participants

\begin{tabular}{|l|l|}
\hline Variable & Coefficients \\
\hline Age & 0.005 \\
& $(0.008)$ \\
\hline Sex & 0.029 \\
& $(0.200)$ \\
\hline Education & 0.021 \\
& $(0.025)$ \\
\hline Household wealth & $-0.036^{* * *}$ \\
& $(0.012)$ \\
\hline Christian & -0.064 \\
& $(0.177)$ \\
\hline Muslim & -0.051 \\
& $(0.281)$ \\
\hline Mobility & $0.025^{* *}$ \\
& $(0.011)$ \\
\hline Constant & 0.268 \\
& $(0.480)$ \\
\hline Observations & 180 \\
Wald chi2(7) & 14.96 \\
Prob $>$ chi2 & 0.0365 \\
Pseudo R2 & 0.0389 \\
Log pseudolikelihood & -116.80653 \\
\hline
\end{tabular}




\section{CHAPTER 6}

\section{Synthesis}

\subsection{Introduction}

Agriculture which is dependent on water resources is a panacea in alleviating poverty in developing countries. Amidst climate change concerns, population growth, and urbanization, among other factors, there is no doubt that irrigation can help in maximizing the use of scarce water resources. Irrigation resources are common pool resources and if care is not taken, they can often be overexploited or create negative externalities that may worsen the changing trends of socioecological systems. Good governance is imperative for effective and efficient use of scarce resources (Agrawal, 2003; Ostrom, 1990; Yu et al., 2016).

Governance is broad, involving different actors at different levels. It is generally implemented through the use of rules and regulations to control resource use (Herrera et al., 2014). Proper governance of common pool resources, such as communal irrigation schemes, depends on the specific institutional arrangements that are in place (Agrawal, 2003; Norton, 2004; Howarth et al., 2005; Venot and Hirvonen, 2013; Poussin et al., 2015). As broad as governance may be, its effectiveness in resource use can be assessed from different dimensions such as accountability, participation, transparency, and cooperation (Goran and Court, 2002; GWP 2009; Tortajada, 2010; Lautze et al., 2011). 
In Ghana, irrigation schemes are mostly constructed to improve rural livelihoods. As such, most schemes are small-scale in nature and are situated in local communities. The prevalence of management and coordination challenges in large-scale irrigation schemes has created a preference for small-scale irrigation (Birner et al., 2010; van Edig et al., 2003). These schemes are managed by Water User Associations (WUAs), just as in most parts of Africa and beyond (Mutambara et al., 2016). The daily activities of these user groups play an important role in the sustainability of the schemes. The involvement of users in irrigation management inculcates in users a sense of ownership of the resources (for effective maintenance) and also eases burdens on governments. The underperformance and unsustainability of most irrigation facilities in Africa is however partly blamed on poor operation and maintenance by user groups (Mutambara et al., 2016; Namara et al., 2011; Lamptey et al., 2011). Good governance of irrigation systems makes three kinds of impacts: high production performance, satisfied users (quality of life and benefits from irrigation systems), and sustainable systems over a long period of time (Abernethy, 2010).

In this thesis, we assessed and discussed governance dimensions of WUAs that affect the development and sustainability of small-scale irrigation systems in northern Ghana. To do so, we collected and used primary data from northern Ghana, complemented with field experiments. This thesis contributes to the understanding of interlinkages that yield better performance and sustainability of irrigation systems necessary for improving irrigated agriculture. As broad as governance is, it may be better assessed through its dimensions (Chapter 2). The performance of irrigation schemes may be dependent on governing strategies of WUAs (Chapter 3). For self-governed resources such as irrigation systems, users play key roles in sustaining irrigation resources by contributing to collective maintenance (Chapter 4). User contributions are forms of investments that may be influenced by the time preferences of users (Chapter 5). Relevant theoretical frameworks are used in each chapter to guide empirical analyses. The main message from the different chapters is that governance affects decisions that water users take; either to take part in sustainable governance, or not to take part. In the following sections we present the main findings from each chapter and deliberate on policy implications. 


\subsection{Measuring irrigation governance}

The claim that good governance is essential for adequate performance of irrigation systems cannot be overemphasized. The question is: what measures of irrigation governance can be used to assess the performance and sustainability of WUA-managed irrigation schemes? In Chapter 2, we assessed irrigation governance in northern Ghana from a user-based approach. Measures of irrigation governance are often challenged with a lack of availability of objective data. Additionally, for common pool resources, local users have the greatest stake in the sustainability of resources (Abernethy, 2010; Agrawal, 2002). Incentives may drive their actions in resource use and maintenance. Inadequate records of irrigation management data in Ghana and the fact that certain aspects of governance are best measured subjectively to reflect the reality on the ground (Kaufmann et al. 2011, 2009, 2004) also motivated the use of subjective measures.

Following resource governance frameworks in Agrawal (2003) and Ostrom (2009), we devised indicators that can be used to assess sustainable irrigation governance. The indicators were characterized into six dimensions of governance: participation, accountability, conflict management, transparency and cooperation, equity and fairness, and sustainable use. These dimensions were rated by local water users through their indicators. We also examined the relationship between the resulting irrigation governance dimensions and some objective factors that possibly drive users' assessm ents of governance.

We found that, on average, overall irrigation governance in northern Ghana is "good" even though one would have preferred a "very good" outcome. The different dimensions of governance however had varied ratings. Conflict management had the best score while sustainable use had the lowest score. The lack of progress in some irrigation facilities in northern Ghana, attributed to bad governance (Dittoh et al., 2013a; Poussin et al., 2015; Venot and Hirvonen, 2013), may therefore be specific to some dimensions of governance depending on physical conditions and characteristics of governing WUAs, which may need attention.

We also found that the availability of water through high precipitations and plot locations of irrigators are factors that significantly influence irrigation governance perceptions. Farmers 
located at both head-ends and tail-ends significantly assessed sustainability as being low due to infrastructural damages that need urgent attention. A question arising from these assessments is whether the sustainability of irrigation facilities is better looked at as an issue of infrastructural functionality or that of WUA's functionality. Constructing irrigation facilities and constituting WUAs for effective management helps to reduce poverty, but it is more important to ensure that all defects are corrected and that broken parts are replaced. If this is not done, users may abandon them as reported in Birner et al. (2010), in which case the aim to eradicate poverty would have been defeated. Routine repairs of major infrastructural damages beyond the capacity of farmer groups are important in sustaining irrigation facilities. Group existence is important for sustainable management of the commons but the survival of the commons should be the main target for sustainable production.

Measuring irrigation governance as done in this study is the first in its kind. It may be good to replicate it in similar environments to ascertain to what extent our findings are plausible.

\subsection{Irrigation governance and performance}

The main goal for irrigation infrastructural investments in dry areas of Africa is to improve the productivity of agriculture in order to reduce hunger and poverty (Oates et al., 2015; Svendsen et al., 2009). A number of studies indicate that the area currently under irrigation in Ghana is underperforming in terms of yield and cropping intensity (Namara et al., 2011; Venot and Hirvonen, 2013). Some attribute this to poor governance (Venot and Hirvonen, 2013; Dittoh et al., 2013b; Poussin et al., 2015). Mutambara et al. (2016) blame part of the poor performance of African schemes on weak Irrigation Management Committees or WUAs. In Chapter 3, we contribute to the debate on the role of governance in sustaining common pool resources by empirically testing the association between governance dimensions (as measured in Chapter 1) and irrigation performance as measured by crop yields.

We found that participation perception strongly associates with crop yields of irrigated land. Estimated coefficients for the other dimensions are either significant or even negative. This 
suggests that participation in the joint management of irrigation schemes is a crucial dimension in sustaining irrigation schemes through improved performance. Conflict management, on the other hand, had a significant negative association with crop yields. The implication of this unanticipated finding is that rules and regulations put in place to avert conflicts contribute to free riding and other anti-social behaviour by users. More research is needed to examine whether this result can also be found in jointly managed irrigation schemes located elsewhere and in other common pool resources, and to what extent the potential explanation that we offer can be validated.

That notwithstanding, we do not know of any empirical study of irrigation schemes that have opened this black box of governance and identified the relative contribution of each dimension to the performance of schemes. For further research, it may be good to also assess water use effects on farm productivity directly as opposed to indirect assessments through governance as done in this study. This is necessary because efficient use of water maximizes productivity of scarce water resources. However, we could not measure this effect directly because irrigation water use in Ghana is not measured volumetrically.

\subsection{Cooperativeness in sustaining irrigation systems}

Maintenance is part and parcel of sustaining resources. For self-managed resources, the user plays a critical role in maintaining resources through their contributions, mostly in the form of com munal labour. Users' contributions associate with many factors, including their perceived governance and cooperativeness, i.e. the willingness of users to cooperate in collective activities. Collective maintenance is difficult without cooperation among members.

In Chapter 4, we assessed how users' governance perceptions and cooperativeness relate to users' contributions towards irrigation resource maintenance. We estimated cooperativeness through a Voluntary Contribution Mechanism (VCM) game on survey respondents. We also examined the relation of perceived governance to users' cooperativeness. The results confirmed our expectation that positive governance perceptions and cooperativeness increases users' labour contribution towards m aintenance. Sustainable use is the governance 
perception dimension that influences labour contributions. User perceptions of accountability relates positively with cooperativeness while conflict management is found to have a negative relation to cooperativeness. The negative association between conflict management and cooperation comes somewhat as a surprise. Maybe it is a result of selfish desires, where users take the opportunity to free-ride in their contributions when they observe a congenial environment in their group with good management of conflicts. Users who perceive conflict management to be good may cooperate less when they expect that disagreements will probably be well handled.

These findings have implications for policy directions in sustaining resources. Conflict management for instance had the best assessment, yet related to cooperativeness negatively. This could mean that aspects of governance that are thought to be well handled by users are seen as norm al practices and $\mathrm{m}$ ay not necessarily influence users' labour contributions significantly. In tackling free-rider problems in CPRs, care needs to be taken not to underrate the potential positive impact that some good indicators can have on free riding.

\subsection{Time preference and collective maintenance}

Tim e preference is an integral part of farm ers' decisions regarding production activities including participation in conservation practices (Duquette et al., 2011; Shiferaw et al., 2009). Time preference can be affected by many past and current experiences, among which poverty is one of the most cited. In Chapter 5, we explained that labour contribution to maintenance is a form of investment with expected future returns and, therefore, is associated with the time preferences of users. Users with high time preference (considered as being more impatient) are less likely to invest in maintenance, other things being equal.

We elicited the time preference of water users from a field experiment using a Convex Time Budget (CTB) method. This chapter further examined factors that explain time preferences in farmers. The time preferences estimated through the experiment are found to have a negative but not statistically significant association with labour contributions. Wealth is found to have a negative correlation with time preferences (in accordance with Tanaka and Munro, 2012; 
Yesuf, 2004), but the estimated coefficient is only significantly different from zero when total household wealth is used as an indicator instead of wealth per capita. Evidence also suggests that farmers with plots in the head-ends and farmers growing tomatoes or onions tend to have relatively high time preferences.

There is an increasing body of research on factors associated with time preferences, but as far as we know, the role of time preference and its determinants in decisions regarding maintenance of small-scale irrigation systems has not yet been examined. Our findings thus contribute to the body of literature.

\subsection{Concluding remarks}

Insights from the different chapters in this thesis support the notion that good governance is important in the sustenance of irrigation resources as commons. It is expected that good governance contributes to higher yields and lower poverty levels among irrigated-farm households. The problem had been of how to measure governance. This study has paved the way for more debates on governance measures and their effects on sustaining irrigation resources. The user-based approach in the study confirms that, indeed, perceptions matter in the assessment of governance, as explained by Kaufmann et al. (2011).

With subjective measures, one is able to assess core governance issues that are very relevant (especially for cooperativeness in CPRs) yet mostly go unnoticed or unrecorded, e.g. "fairness", which is an observed phenomenon that is subjective. For common pool resources, fairness in actions and inactions can deter users from doing the right things to sustain resources. The ability to judge fairness depends however on what is observed and interpreted by the concerned, the water user. Indicators of governance may however correlate as it becomes difficult to perfectly distinguish the different dimensions of governance. Factor analysis can help in identifying underlying constructs that capture governance perceptions. The correlations among the governance dimensions in this study are not severe as the VIFs are not that high (all of them are less than 5). We therefore prefer to stick to the six dimensions of governance that we identified in Chapter 2. 
Findings from this thesis indicate that good governance by WUAs is important in sustaining small-scale irrigation in northern Ghana. But to say that bad governance has resulted in the collapse of common pool resources may be stretching the point. For effective interventions, specific dimensions of governance could be tackled. Users' participation in the joint management of irrigation schemes however seem to be a crucial dimension in successful governance of irrigation schemes. Participation affects performance of irrigation systems and collective maintenance, confirming the need for users' inclusiveness in the management of CPRs as advocated by scholars.

The government of Ghana is currently introducing a policy in the agricultural sector to help fight poverty, dubbed "planting for food and jobs". The aim is to construct more dam $\mathrm{s}$ in farming communities to boost agriculture. This study may help to identify which aspects of the governance of WUAs need attention for achieving sustainable production, and so provide support for the "planting for food and jobs" agenda. A concern of interest is whether surface water irrigation through canals is a good approach in tackling agricultural production in Ghana and in dry clim ates in general. 'Sustainable use' as a governance dim ension had the lowest score among the dimensions assessed in this thesis. The method of water allocation in Ghana is not volumetric (not measured by quantity) but judged through time allowed for water use per day. A lot of water is wasted through this method coupled with wastage through seepage and evapotranspiration in high temperatures. Water reservoirs (dams) are good communal resources but may be better maintained for domestic and livestock watering. Promoting the use of water-conserving irrigation techniques such as drip irrigation, and ground water techniques is essential. With ground water, surface water reservoirs may only serve as means to recharge water channels. 


\section{References}

Abernethy, C. L. (2010). Governance of Irrigation Systems: Does History Offer Lessons for Today? Irrigation and Drainage, 59(1), 31-39.

Acheampong, E. N., and Venot, J. (2010). Water User Associations in Northern Ghana:

From Institutional Panacea to Reality Check. Accra: IWMI.

ADF (African Development Fund). (2008). Ghana Country Gender Profile.

AGRA. (2013). Africa Agriculture Status Report: Focus on Staple Crops. Alliance for a Green Revolution in Africa. Nairobi, Kenya.

Agrawal, A. (2001). Common Property Institutions and Sustainable Governance of Resources. World Development, 29(10), 1649-1672.

Agrawal, A. (2002). Common Resources and Institutional Sustainability. In E. Ostrom, T.

Dietz, N. Dolsak, P. C. Stern, S. Stonich, and E. U. Weber (Eds.), The Drama of the Commons (pp. 41-54). Washington, D.C.: National Academy Press.

Agrawal, A. (2003). Sustainable Governance of Common Pool Resources: Context, Methods, and Politics. Annual Review of Anthropology, 32(1), 243-262.

Agrawal, A. (2014). Studying the Commons, Governing Common-pool Resource Outcomes:

Some Concluding Thoughts. Environmental Science and Policy, 36, 86-91.

Aida, T. (2012). Social Capital as an Instrument for Common Pool Resource Management: A Case Study of Irrigation Management in Sri Lanka. Journal of Behavioral Economics and Finance, 5, 225-230.

Akresh, R., Chen, J. J., and Moore, C. (2016). Altruism , Cooperation, and Efficiency: Agricultural Production in Polygynous Households. Economic Development and Cultural Change, 64(4), 661-696.

Akudugu, M. A., Nyamadi, B. V., and Dittoh, S. (2016). Transforming Smallholder Agriculture in Africa through Irrigation : An Assessm ent of Irrigation Im pact Pathways in Ghana. Invited paper presented at the 5th International Conference of the African Association of Agricultural Economists, September 23-26, 2016, Addis Ababa, Ethiopia. Anderies, J. M., Janssen, M. A., Bousquet, F., Cardenas, J. C., Castillo, D., Lopez, M. C., Wutich, A. (2011). The Challenge of Understanding Decisions in Experimental Studies of Common Pool Resource Governance. Ecological Economics, 70(9), 1571-1579. Andersen, S., Harrison, G. W., Lau, M. I., and Rutström, E. E. (2008). Eliciting Risk and Time Preferences. Econometrica, 76(3), 583-618. 
Andreoni, J., Kuhn, M. A., and Sprenger, C. (2013). Measuring Time Preferences (NBER Working Paper Series No. 19392). Cambridge: National Bureau of Economic Research. Andreoni, J., and Sprenger, C. (2010). Estimating Time Preferences from Convex Budgets. Cambridge: National Bureau of Economic Research.

Andreoni, J., and Sprenger, C. (2012). Estimating Time Preferences from Convex Budgets. American Economic Review, 102(7), 3333-3356.

Araral, E. (2009). What Explains Collective Action in the Commons? Theory and Evidence from the Philippines. World Development, 37(3), 687-697.

Baerlein, T., Kasymov, U., and Zikos, D. (2015). Self-Governance and Sustainable Common Pool Resource Management in Kyrgyzstan. Sustainability, 7, 496-521.

Balmisse, S., Faure, G., and Ilu, I. Y. (2003). Integration of Existing Farming Systems in Hadejia Valley Irrigation Project. In J. Y. Jamin, B. L. Seiny, and C. Floret (Eds.), Savanes africaines: des espaces en mutation, des acteurs face à de nouveaux défis (p. 5). Garoua, Cameroun: Cirad-Prasac.

Bardhan, P. (1993). Analytics of the Institutions of Informal Cooperation in Rural Development. World Development, 21(4), 633-639.

Bardhan, P., and Dayton-Johnson, J. (2002). Unequal Irrigators: Heterogeneity and Commons Management in Large-Scale Multivariate Research. In E. Ostrom, T. Dietz, N. Dolšak, P. C. Stern, S. Stonich, and E. U. Weber (Eds.), The Drama of the Commons (pp. 87112). Washington DC: National Academy Press.

Bassi, N., Rishi, P., and Choudhury, N. (2010). Institutional Organizers and Collective Action: The Case of Water Users' Associations in Gujarat, India. Water International, 35(1), 18-33.

Becker, G. S., and Mullingan, C. B. (1997). The Endogenous Determination of Time Preference. The Quarterly Journal of Economics, 112(3), 729-758.

Bhanumurthy, K. V. (2002). Arguing a Case for the Cobb-Douglas. Review of Commerce Studies, 75-91.

Birner, R., McCarthy, N., Robertson, R., Waale, D., and Schiffer, E. (2010). Increasing Access to Irrigation: Lessons Learned from Investing in Small Reservoirs in Ghana. Paper Presented at the Workshop on "Agricultural Services, Decentralization, and Local Governance.” Accra, Ghana: International Food Policy Research Institute (IFPRI) - Ghana Strategy Support Program (GSSP).

Birner, R., Schiffer, E., Asante, F., Gyasi, O., and McCarthy, N. (2005). Analysis of 
Governance Structures for Water Resources Management in the White Volta Basin Ghana. Washington DC, USA.

Bos, M. G. (1997). Performance Indicators for Irrigation and Drainage. Irrigation and Drainage Systems, 11, 119-137.

Bos, M. G., Burton, M. a., and Molden, D. J. (2005). Irrigation and Drainage Performance Assessment - Practical Guidelines. Cambridge, USA: CABI Publishing.

Bravo, G., and Marelli, B. (2008). Irrigation Systems as Common-pool Resources. Journal of Alpine Research, 96(3), 15-26.

Burger, K., Warner, J., and Derix, E. (2010). Governance of the World Food System and

Crisis Prevention. Wageningen.

Cagetti, M. (2003). Wealth Accumulation Over the Life Cycle and Precautionary Savings. Journal of Business and Economic Statistics, 21(3), 339-353.

Cameron, A. C., and Miller, D. L. (2015). A Practitioner's Guide to Cluster- Robust Inference. Journal of Human Resouces, 50(2), 317-372.

Campbell, I. C. (2007). Perceptions, Data, and River Management: Lessons from the Mekong River. Water Resources Research, 43(2), 1-13.

Cardenas, J. C. (2011). Social Norms and Behavior in the Local Commons as seen through the Lens of Field Experiments. Environmental and Resource Economics, 48, 451-485.

Cárdenas, J. C., and Ostrom, E. (2004). What do People Bring into the Game? Experiments in the Field about Cooperation in the Commons. Agricultural Systems, 82(3), 307-326.

Cardenas, J. C., Rodriguez, L. A., and Johnson, N. (2011). Collective Action for Watershed Management: Field Experiments in Colombia and Kenya. Environment and Development Economics, 16(3), 275-303.

Carletto, C., Savastano, S., and Zezza, A. (2013). Fact or Artifact: The Impact of Measurement Errors on the Farm Size-Productivity Relationship. Journal of Development Economics, 103(1), 254-261.

Charness, G., and Viceisza, A. (2011). Comprehension and risk elicitation in the field: evidence from rural Senegal. mimeo.

Chea, C., Nang, P., Whitehead, I., Hirsch, P., and Thompson, A. (2011). Decentralised Governance of Irrigation Water in Cambodia: Matching Principles to Local Realities (CDRI Working Paper Series No. 62). Phnom Penh, Cambodia.

Chhotray, V., and Stoker, G. (2009). Governance Theory and Practice: A Cross-Disciplinary Approach. England, UK: Palgrave Macmillan. 
Chowdhury, S., and Squire, L. (2006). Setting Weights for Aggregate Indices: An application to the Commitment to Development Index and Human Development Index. Journal of Development Studies, 42(5), 761-771.

Cooke, E., Hague, S., and Mckay, A. (2016). The Ghana Poverty and Inequality Report: Using the $6^{\text {th }}$ Ghana Living Standards Survey. University of Sussex.

Cookey, P. E., Darnsawasdi, R., and Ratanachai, C. (2016). Performance Evaluation of Lake Basin Water Governance Using Composite Index. Ecological Indicators, 61, 466-482. Cornia, G. A. (1985). Farm Size, Land Yields and the Agricultural Production Function: An Analysis for Fifteen Developing Countries. World Development, 13(4), 513-534.

Cotula, L., Vermeulen, S., Leonard, R., and Keeley, J. (2009). Land Grab or Development Opportunity? Agricultural Investments and International Land Deals in Africa. London/Rome: IIED/FAO/IFAD.

De Janvry, A., and Sadoulet, E. (2016). Development Economics: Theory and Practice. London and New York: Routledge.

Delaney, S. (2012). Challenges and Opportunities for Agricultural Water Management in West and Central Africa: Lessons from IFAD Experience. (S. Delaney, Ed.). Rome, Italy: International Fund for Agricultural Development (IFAD).

Dietz, T., Bym olt, R., Belem vire, A., Van der Geest, K., de Groot, D., Millar, D., .. Zaal, F. (2013). PADev Guidebook: Participatory Assessment of Development. Amsterdam: KIT Publishers.

Dietz, T., Millar, D., Dittoh, S., Obeng, F., and Ofori-Sarpong, E. (2004). Climate and Livelihood Change in North East Ghana. In A.J.Dietz, R.Ruben, and A.Verhagen (Eds.), The Impact of Climate Change on Drylands with a Focus on West Africa (Vol. 39, pp. 149-172). Dordrecht/Boston/London: Kluwer Academic Publishers. Environment and Policy Series.

Dietz, T., Ostrom, E., and Stern, P. C. (2003). The Struggle to Govern the Commons. Science, 302, 1907-1912.

Dittoh, S., Bhattarai, M., and Akuriba, M. A. (2013a). Micro Irrigation-Based Vegetable Farming for Income, Employment and Food Security in West Africa. In M. A. Hanjra (Ed.), Global Food Security (pp. 177-199). Nova Science Publishers, Inc.

Dittoh, S., Awuni, J. A., and Akuriba, M. A. (2013b). Small Pumps and the Poor: A Field Survey in the Upper East Region of Ghana. Water International, 38(4), 449-464. Drechsel, P., and Olaleye, A. (2005). Adoption Driver and Constraints of Resource 
Conservation Technologies in sub-Saharan Africa. Accra.

Dreyfus, M. K., and Viscusi, W. K. (1995). Rates of Time Preference and Consumer Valuations of Automobile Safety and Fuel Efficiency. The Journal of Law and Economics, 38(1), 79-105.

Duflo, E., Kremer, M., and Robinson, J. (2011). Nudging Farm ers to Use Fertilizer : Theory and Experimental Evidence from Kenya. American Economic Review, 101(6), 23502390.

Duquette, E., Higgins, N. A. H., and Horowitz, J. (2011). Farm er Discount Rates :

Experimental Evidence. American Journal of Agricultural Economics, 94(2), 451-456.

FAO. (2011). The State of the World's Land and Water Resources for Food and Agriculture,

Managing Systems at Risk. London: Food and Agriculture Organization of the United

Nations, Rome and Earthscan.

FAO. (2014). Building a Common Vision for Sustainable Food and Agriculture: Principles

and Approaches. Rome: Food and Agriculture Organization of the United Nations.

Farrar, D. E., and Glauber, R. R. (1967). Multicollinearity in Regression Analysis: The

Problem Revisited. The Review of Economics and Statistics, 49(1), 92-107.

Faulkner, J. W., Steenhuis, T., Van De Giesen, N., Andreini, M., and Liebe, J. R. (2008).

Water Use and Productivity of Two Sm all Reservoir Irrigation Schem es in Ghana's

Upper East Region. Irrigation and Drainage, 57, 151-163.

Faures, J. M., and Mukherji, A. (2009). Trends and Drivers of Asian Irrigation. Rome.

Fehr, E., and Fischbacher, U. (2002). Why Social Preferences Matter - The Impact of Non-

Selfish Motives on Competition, Cooperation and Incentives. The Economic Journal, 112(478), 1-33.

Fehr, E., and Schmidt, K. M. (1999). A Theory of Fairness, Competition, and Cooperation.

Quarterly Journal of Economics, 114(3), 817-868.

Frederick, S., Loewenstein, G., and O’Donoghue, T. (2002). Tim e Discouning and

Preference : A Critical Tim e Review.Journal of Economic Literature, 40(2), 351-401.

Fujiie, M., Hayami, Y., and Kikuchi, M. (2005). The Conditions of Collective Action for

Local Commons Management: The case of Irrigation in the Philippines. Agricultural Economics, 33(2), 179-189.

Gallego-Ayala, J., Dimene, C. D. S., Munhequete, A., and Amos, R. (2014). Assessing the

Performance of Urban Water Utilities in Mozambique Using a Water Utility

Performance Index. Water SA, 40(4), 665-676. 
Garriga, R. G., and Foguet, A. P. (2010). Improved Method to Calculate a Water Poverty Index at Local Scale. Journal of Environmental Engineering, 136, 1287-1298.

Gelb, A., Ramachandran, V., Shah, M. K., and Turner, G. (2007). What Matters to African Firms? The Relevance of Perceptions Data. World Bank Policy Research Working Paper Series.

George, D., and Mallery, P. (2003). SPSS for Windows Step by Step: Answers to Selected Exercises (4th ed.). Boston: Allyn and Bacon.

Gleick, P. H. (2000). A Look at Twenty-first Century Water Resources Development. Water International, 25(1), 127-138.

Gliem, J. A., and Gliem, R. R. (2003). Calculating, Interpreting, and Reporting Cronbach 's Alpha Reliability Coefficient for Likert-Type Scales. In 2003 Midwest Research to Practice Conference in Adult, Continuing, and Community Education (pp. 82-88). Columbus.

GLSS6. (2014). Ghana Living Standards Survey Round 6: Main Report. Accra: Ghana Statistical Services.

Godoy, R., Jacobson, M., Castro, J. De, Aliaga, V., Rom ero, J., Godoy, R., ... Davis, A. (1998). The Role of Tenure Security and Private Time Preference in Neotropical Deforestation. Land Economics, 74(2), 162-170.

Greene, W. H. (1993). Econometric Analysis. Second edition. New York: Macmillan. GWP (Global Water Partnership). (2009). Assessment of Water Governance in Ghana. Ouagadougou, Burkina Faso: Global Water Partnership West Africa.

Gyasi, O., Schiffer, E., and Mccarthy, N. (2005). Community Needs Assessment and Local Water Governance Appraisal in the Upper East Region. Tamale Ghana.

Hardin, G. (1968). The Tragedy of the Commons. Science, 162(3859), 1243-1248.

Harmancioglu, N., Barbaros, F., and Cetinkaya, C. (2013). Sustainability Issues in Water Management. Water Resources Management, 27(6), 1867-1891.

Hausman, J. A. (1979). Individual Discount Rates and the Purchase and Utilization of Energy-using Durables. The Bell Journal of Economics, 10(1), 33-54.

Heltberg, R. (1998). Rural Market Imperfections and the Farm Size- Productivity Relationship: Evidence from Pakistan. World Development, 26(10), 1807-1826. Herrera, P. M., Davies, J., and Baena, P. M. (2014). Governance of the Rangelands in a Changing World. In P. M. Herrera, J. Davies, and P. M. Baena (Eds.), The governance of rangelands: Collective action for sustainable pastoralism (pp. 32-44). New York: 
Routledge.

Holden, S. T., Shiferaw, B., and Wik, M. (1998). Poverty, Market Imperfections and Time

Preferences : Of Relevance for Environm ental policy? Environment and Development Economics, 3, 105-130.

Hoogesteger, J. (2014). Building Blocks for Users' Participation in Water Governance:

Irrigators' Organizations and State Reforms in Ecuador. International Journal of Water Governance, 2(1), 1-18.

Howarth, S. E., Parajuli, U. N., Baral, J. R., Nott, G. A., Adhikari, B. R., and Gautam, D. R.

(2005). Prom oting Good Governance of Water Users' Associations in Nepal. Nepal:

Department of Irrigation of His Majesty's Governm ent of Nepal.

Howarth, S., Nott, G., Parajuli, U., and Dzhailobayev, N. (2007). Irrigation, Governance and

Water Access : Getting Better Results for the Poor. Water.

Hussain, I., and Hanjra, M. A. (2003). Does Irrigation Water Matter for Rural Poverty

Alleviation? Evidence from South and South-East Asia. Water Policy, 5(5-6), 429-442.

Hyden, G., and Court, J. (2002). Governance and Development. World Governance Survey

Discussion Paper 1. UNU, Tokyo.

Index, R. G. (2013). A Measure of Transparency and Accountability in the Oil, Gas, and

Mining Sector. The 2013 Resource Governance Index. New York: Revenue Watch.

Inocencio, A., Kikuchi, M., Tonosaki, M., Maruyama, A., Merrey, D., Sally, H., and de Jong,

I. (2007). Costs and Performance of Irrigation Projects; A comparison of Sub-Saharan

Africa and Other Developing Regions (Vol. 109). Kumasi, Ghana: IWMI.

Jacobson, S., and Petrie, R. (2009). Learning from Mistakes: What Do Inconsistent Choices over Risk Tell Us? Journal of Risk and Uncertainty 38 (2): 143-58.

Janaiah, A., Boss, M. L., and Agrawal, A. G. (2000). Poverty and Income Distribution in Rainfed and Irrigated Ecosystems: Village Studies in Chhattisgarh. Economic and Political Weekly, 35(52/53), 4664-4669.

Jones, L., and Tanner, T. (2015). Measuring “ Subjective Resilience ” using People 's Perceptions to Quantify Household Resilience (No. 423). London.

Joshi, A. (2010). Review of Impact and Effectiveness of Transparency and Accountability Initiatives. Transparency and Accountability Initiative. Londo, UK: Institute of Development Studies.

Kaufmann, D., Kraay, A., and Massimo Mastruzzi. (2009). Governance Matters VIII: Aggregate and Individual Governance Indicators, 1996-2008. (World bank policy 
research working paper No. 4978). Washington, D.C.

Kaufmann, D., Kraay, A., and Mastruzzi, M. (2004). Governance Matters III: Governance Indicators for 1996, 1998, 2000, and 2002. The World Bank Economic Review, 18(2), $253-287$.

Kaufmann, D., Kraay, A., and Mastruzzi, M. (2006). Measuring Governance Using CrossCountry Perceptions Data. In S. Rose-Ackerman (Ed.), International Handbook on the Economics of Corruption (p. 52). Cheltenham, UK: Edward Elgar Publishing Limited. Kaufmann, D., Kraay, A., and Mastruzzi, M. (2011). The Worldwide Governance Indicators: Methodology and Analytical Issues. Hague Journal on the Rule of Law, 3(2), 220-246. Kock, N., and Lynn, G. S. (2012). Lateral Collinearity and Misleading Results in Variance-

Based SEM : An Illustration and Recom m endationsJournal of the Association for Information Systems, 13(7), 546-580.

Kramm, J., and Wirkus, L. (2010). Local Water Governance : Negotiating Water Access and Resolving Resource Conflicts in Tanzanian Irrigation Schemes (MICROCON Research Working Paper No. 33). Brighton.

Kuzdas, C., Warner, B., Wiek, A., Yglesias, M., Vignola, R., and Ramirez-Cover, A. (2016). Identifying the Potential of Governance Regimes to Aggravate or Mitigate Local Water Conflicts in Regions Threatened by Climate. Local Environment.

Kyei-Baffour, N., and Ofori, E. (2007). Irrigation Development and Management in Ghana:

Prospects and Challenges. Journal of Science and Technology (Ghana), 26(2), 148-159.

Lam, W. F., and Ostrom, E. (2010). Analyzing the Dynamic Complexity of Development Interventions: Lessons from an Irrigation Experiment in Nepal. Policy Sciences, 43(1), $1-25$.

Lamptey, D., Nyamdi, B., and Minta, A. (2011). National Irrigation Policy, Strategies and Regulatory Measures. Ghana Irrigation Development Authority, Accra, Ghana. Lautze, J., Silva, S. De, Giordano, M., Sanford, L., and De Silva, S. (2011). Putting the Cart Before the Horse:Water governance and IWRM. Natural Resources Forum, 35(1), 1-8. Ledyard, J. O. (1995). Public Goods: A Survey in Experimental Research. Handbook of Experimental Economics.

Levitt, S. D., and List, J. A. (2007). About the Real World? Journal of Economic Perspectives, 21(2), 153-174.

Mainhardt-Gibbs, H. (2010). Survey of Civil Society Participation in the Extractive Industries Transparency Initiative and the Role of the World Bank. Bank Information Center, New 
York.

Mansungu, E. (2004). Water For All: Improving Water Resource Governance in Southern Africa (No. 113). Gatekeeper Series. London: International Institute for Environment and Development.

Marimbe, S., and Manzungu, E. (2003). Challenges of Communicating Integrated Water Resource Management in Zimbabwe Simbiso. Physics and Chemistry of the Earth, 28, 1077-1084.

Mazziotta, M., and Pareto, A. (2013). Methods for Constructing Composite Indicators: One for All or All for One? Rivista Italiana Di Economia Demografia E Statistica, 67(2), 67-80.

McCulloch, C. E. (2000). Generalized Linear Models. Journal of the American Statistical Association, 95(452), 1320-1324.

McGinty, M., and Milam, G. (2013). Public Goods Provision by Asymmetric Agents:

Experimental Evidence. Social Choice and Welfare, 40(4), 1159-1177.

Mdemu, M. V., Rodgers, C., Vlek, P. L. G., and Borgadi, J. J. (2009). Water Productivity in Reservoir Irrigated Schemes in the Upper East Region of Ghana. Physics and Chemistry of the Earth, 34(4-5), 324-328.

Meinzen-Dick, R., Raju, K. V, and Gulati, A. (2002). What Affects Organization and Collective Action for Managing Resources? Evidence from Canal Irrigation Systems in India. World Development, 30(4), 649-666.

Meier, S., and Sprenger, C. (2010). Present-Biased Preferences and Credit Card Borrowing. American Economic Journal: Applied Economics 2 (1): 193-210.

Meinzen-Dick, R., and Zwarteveen, M. (1998). Gendered Participation in Water Managem ent : Issues and Illustrations from Water Users Associations in South Asia. Agriculture and Human Values, 15, 337-345.

Mendes D. M., Paglietti L., Jackson D., and A. A. G. (2014). Ghana: Irrigation Market Brief. FAO Investment Centre, Rome.

Mengistie, D., and Kidane, D. (2016). Assessment of the Impact of Small-Scale Irrigation on Household Livelihood Improvement at Gubalafto District, North Wollo, Ethiopia. Agriculture, 6(3), 27.

Mildner, S., Fellow, S., and Wissenschaft, S. (2011). Scarcity and Abundance Revisited: A Literature Review on Natural Resources and Conflict. International Journal of Conflict and Violence, 5(1), 155-172. 
MoFA. (2011). Agriculture in Ghana: Facts and Figures. Accra, Ghana: Statistics, Research, and Information Directorate, (2010).

Mollinga, P. P. (2008). Water, Politics and Developm ent : Fram ing a Political Sociology of Water Resources Management. Water Alternatives, 1(1), 7-23.

Muchara, B., Ortmann, G., Wale, E., and Mudhara, M. (2014). Collective Action and Participation in Irrigation Water Managem ent : A Case Study of Mooi River Irrigation Scheme in KwaZulu-Natal Province, South Africa. Water SA, 40(4), 699-708.

Mul, M., Obuobie, E., Appoh, R., Kankam-, K., Bekoe-obeng, E., Amisigo, B., ... Mccartney, M. (2015). Water Resources Assessment of the Volta River Basin (IWMI Working Paper No. 166). Colombo, Sri Lanka.

Mutambara, S., Darkoh, M. B. K., and Atlhopheng, J. R. (2016). A Comparative Review of Water Management Sustainability Challenges in Smallholder Irrigation Schemes in Africa and Asia. Agricultural Water Management, 171, 63-72.

Nagrah, A., Chaudhry, A. M., and Giordano, M. (2016). Collective Action in Decentralized Irrigation System s : Evidence from Pakistan.World Development, 84, 282-298.

Namara, R. E., Hanjra, M. A., Castillo, G. E., Ravnborg, H. M., Smith, L., and Van Koppen, B. (2010). Agricultural Water Management and Poverty Linkages. Agricultural Water Management, 97(4), 520-527.

Namara, R. E., Horowitz, L., Nyamadi, B., and Barry, B. (2011). Irrigation Development in Ghana: Past experiences, emerging opportunities, and future directions (Ghana Strategy Support Program (GSSP) Working Papers No. 27). Accra.

NEPAD. (2003). Comprehensive Africa Agriculture Development Programme. Midrand, South Africa.

Norton, R. D. (2004). Agricultural Development Policy: Concepts and Experiences. West Sussex, England: John Wiley and Sons.

Oates, N., Jobbins, G., Mosello, B., and Arnold, J. (2015). Pathways for irrigation development in Africa - insights from Ethiopia, Morocco and Mozambique, (June).

OECD (Organisation for Economic Co-operation and Development). (2008). Handbook on Constructing Composite Indicators: Methodology and User Guide (Vol. 3). France: OECD.

Olson, M. (1965). The Logic of Collective Action. Cambridge: Harvard University Press.

Opoku-Ankomah, Y., Dembele, Y., Ampomah, B. Y., and Some, L. (2006). Hydro-political Assessment of Water Governance from the Top-down and Review of Literature on Local 
Level Institutions and Practices in the Volta Basin (No. 111). Colombo, Sri Lanka.

Ostrom, E. (1990). Governing the Commons: The Evolution of Institutions for Collective Action. Cambridge, UK: Cambridge University Press.

Ostrom, E. (2000). Reformulating the Commons. Swiss Political Science Review, 6(1), 2952.

Ostrom, E. (2009). A General Framework for Analyzing Sustainability of Social-Ecological Systems. Science, 325(July), 419-423.

Ostrom, E., and Gardner, R. (1993). Coping with Asymmetries in the Commons: Selfgoverning Irrigation Systems can Work. The Journal of Economic Perspectives, 7(4), 93-112.

Ostrom, E., Gardner, R., and Walker, J. (1994). Rules, Games, and Common-Pool Resource. University of Michigan Press.

Otsuka, K., Liu, Y., and Yamauchi, F. (2016). The Future of Small Farms in Asia. Development Policy Review, 34(3), 441-461.

Pahl-wostl, C. (2007). Transitions towards Adaptive Management of Water Facing Climate and Global Change. Water Resources Management, 21, 49-62.

Pereira, L. S., Oweis, T., Zairi, A., and Santos, L. (2002). Irrigation Management Under Water Scarcity. Agricultural Water Management, 57(3), 175-206.

Phirun, N. A. N. G., and Chhuong, O. U. C. H. (2014). Gender and Water Governance: Women's Role in Irrigation Management and Development in the Context of Climate Change (CDRI Working Paper Series No. 89). Phnom Penh, Cambodia.

Pimentel, D., Berger, B., Filiberto, D., Newton, M., Wolfe, B., Karabinakis, E., ... Nandagopal, S. (2004). Water Resources : Agricultural and Environm ental Issues. BioScience, 54(10), 909-918.

Poussin, J. C., Renaudin, L., Adogoba, D., Sanon, A., Tazen, F., Dogbe, W., ... Cecchi, P. (2015). Performance of Small Reservoir Irrigated Schemes in the Upper Volta Basin: Case Studies in Burkina Faso and Ghana. Water Resources and Rural Development, 6, $50-65$.

Rogers, P., and Hall, A. W. (2003). Effective Water Governance (TEC Background Papers No. 7) (Vol. 7). Stockholm: Global Water Partnership.

Sakthivadivel, R., De Fraiture, C., Molden, D. J., Perry, C., and Kloezen, W. (1999). Indicators of Land and Water Productivity in Irrigated Agriculture. International Journal of Water Resources Development, 15(1-2), 161-179. 
Sarker, A., and Itoh, T. (2001). Design Principles in Long-enduring Institutions of Japanese Irrigation Common-pool Resources. Agricultural Water Management, 48(2), 89-102.

Sehring, J. (2009). Path Dependencies and Institutional Bricolage in Post-Soviet Water Governance. Water Alternatives, 2(1), 61-81.

Shiferaw, B. A., Okello, J., and Reddy, R. (2009). Adoption and Adaptation of Natural Resource Management Innovations in Smallholder Agriculture: Reflections on Key Lessons and Best Practices. Environment Development and Sustainability, 11, 601-619. Silverm an, I. W. (2003). Gender Differences in Delay of Gratification : A MetaAnalysis. Sex Roles, 49(9/10), 451-452.

Sokile, C. S., and van Koppen, B. (2004). Local Water Rights and Local Water User Entities: The Unsung Heroines of Water Resource Management in Tanzania. Physics and Chemistry of the Earth, 29(15), 1349-1356.

Sullivan, G. M., and Artino Jr, A. R. (2013). Analyzing and Interpreting Data From LikertType Scales. Journal of Graduate Medical Education, (December), 541-542.

Svendsen, M., Ewing, M., and Msangi, S. (2009). Measuring Irrigation Performance in Africa (IFPRI Discussion Paper No. 894). Washington DC, USA.

Svendsen, M., and Meinzen-Dick, R. (1997). Irrigation management institutions in transition: a look back, a look forward. Irrigation and Drainage Systems, 11, 139-156.

Tafesse, M. (2003). Small - scale Irrigation for Food Security in Sub - Saharan Africa (Report and recommendations of a CTA study visit No. CTA Working Document Number 8031). Ethiopia.

Tanaka, T., Camerer, C. F., and Nguyen, Q. (2010). Risk and Time Preferences : Linking Experimental and Household Survey Data from Vietnam. The American Economic Review, 100(1), 557-571.

Tanaka, Y., and Munro, A. (2012). Regional Variation in Risk and Time Preferences:

Evidence From a Large-Scale Field Experiment in Rural Uganda. Tokyo, Japan:

National Graduate Institute for Policy Studies.

Tortajada, C. (2010). Water Governance: Some Critical Issues. International Journal of Water Resources Development, 26(2), 297-307.

UNDP. (2004). Water Governance for Poverty Reduction: Key Issues and the UNDP Response to Millenium Development Goals. (K. Lewis, Ed.). New York: United Nations Development Programme.

UNESCO. (2007). Water: A Shared Responsibility - The United Nations World Water 
Development Report 2. Development in Practice, 17(2), 309-311.

UNESCO. (2015). The United Nations World Water Development Report 2015: Water for a Sustainable World. France: UNESCO.

van Edig, A., Engel, S., and Laube, W. (2003). Ghana's Water Institutions in the Process of Reform : from the International to the Local Level. In S. Neubert, W. Scheum anmand A. Van Edig (Eds.), Reforming Institutions for Sustainable Water Management (pp. 3151). Bonn, Germany: German Development Institute.

Venot, J.-P., and Hirvonen, M. (2013). Enduring Controversy: Small Reservoirs in SubSaharan Africa. Society and Natural Resources, 26(8), 883-897.

Venot, J.-P., and Suhardiman, D. (2014). Governing the Ungovernable: Practices and Circumstances of Governance in the Irrigation Sector. International Journal of Water Governance, 2(2), 41-60.

Wade, R. (1994). Village Republics: Economic Conditions for Collective Action in South India. Oakland (Vol. 40.). San Francisco: International Center for Self-governance. Wang, J., Huang, J., Zhang, L., Huang, Q., and Rozelle, S. (2010). Water Governance and Water Use Efficiency: The Five Principles of WUA Management and Performance in China. Journal of the American Water Resources Association, 46(4), 665-685.

Wang, M., Oliver, M., and Hens, T. (2016). How Tim e Preferences Differ : Evidence from 53 Countries. Journal of Economic Psychology, 52, 115-135.

Wang, M., Rieger, M. O., and Hens, T. (2011). How Tim e Preferences Differ : Evidence from 45 Countries. Institute for Foretaksokonomi.

Wang, Y., Chen, C., and Araral, E. (2016). The Effects of Migration on Collective Action in the Commons: Evidence from Rural China. World Development, 88(December), 79-93.

Wichelns, D., and Oster, J. D. (2006). Sustainable Irrigation is Necessary and Achievable, but

Direct Costs and Environmental Impacts can be Substantial. Agricultural Water Management, 86(1-2), 114-127.

Wiek, A., and Larson, K. L. (2012). Water, People, and Sustainability - A Systems Framework for Analyzing and Assessing Water Governance Regimes. Water Resources Development, 26(September), 3153-3171.

Winship, C., and Mare, R. D. (1984). Regression Models with Ordinal Variables. American Sociological Review, 49(4), 512-525.

Wood, T. N. (2013). Agricultural Development in the Northern Savannah of Ghana. Lincoln: University of Nebraska. 
WorldBank. (2007). World Development Report 2008: Agriculture for Development.

Washington DC.

Yami, M. (2013). Sustaining Participation in Irrigation Systems of Ethiopia: What Have We Learned about Water User Associations? Water Policy, 15(6), 961-984.

Yesuf, M. (2004). Risk, Time and Land Management Under Market Imperfections : Applications to Ethiopia. Goteborg: Thesis. Goteborg University.

Yu, H. H., Edmunds, M., Lora-Wainwright, A., and Thomas, D. (2016). Governance of the Irrigation Commons under Integrated Water Resources Management - A Comparative Study in Contemporary Rural China. Environmental Science and Policy, 55, 65-74.

Zhang, L., Heerink, N., Dries, L., and Shi, X. (2013). Water Users Associations and Irrigation Water Productivity in Northern China. Ecological Economics, 95, 128-136. 


\section{Summary}

This thesis assesses irrigation governance in northern Ghana. Irrigated agriculture is assumed to improve agricultural productivity and rural livelihoods as compared to rain-fed agriculture in developing countries. In Ghana, small-scale irrigation schemes are mostly constructed for this purpose. These schemes are managed by water user associations (WUAs). The daily activities of these user associations play an important role in the sustainability of the schemes. Available reports indicate that most irrigation facilities in Ghana, and in other parts of sub-Saharan Africa, are underperforming and are unsustainable. This is partly blamed on poor operation and maintenance by WUAs, suggesting that the governance of WUAs is ineffective and poorly coordinated.

Governance embraces several dimensions, such as participation, accountability and conflict management, which may play different roles in sustaining irrigation resources. Little is known about the relative importance of these different dimensions. This thesis aims at assessing the strength of the relationships between different dimensions of WUAs' governance and the performance and sustainability of small-scale irrigation systems in northern Ghana. To do so, we use primary data from northern Ghana, complemented with field experiments, to answer the following research questions.

1. What measures of irrigation governance can be used to assess the performance and sustainability of WUA-managed irrigation schemes?

2. To what extent are users' perceptions of different dimensions of irrigation governance related to the performance of irrigation schemes?

3. Are users' governance perceptions and cooperativeness related to users' contributions towards irrigation resource maintenance?

4. To what extent is a farm er's labour contribution to irrigation scheme maintenance associated with his or her perception of local governance performance and with his or her time preference? 
Northern Ghana is a semi-arid region and has a short rainy season. Dry-season irrigation is practiced by communities with access to water bodies to complement rain-fed harvest for livelihoods. Surface water irrigation from small reservoirs, constructed by government and donor organizations, are predominant. Irrigated crops are mainly rice and vegetables including tomatoes, onions, pepper, and leafy vegetables. Chapter 1 gives a background to the study, and outlines the methodology of the thesis.

In Chapter 2, we assess and measure irrigation governance from a user-based approach. Following resource governance frameworks, we devise indicators that can be used to assess irrigation governance. The indicators are characterized into six governance dimensions: Participation, accountability, conflict management, transparency and cooperation, equity and fairness, and sustainable use. These dimensions are rated by local water users through several indicators. Test results, based on Cronbach alpha test, indicate that the set of items included in each governance dimension are closely related as a group. We also examine the relationship between resulting irrigation governance dimensions and some objective factors that possibly drive users' assessm ents of governance. On average, irrigation governance in northern Ghana is rated as "good". The mean ratings of the governance dimensions are all above average but none is rated as "excellent". Sustainable use scores worst am ong the dimensions while conflict management scores best. We infer that the lack of progress in some irrigation facilities in northern Ghana being attributed to bad governance may be specific to some dimensions of governance and not governance in general. The availability of water through high precipitations and plot locations of irrigators are factors found to significantly influence irrigation governance perceptions. Our hypotheses on precipitations and plot location are supported by the study while hypotheses on group size and main crop grown in a scheme are rejected.

Chapter 3 assesses the extent to which users' perceptions of different dim ensions of governance are related to irrigation performance in terms of productivity. It is found that crop yields of irrigated land are significantly related to the participation dimension of governance. Conflict management on the other hand, has a significant negative association with crop yields. A potential explanation of the latter, unanticipated, finding is that rules and regulations put in place to avert conflicts contribute to free riding and other asocial behaviour 
by users. Estimated coefficients for the other four dimensions are either weakly significant or insignificant.

In Chapter 4, we examine the role of users in sustaining irrigation resources through maintenance activities, paying particular attention to perceptions of governance perceptions and the cooperativeness of users. We estimated cooperativeness through a Voluntary Contribution Mechanism (VCM) game held among survey respondents. We also examine the relationships between (different dimensions of) perceived governance and users' cooperativeness. The results indicate that positive overall governance perceptions and cooperativeness are associated with larger users' labour contributions towards maintenance. Out of the six governance dimensions, sustainable use has a statistically significant relation to labour contribution. User perceptions of participation, accountability and/or transparency and cooperation are positively related to labour contributions to maintenance, but our data set unfortunately cannot adequately distinguish the separate relationships of each dimension due to the high correlations between them. We further find that perceptions of conflict management have an unexpected negative association with cooperativeness. This may be a result of selfish desires, where users take opportunity to free-ride in their contributions when they observe a congenial environment in their group with good management of conflicts.

Labour contribution to maintenance is a form of investment with expected future returns, and therefore is likely to be related to time preferences of users. Chapter 5 examines the extent to which a farm er's labour contribution to irrigation schem e m aintenancés associated with his or her perception of local governance performance and with his or her time preference. We elicited time preference of water users from a field experiment using a Convex Time Budget (CTB) approach. We find that time preferences estimated from the experiment have a negative but statistically insignificant association with labour contributions. Time preferences in turn are found to be negatively influenced by (total) household wealth, as found in previous studies. We also find evidence suggesting that farmers with plots in the head-ends, and farmers growing tomatoes or onions tend to have relatively high time preferences while farmers located in regions with relative high poverty tend to have low time preferences. 
Finally, chapter 6 synthesizes main findings and discusses their implications for the development of irrigated agriculture. Findings from this thesis indicate that good governance by WUAs is important in sustaining small-scale irrigation in northern Ghana. For effective interventions however, specific dimensions of governance need to be taken into account. Users' participation in the joint $m$ anagem ent of irrigation schem es seem to be a crucial dimension in successful governance of irrigation schemes. Participation affects performance of irrigation system s and collective $\mathrm{m}$ aintenance, confirm ing the need for users' inclusiveness in the management of CPRs as advocated by scholars. 


\section{Acknowledgements}

The journey through this $\mathrm{PhD}$ process has been made possible by many individuals and organisations. I thank everyone who contributed to this achievement. I am grateful to the Netherlands government for giving me scholarship under the Nuffic program to undertake the study. I also thank my employers, the University for Development Studies in Ghana, for granting me study leave.

I thank my promotor, Prof. Erwin Bulte for accepting me into the Development Economics Group of Wageningen University and Research, and for his timely comments and suggestions that shaped the outcome of the thesis. I am specially indebted to Dr Kees Burger of blessed memory, who played a key role in defining the scope of the research which eventually secured me admission into the $\mathrm{PhD}$ programme. His guidance and counsel during the proposal writing and design of field instruments laid a good foundation for this final outcome. I am deeply grateful to my co-promotors, Dr Rein Haagsma, Dr Nico Heerink, and Prof. Saa Dittoh for their excellent supervision. The countless brainstorming sessions you had with me greatly impacted my analytical ability and academic skills. Thank you for your valuable inputs and for inspiring me to success.

I am grateful to Gilbert, Salifu, Victoria, George, Hanna, Joe and to the many extension agents who assisted me to collect data. I thank the leaders and members of the Water User Associations for their participation in this research and for the valuable information they offered me. I also thank the regional directorates of the Ghana Irrigation Development Authority for assisting me with the needed data.

I wish to also thank the administrative staff of the Development Economics Group especially Dineke, Karen, Marian, and Betty for their kind support and assistance in and outside Wageningen. I also acknowledge colleagues and friends in the group for the warm welcome and friendly atmosphere. I am particularly thankful to Zihan Nie for assisting me in some analysis. To my 3104 office mates - Prossy, Aisha, Maria and Fausta, I am grateful I met you and will forever cherish our friendship. 
To the many friends and families I made in Wageningen - Aunty Monica and Uncle Sam and their families, the leadership and members of Amazing Grace Parish, Clara, Fulera, and the Sikaman community, thank you for your support and making me feel at home during the entire period. I also wish to thank Isaac and Marian Bos, and Tony and Jackie Monserrate for offering me their homes when I needed private rooms during my maternity periods in the Netherlands. Thank you all for your kindness.

Finally, I thank my families for their support and encouragement. I appreciate my mother and sister particularly for their devotion in taking care of my children whenever I was away. My sister had to travel several miles and several times to seek medical care for my son while I was away. I am highly indebted to you Vic. I am also deeply grateful to my husband Joshua and our children, Wontemi and Akunala for their understanding, encouragement, and endurance. You made this achievement a reality, thank you dearly. 
Margaret Atosina Akuriba

Wageningen School of Social Sciences (WASS)

Completed Training and Supervision Plan

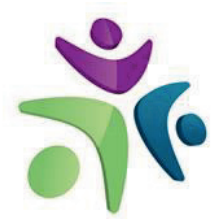

Wageningen School

of Social Sciences

\section{Name of the learning activity \\ A) Project related competences}

Department/Institute

Year ECTS*

Economic Models, AEP 30806

Advanced Microeconomics, ECH 32306

Theory and Practice of Efficiency and

Productivity Measurement: Static and

Dynamic Analysis

\section{B) General research related competences}

WASS introduction course
Research Methodology: From topic to
proposal
Irrigation governance and performance:
the case of smallholder irrigated
agriculture in Northern Ghana

WASS

$2013 \quad 1$

WASS

Conference of the Ghana

Association of Agricultural

Economists, Tamale, Ghana

Conference of the Centre for the

Study of African Economies, St

Catherine's College, University of

Oxford, UK

Sustaining small-scale irrigation systems: the role of users

$\begin{array}{ll}2013 & 6 \\ 2013 & 6 \\ 2013 & 6\end{array}$

20134

2017

$2018 \quad 1$

$2018 \quad 1$ $30^{\text {th }}$ International Conference of

Agricultural Economists,

Vancouver, British Columbia,

Canada

1

20136

$2013 \quad 1.2$

Techniques for writing and presenting a WASS

$2013 \quad 0.6$

Information Literacy including Endnote WGS

$2017 \quad 0.1$ Introduction (ILP)

WGS

0.1

\section{Total}

${ }^{*}$ One credit according to ECTS is on average equivalent to 28 hours of study load 


\section{Funding}

This research received funding from The Netherlands Fellowship Program, Nuffic. 